\title{
Composition changes after the "Halloween" solar proton event: the High Energy Particle Precipitation in the Atmosphere (HEPPA) model versus MIPAS data intercomparison study
}

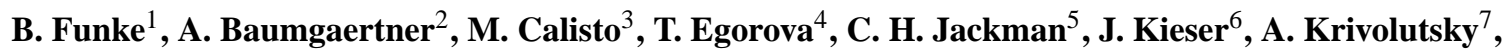 \\ M. López-Puertas ${ }^{1}$, D. R. Marsh ${ }^{8}$, T. Reddmann ${ }^{9}$, E. Rozanov ${ }^{3,4}$, S.-M. Salmi ${ }^{11,12}$, M. Sinnhuber ${ }^{9,10}$, G. P. Stiller ${ }^{9}$, \\ P. T. Verronen ${ }^{11}$, S. Versick ${ }^{9,14}$, T. von Clarmann ${ }^{9}$, T. Y. Vyushkova ${ }^{7}$, N. Wieters ${ }^{10}$, and J. M. Wissing ${ }^{13}$ \\ ${ }^{1}$ Instituto de Astrofísica de Andalucía, CSIC, Granada, Spain \\ ${ }^{2}$ Max Planck Institute for Chemistry, Mainz, Germany \\ ${ }^{3}$ Institute for Atmospheric and Climate Science ETH, Zurich, Switzerland \\ ${ }^{4}$ Physical-Meteorological Observatory/World Radiation Center, Davos, Switzerland \\ ${ }^{5}$ NASA Goddard Space Flight Center, Greenbelt, MD 20771, USA \\ ${ }^{6}$ Max Planck Institute for Meteorology, Hamburg, Germany \\ ${ }^{7}$ Central Aerological Observatory (CAO), Dolgoprudny, Moscow Region, Russia \\ ${ }^{8}$ National Center for Atmospheric Research, Boulder, CO, USA \\ ${ }^{9}$ Karlsruhe Institute of Technology, Institute for Meteorology and Climate Research, Karlsruhe, Germany \\ ${ }^{10}$ Institute of Environmental Physics, University of Bremen, Bremen, Germany \\ ${ }^{11}$ Earth Observation Unit, Finnish Meteorological Institute, Helsinki, Finland \\ ${ }^{12}$ Department of Physics, University of Helsinki, Helsinki, Finland \\ ${ }^{13}$ FB Physik, University of Osnabrück, Osnabrück, Germany \\ ${ }^{14}$ Steinbuch Centre for Computing, Karlsruhe, Germany
}

Received: 23 December 2010 - Published in Atmos. Chem. Phys. Discuss.: 22 March 2011

Revised: 27 June 2011 - Accepted: 21 August 2011 - Published: 5 September 2011

\begin{abstract}
We have compared composition changes of NO, $\mathrm{NO}_{2}, \mathrm{H}_{2} \mathrm{O}_{2}, \mathrm{O}_{3}, \mathrm{~N}_{2} \mathrm{O}, \mathrm{HNO}_{3}, \mathrm{~N}_{2} \mathrm{O}_{5}, \mathrm{HNO}_{4}, \mathrm{ClO}, \mathrm{HOCl}$, and $\mathrm{ClONO}_{2}$ as observed by the Michelson Interferometer for Passive Atmospheric Sounding (MIPAS) on Envisat in the aftermath of the "Halloween" solar proton event (SPE) in late October 2003 at $25-0.01 \mathrm{hPa}$ in the Northern Hemisphere $\left(40-90^{\circ} \mathrm{N}\right)$ and simulations performed by the following atmospheric models: the Bremen 2-D model (B2dM) and Bremen 3-D Chemical Transport Model (B3dCTM), the Central Aerological Observatory (CAO) model, FinROSE, the Hamburg Model of the Neutral and Ionized Atmosphere (HAMMONIA), the Karlsruhe Simulation Model of the Middle Atmosphere (KASIMA), the ECHAM5/MESSy Atmospheric Chemistry (EMAC) model, the modeling tool for SOlar Climate Ozone Links studies (SOCOL and SOCOLi), and the Whole Atmosphere Community Climate Model (WACCM4). The large number of participating models allowed for an evaluation of the overall ability of atmo-
\end{abstract}

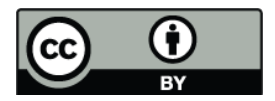

Correspondence to: B. Funke (bernd@iaa.es) spheric models to reproduce observed atmospheric perturbations generated by SPEs, particularly with respect to $\mathrm{NO}_{\mathrm{y}}$ and ozone changes. We have further assessed the meteorological conditions and their implications for the chemical response to the SPE in both the models and observations by comparing temperature and tracer $\left(\mathrm{CH}_{4}\right.$ and $\left.\mathrm{CO}\right)$ fields.

Simulated SPE-induced ozone losses agree on average within $5 \%$ with the observations. Simulated $\mathrm{NO}_{\mathrm{y}}$ enhancements around $1 \mathrm{hPa}$, however, are typically $30 \%$ higher than indicated by the observations which are likely to be related to deficiencies in the used ionization rates, though other error sources related to the models' atmospheric background state and/or transport schemes cannot be excluded. The analysis of the observed and modeled $\mathrm{NO}_{\mathrm{y}}$ partitioning in the aftermath of the SPE has demonstrated the need to implement additional ion chemistry $\left(\mathrm{HNO}_{3}\right.$ formation via ion-ion recombination and water cluster ions) into the chemical schemes. An overestimation of observed $\mathrm{H}_{2} \mathrm{O}_{2}$ enhancements by all models hints at an underestimation of the $\mathrm{OH} / \mathrm{HO}_{2}$ ratio in the upper polar stratosphere during the SPE. The analysis of chlorine species perturbations has shown that the encountered

Published by Copernicus Publications on behalf of the European Geosciences Union. 
differences between models and observations, particularly the underestimation of observed $\mathrm{ClONO}_{2}$ enhancements, are related to a smaller availability of $\mathrm{ClO}$ in the polar night region already before the SPE. In general, the intercomparison has demonstrated that differences in the meteorology and/or initial state of the atmosphere in the simulations cause a relevant variability of the model results, even on a short timescale of only a few days.

\section{Introduction}

Energetic particle precipitation has important implications for atmospheric chemistry. In particular, protons and associated electrons, generated during solar eruptions, cause sporadical in-situ production of $\mathrm{NO}_{\mathrm{x}}$ and $\mathrm{HO}_{\mathrm{x}}$ radicals involved in catalytic ozone destruction. These solar proton events (SPEs) thus represent an important Sun-Earth connection which contributes to the natural ozone variability. The quasi-instantaneous increase of odd nitrogen and hydrogen due to SPEs induces perturbations of the chemical composition of the middle atmosphere on a short-time scale. In this sense, SPE-induced perturbations of the atmospheric composition represent an ideal natural laboratory for studying stratospheric and mesospheric chemistry (see also Jackman and McPeters, 1987).

In recent years, there have been two large SPEs (October/November 2003 and January 2005) (Jackman et al., 2008) which have been intensively observed by several instruments on different satellite platforms, including, for example, NOAA 16 SBUV/2 and HALOE data (Jackman et al., 2005a,b; Randall et al., 2005); MIPAS, GOMOS and SCIAMACHY on Envisat (López-Puertas et al., 2005a,b; von Clarmann et al., 2005; Orsolini et al., 2005; Seppälä et al., 2004; Rohen et al., 2005); and MLS on AURA (Verronen et al., 2006). In particular, during late October and early November 2003, three active solar regions produced solar flares and solar energetic particles of extremely large intensity, including the fourth largest event observed in the past forty years (Jackman et al., 2005b, 2008), known as the "Halloween" storm. During and after this event, the MIPAS instrument observed global changes (e.g. in both the Northern and Southern polar regions, during day and nighttime) in the stratospheric and lower mesospheric composition. This includes enormous enhancements in $\mathrm{NO}_{\mathrm{x}}$, e.g. in $\mathrm{NO}$ and $\mathrm{NO}_{2}$, and large depletions in $\mathrm{O}_{3}$ (López-Puertas et al., 2005a) as well as significant changes in other $\mathrm{NO}_{\mathrm{y}}$ species, such as $\mathrm{HNO}_{3}, \mathrm{~N}_{2} \mathrm{O}_{5}, \mathrm{ClONO}_{2}$ (López-Puertas et al., 2005b), and $\mathrm{N}_{2} \mathrm{O}$ (Funke et al., 2008). In addition, there also have been observed changes in $\mathrm{ClO}$ and $\mathrm{HOCl}$ as evidence of perturbations by solar protons on the $\mathrm{HO}_{\mathrm{x}}$ and chlorine species abundances (von Clarmann et al., 2005).

Several model studies, aiming at reproducing observed short- and medium-term composition changes after this par- ticular event (Jackman et al., 2008; Verronen et al., 2008; Funke et al., 2008; Baumgaertner et al., 2010; Egorova et al., 2011) and evaluating SPE-induced long-term effects (Jackman et al., 2009) have been carried out in the past.

The High Energy Particle Precipitation in the Atmosphere (HEPPA) model vs. data intercomparison initiative has brought together scientists involved in atmospheric modeling using state-of-the art general circulation models (GCMs) and chemistry-transport models (CTMs) on the one hand and scientists involved in the analysis and generation of observational data on the other hand. The objective of this community effort is (i) to assess the ability of state-of-the-art atmospheric models to reproduce composition changes induced by particle precipitation, (ii) to identify and - if possible remedy deficiencies in chemical schemes, and (iii) to serve as a platform for discussion between modelers and data producers. This is achieved by a quantitative comparison of observed and modeled composition changes after particle precipitation events, as well as by inter-comparing the simulations performed by the different models.

In this study we report results from the intercomparison of MIPAS/Envisat data obtained during 26 October30 November 2003, before and after the Halloween SPE, at altitudes from $25-75 \mathrm{~km}(25-0.01 \mathrm{hPa})$ with simulations performed using the following GCMs and CTMs: the Bremen 2d Model (B2dM) (Sinnhuber et al., 2003a; Winkler et al., 2009), the Bremen 3d Chemical Transport Model (B2dM and B3dCTM) (Sinnhuber et al., 2003b), the Central Aerological Observatory (CAO) model (Krivolutsky and Vyushkova, 2002), FinROSE (Damski et al., 2007b), the Hamburg Model of the Neutral and Ionized Atmosphere (HAMMONIA) (Schmidt et al., 2006), the Karlsruhe Simulation Model of the Middle Atmosphere (KASIMA) (Kouker et al., 1999), the ECHAM5/MESSy Atmospheric Chemistry (EMAC) model (Jöckel et al., 2006), the modeling tool for SOlar Climate Ozone Links studies (SOCOL and SOCOLi) (Egorova et al., 2005; Schraner et al., 2008; Egorova et al., 2011), and the Whole Atmosphere Community Climate Model (WACCM4) (Garcia et al., 2007). Among the species affected by SPEs we focus here on $\mathrm{NO}, \mathrm{NO}_{2}, \mathrm{H}_{2} \mathrm{O}_{2}$, $\mathrm{O}_{3}, \mathrm{~N}_{2} \mathrm{O}, \mathrm{HNO}_{3}, \mathrm{~N}_{2} \mathrm{O}_{5}, \mathrm{HNO}_{4}, \mathrm{ClO}, \mathrm{HOCl}$, and $\mathrm{ClONO}_{2}$. For these species a significant perturbation well above the detection limit has been observed by MIPAS. We have further assessed the meteorological background conditions in both the models and the real atmosphere as observed by MIPAS by comparing temperature and tracer fields $\left(\mathrm{CH}_{4}\right.$ and $\left.\mathrm{CO}\right)$. Although SPE-induced composition changes during the Halloween event have been reported in both hemispheres, we restrict our analysis to the Northern Hemisphere $(\mathrm{NH})$ in the latitude range $40-90^{\circ} \mathrm{N}$ where most pronounced effects have been observed and composition changes can be well distinguished from the background variability.

Apart from the initial particle forcing leading to atmospheric ionization, SPE-induced composition changes are controlled by several other factors such as the neutral and 
Table 1. Used MIPAS data versions (indicated by the last digits of the retrieval version) for all species on a daily basis within the period 26 October-30 November 2003.

\begin{tabular}{|c|c|c|c|c|c|c|c|c|c|c|c|c|c|c|c|c|c|c|c|c|c|c|c|c|c|c|c|c|c|c|c|c|c|c|c|c|}
\hline Day & 26 & 27 & 28 & 29 & 30 & 31 & 1 & 2 & 3 & 4 & 5 & 6 & 7 & 8 & 9 & 10 & 11 & 12 & 13 & 14 & 15 & 16 & 17 & 18 & 19 & 20 & 21 & 22 & 23 & 24 & 25 & 26 & 27 & 28 & 29 & 30 \\
\hline Temp. & 9 & 10 & 10 & 9 & 9 & 9 & 9 & 9 & 9 & 9 & 9 & 10 & 10 & 9 & 9 & 9 & 9 & 10 & 10 & 10 & 9 & 9 & 9 & 9 & 9 & ? & 9 & 9 & 10 & 10 & 10 & 10 & 9 & 9 & 9 & , \\
\hline $\mathrm{CH}_{4}$ & 12 & 12 & 12 & 12 & 12 & 12 & 12 & 12 & 12 & 12 & 12 & 12 & 12 & 12 & 12 & 12 & 12 & 12 & 12 & 12 & 12 & 12 & 12 & 12 & 12 & 12 & 12 & 12 & 12 & 12 & 12 & 12 & 12 & 12 & 12 & 12 \\
\hline $\mathrm{CO}$ & 9 & 11 & 11 & 9 & 10 & 10 & 9 & 9 & 10 & 10 & 0 & 11 & 11 & 10 & 10 & 10 & 9 & 11 & 11 & 11 & 10 & 10 & 10 & 9 & 10 & 10 & 9 & 10 & 11 & 11 & 11 & 11 & 9 & 10 & 10 & 10 \\
\hline NO & 14 & 14 & 14 & 14 & 14 & 14 & 14 & 14 & 14 & 14 & 14 & 14 & 14 & 14 & 14 & 14 & 14 & 14 & 14 & 14 & 14 & 14 & 14 & 14 & 14 & 14 & 14 & 14 & 14 & 14 & 14 & 14 & 14 & 14 & 14 & 14 \\
\hline $\mathrm{NO}_{2}$ & 14 & 13 & 13 & 14 & 11 & 11 & 14 & 14 & 11 & 11 & 14 & 13 & 13 & 11 & 11 & 11 & 14 & 13 & 13 & 13 & 11 & 11 & 11 & 14 & 11 & 11 & 14 & 11 & 13 & 13 & 13 & 13 & 14 & 11 & 11 & 11 \\
\hline $\mathrm{N}_{2} \mathrm{O}$ & 12 & 12 & 12 & 12 & 12 & 12 & 12 & 12 & 12 & 12 & 12 & 12 & 12 & 12 & 12 & 12 & 12 & 12 & 12 & 12 & 12 & 12 & 12 & 12 & 12 & 12 & 12 & 12 & 12 & 12 & 12 & 12 & 12 & 12 & 12 & 12 \\
\hline $\mathrm{HNO}_{3}$ & 9 & 9 & 9 & 9 & 9 & 9 & 9 & 9 & 9 & 9 & 9 & 9 & 9 & 9 & 9 & 9 & 9 & 9 & 9 & 0 & 9 & 9 & 9 & 9 & 9 & 0 & 9 & 9 & 9 & 9 & 9 & 9 & 9 & 9 & 9 & 9 \\
\hline $\mathrm{N}_{2} \mathrm{O}_{5}$ & 9 & 10 & 10 & 10 & 10 & 10 & 9 & 10 & 10 & 10 & 10 & 10 & 10 & 10 & 10 & 10 & 9 & 10 & 10 & 10 & 10 & 10 & 10 & 10 & 10 & 10 & 9 & 10 & 10 & 10 & 10 & 10 & 10 & 10 & 10 & 10 \\
\hline $\mathrm{HNO}_{4}$ & 12 & 12 & 12 & 12 & 12 & 12 & 12 & 12 & 12 & 12 & 12 & 12 & 12 & 12 & 12 & 12 & 12 & 12 & 12 & 12 & 12 & 12 & 12 & 12 & 12 & 12 & 12 & 12 & 12 & 12 & 12 & 12 & 12 & 12 & 12 & 12 \\
\hline $\mathrm{O}_{3}$ & 9 & 9 & 9 & 9 & 9 & 9 & 9 & 9 & 9 & 9 & 9 & 9 & 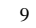 & 9 & 9 & 9 & 9 & 9 & 9 & 9 & 9 & 9 & 9 & 9 & 9 & 9 & 9 & 9 & 9 & 9 & 9 & 9 & 9 & 9 & 9 & 9 \\
\hline $\mathrm{H}_{2} \mathrm{O}_{2}$ & 4 & 4 & 4 & 4 & 4 & 4 & 4 & 4 & 4 & 4 & 4 & 4 & 4 & 4 & 4 & 4 & 4 & 4 & 4 & 4 & 4 & 4 & 4 & 4 & - & 4 & 4 & 4 & 4 & 4 & 4 & 4 & 4 & 4 & 4 & 4 \\
\hline $\mathrm{ClO}$ & 10 & 11 & 11 & 11 & 11 & 11 & 10 & 11 & 11 & 11 & 11 & 11 & 11 & 11 & 11 & 11 & 10 & 11 & 11 & 11 & 11 & 11 & 11 & 11 & 11 & 11 & 10 & 11 & 11 & 11 & 11 & 11 & 11 & 11 & 11 & 11 \\
\hline $\mathrm{HOC}$ & 3 & 4 & 4 & 3 & 3 & 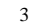 & 3 & 3 & 3 & 3 & 3 & 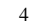 & 4 & 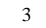 & 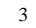 & 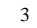 & 3 & 4 & 4 & 4 & 3 & 3 & 3 & 3 & 3 & 3 & 3 & 3 & 4 & 4 & 4 & 4 & 3 & 3 & 3 & 3 \\
\hline $\mathrm{ClONO}_{2}$ & 11 & 12 & 12 & 12 & 12 & 12 & 11 & 12 & 12 & 12 & 12 & 12 & 12 & 12 & 12 & 12 & 11 & 12 & 12 & 12 & 12 & 12 & 12 & 12 & 12 & 12 & 11 & 12 & 12 & 12 & 12 & 12 & 12 & 12 & 12 & 12 \\
\hline
\end{tabular}

ion chemistry responsible for the repartitioning of primarily generated species, the background composition interfering with the chemical repartitioning, and the meteorologi$\mathrm{cal} /$ dynamical conditions. The large number of controlling factors and their interaction introduce a significant spread in the model results and make their analysis difficult. In order to reduce the model variability and to make differences between the simulations more traceable, we have simplified the intercomparison setup such that a common particle-induced ionization source has been used in all models. These ionization rates, accounting for protons $(154 \mathrm{eV}-500 \mathrm{MeV})$ and electrons $(154 \mathrm{eV}-5 \mathrm{MeV})$ have been provided by the AIMOS model (Wissing and Kallenrode, 2009). Different model responses to the particle forcing are hence reduced to differences of the intrinsic model properties, e.g. chemical and dynamical schemes. A major aim of this paper is the assessment of these differences and their implications for the models' ability to correctly describe particle precipitation effects which represent an important source of natural, solar-induced climate variability on short and mid-term scales. Additionally, conclusions on the quality of the description of the external forcing provided by the ionization model can be drawn from the overall agreement of the short-time response of primarily generated constituents (i.e. $\mathrm{NO}_{\mathrm{x}}$ ).

The paper is organized as follows: in Sect. 2 we give an overview on MIPAS observations and data products used in this study, followed by Sect. 3 describing the ionization model AIMOS and Sect. 4 describing the participating global circulation and chemistry transport models. The intercomparison method is described in Sect. 5, followed by the discussion of the results (Sect. 6).

\section{MIPAS observations}

The Michelson Interferometer for Passive Atmospheric Sounding (MIPAS) is a mid-infrared Fourier transform limb emission spectrometer designed and operated for measurement of atmospheric trace species from space (Fischer et al., 2008). It is part of the instrumentation of the European Environmental Satellite (ENVISAT) which was launched into its sun-synchronous polar orbit of $98.55^{\circ} \mathrm{N}$ inclination at about $800 \mathrm{~km}$ altitude on 1 March 2002. MIPAS passes the equator in a southerly direction at 10:00 a.m. local time 14 to 15 times a day, observing the atmosphere during day and night with global coverage from pole to pole. The instrument's field of view is $30 \mathrm{~km}$ in horizontal and approximately $3 \mathrm{~km}$ in vertical direction. MIPAS operated during October/November 2003 at full spectral resolution of $0.035 \mathrm{~cm}^{-1}$ (unapodized) in terms of full width at half maximum. During this period, MIPAS recorded a rear-viewing limb sequence of 17 spectra each $90 \mathrm{~s}$, corresponding to an along track sampling of approximately $500 \mathrm{~km}$ and providing about 1000 vertical profiles per day in its standard observation mode. Tangent heights covered the altitude range from 68 down to $6 \mathrm{~km}$ with tangent altitudes at $68,60,52,47$, and then at $3 \mathrm{~km}$ steps from 42 to $6 \mathrm{~km}$.

Trace gas profiles have been retrieved from calibrated geolocated limb emission spectra with the scientific MIPAS level 2 processor developed and operated by the Institute of Meteorology and Climate Research (IMK) in Karlsruhe together with the Instituto de Astrofísica de Andalucía (IAA) in Granada. The general retrieval strategy, which is a constrained multi-parameter non-linear least squares fitting of measured and modeled spectra, is described in detail in von Clarmann et al. (2003). Its extension to retrievals under consideration of non-LTE (i.e. CO, $\mathrm{NO}$, and $\mathrm{NO}_{2}$ ) is described in Funke et al. (2001). Non-LTE vibrational populations of these species are modeled with the Generic RAdiative traNsfer AnD non-LTE population Algorithm (GRANADA) (Funke et al., 2007) within each iteration of the retrieval.

In contrast to previous work describing MIPAS observations of composition changes during the Halloween SPE (López-Puertas et al., 2005a,b; von Clarmann et al., 2005), we base our analysis here on reprocessed IMK/IAA MIPAS data which have substantially improved with respect to previous data versions. These improvements include updates in the L1B processing (version 4.61/62 instead of 4.59) performed by ESA as well as changes in the L2 processing performed at IMK/IAA. The new data set also offers full temporal coverage over the period of interest (26 October- 

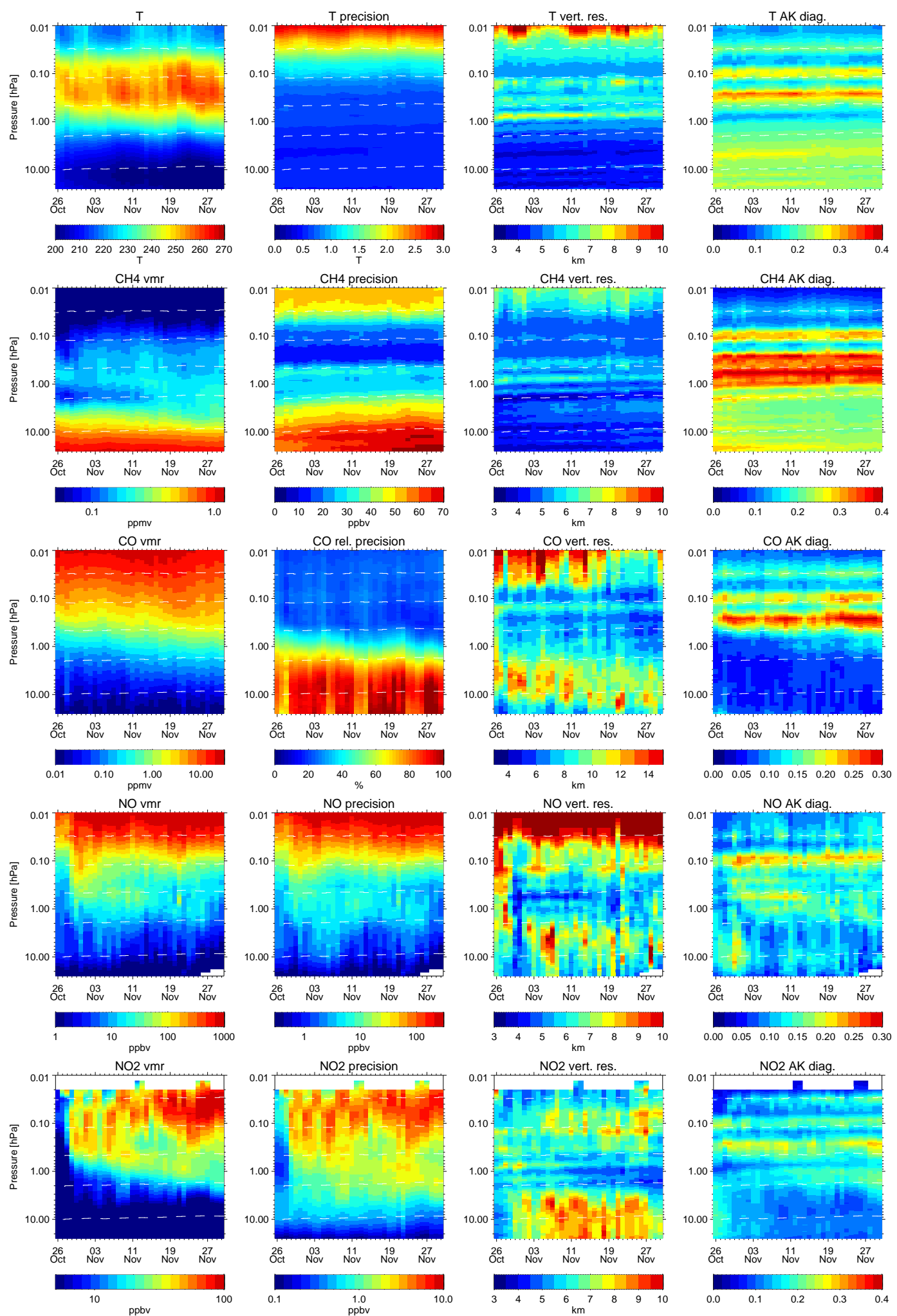

Fig. 1. Temporal evolution of MIPAS temperature, $\mathrm{CH}_{4}, \mathrm{CO}, \mathrm{NO}, \mathrm{NO}_{2}$, (from top to bottom) volume mixing ratio, single measurement precision, vertical resolution, and AK diagonal element profiles (left to right) during 26 October-30 November 2003 averaged over 60$90^{\circ} \mathrm{N}$. White dashed lines indicate 30, 40,50,60, and $70 \mathrm{~km}$ geometric altitude levels. White regions reflect meaningless data (AK diagonal elements smaller than 0.03). 
30 November 2003). In the following, we summarize the improvements of the retrieval setups for each species/parameter and characterize the data used in our analysis in terms of estimated single measurement precision and vertical resolution obtained from the full width at half maximum of the rows of the averaging kernel (AK) matrix (Rodgers, 2000). The AK diagonal elements are also discussed as a measure of the sensitivity of the retrieval at a given profile grid point to the "true" profile. Values close to zero (typically $<0.03$ ) indicate that there is no significant sensitivity to the retrieval parameter at the corresponding altitude and hence are excluded from our analysis. This value may appear unreasonably small but since IMK/IAA retrievals are not constrained by optimal estimation (Rodgers, 2000) but by a first order smoothing constraint using a Tikhonov (1963) formalism, low values do not hint at a large a priori content of the retrieval but only at extensive smearing of information over altitude. A detailed discussion of systematic retrieval errors can be found in previous works describing the individual constituent retrievals which are referenced in the following.

\subsection{Temperature}

Temperature data versions used here are V3O_T_9 and V3O_T_10 (see Table 1), both including as an extension to the original retrieval setup described in von Clarmann et al. (2003) the joint retrieval of horizontal temperature gradients. Differences between both versions are of minor nature and do not noticeably affect the data characteristics. In the period of interest, observed temperatures range at $60-90^{\circ} \mathrm{N}$ from around $200 \mathrm{~K}$ in the lower stratosphere to around $270 \mathrm{~K}$ at the stratopause (see Fig. 1). The single measurement precision ranges from $0.5 \mathrm{~K}$ to $1.5-2.5 \mathrm{~K}$ above the stratopause. Vertical resolution is $3-4 \mathrm{~km}$ below $1 \mathrm{hPa}$ and $5-7 \mathrm{~km}$ above. Meaningful data are obtained in the whole vertical range of interest $(25-70 \mathrm{~km})$.

\section{$2.2 \mathrm{CH}_{4}$}

We use version V3O_CH4_12 (see Table 1) which has been jointly retrieved with $\mathrm{N}_{2} \mathrm{O}$ (V3O_N2O_12). The retrieval setup is similar to that described in Glatthor et al. (2005). The single measurement precision ranges from 10-20 ppbv in the upper stratosphere to 50-70 ppbv above and below (see Fig. 1) Vertical resolution is 3-6 km below $0.03 \mathrm{hPa}$ and slightly higher above. Meaningful data is obtained in the whole vertical range of interest $(25-70 \mathrm{~km})$.

\subsection{CO}

$\mathrm{CO}$ data versions used here are V3O_CO_9, V3O_CO_10, described in detail in Funke et al. (2009), as well as the most recent version V3O_CO_11 (see Table 1). Improvements implemented in the latter version include an extended set of spectral fitting windows resulting in a better precision and vertical resolution in the lower and middle strato- sphere. In the period of interest, the temporal evolution of MIPAS CO abundances at $60-90^{\circ} \mathrm{N}$ indicate polar winter descent of mesospheric air masses of about $10 \mathrm{~km}$ around $1 \mathrm{hPa}$ (see Fig. 1). The single measurement precision ranges from 20-30\% above $1 \mathrm{hPa}$ to $70-80 \%$ in the lower stratosphere. Vertical resolution is $6-12 \mathrm{~km}$ below $0.1 \mathrm{hPa}$. Meaningful data are obtained in the whole vertical range of interest (25$70 \mathrm{~km})$.

\subsection{NO}

We use version V3O_NO_14 (see Table 1), available for the whole time period. This version has substantially improved with respect to the retrieval setup described in Funke et al. (2005) and the data discussed in López-Puertas et al. (2005a) by (i) the use of $\log (\mathrm{vmr})$ instead of vmr (volume mixing ratio) in the retrieval vector, (ii) a revised correction scheme for line of sight variations of the $\mathrm{NO}_{\mathrm{x}}$ partitioning close to the terminator, and iii) joint-fitted vmr horizontal gradients at constant longitudes and latitudes. NO increases of several $100 \mathrm{ppbv}$ have been observed at $60-90^{\circ} \mathrm{N}$ during the intense proton forcing during 29 October- 4 November in the upper stratosphere around $0.2 \mathrm{hPa}$ (see Fig. 1). Above, $\mathrm{NO}$ increases were mainly produced by polar winter descent of upper atmospheric air masses, resulting in vmrs up to $1 \mathrm{ppmv}$ below $70 \mathrm{~km}$. The single measurement precision is of the order of $10 \%$. Vertical resolution ranges from 4 to $8 \mathrm{~km}$ below $70 \mathrm{~km}$. Meaningful data are obtained in the whole vertical range of interest $(25-70 \mathrm{~km})$.

\section{$2.5 \mathrm{NO}_{2}$}

$\mathrm{NO}_{2}$ data versions used here are V3O_NO2_11, V3O_NO2_13, and V3O_NO2_14 (see Table 1). Including the same modifications as described above for NO, these versions have substantially improved with respect to the retrieval setup described in Funke et al. (2005) and the data discussed in López-Puertas et al. (2005a). While differences between the latter two versions do not affect noticeably the data characteristics, a modified regularization scheme and terminator treatment implemented after version V3O_NO2_11 gave rise to non-negligible differences in the newer versions with respect to the previous setup. These differences are visible in the vertical resolution in the mesosphere and middle stratosphere (see Fig. 1, third column) and go along with generally smaller vmrs around the terminator at $70^{\circ} \mathrm{N}$ around $0.1 \mathrm{hPa}$. Similar to $\mathrm{NO}$, increases of 50-80 ppbv were observed during the proton forcing in the upper stratosphere, descending by approximately $10 \mathrm{~km}$ by the end of November. Polar winter descent of $\mathrm{NO}_{\mathrm{x}}$ led to mesospheric $\mathrm{NO}_{2}$ increases of more then $100 \mathrm{ppbv}$, particularly in the second half of November. The single measurement precision is of the order of $5-10 \%$. Vertical resolution ranges from 4 to $8 \mathrm{~km}$ below $70 \mathrm{~km}$. Meaningful 

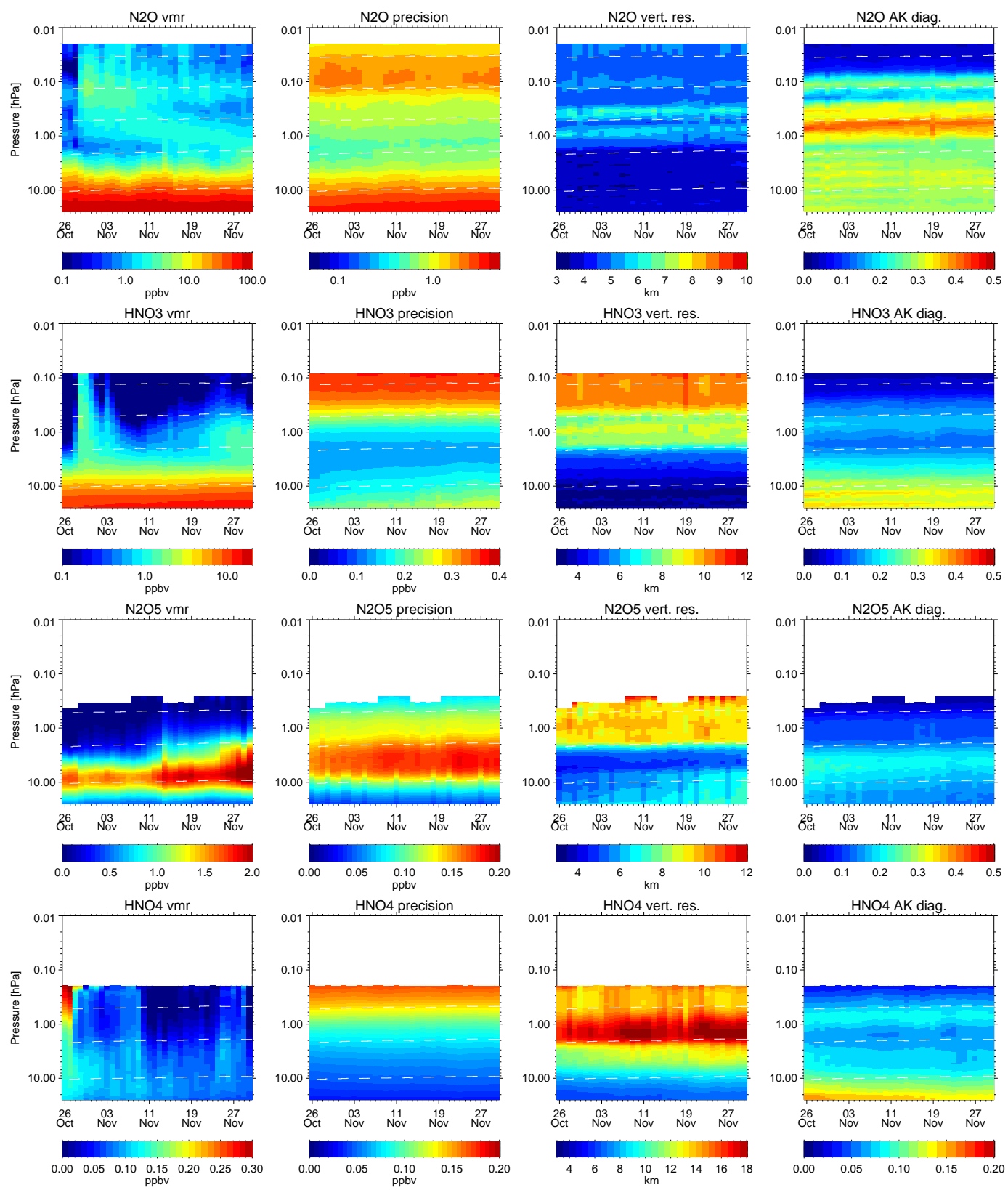

Fig. 2. Same as Fig. 1, but for $\mathrm{N}_{2} \mathrm{O}, \mathrm{HNO}_{3}, \mathrm{~N}_{2} \mathrm{O}_{5}$, and $\mathrm{HNO}_{4}$.

data are obtained in the whole vertical range of interest $(25-70 \mathrm{~km})$.

\section{$2.6 \mathrm{~N}_{2} \mathrm{O}$}

We use version V3O_N2O_12 (see Table 1), available for the whole time period. This version has already been used for the previous analysis of $\mathrm{N}_{2} \mathrm{O}$ abundance changes during the Halloween SPE (Funke et al., 2008) and differs from other versions by a relaxed regularization above approximately $40 \mathrm{~km}$, which allows for vertically resolving the upper stratospheric and mesospheric enhancements. At $60-90^{\circ} \mathrm{N}$, these en- hancements of around 5-7 ppbv appeared around 30 October and descended during November to the middle stratosphere (see Fig. 2). The single measurement precision ranges from $0.5 \mathrm{ppbv}$ in the upper stratosphere to $2 \mathrm{ppbv}$ in the mesosphere. Vertical resolution is $4-6 \mathrm{~km}$. Meaningful data are obtained in the whole vertical range of interest $(25-70 \mathrm{~km})$.

\section{$2.7 \mathrm{HNO}_{3}$}

We use version V3O_HNO3_9 (see Table 1), available for the whole time period, and which is based on the retrieval setup described in Wang et al. (2007). $\mathrm{HNO}_{3}$ increases of around 
$3 \mathrm{ppbv}$ up to altitudes of $0.1 \mathrm{hPa}$ during the proton forcing and a further buildup at slightly lower altitudes at the end of November are visible in Fig. 2, consistent with previous findings (López-Puertas et al., 2005b). The single measurement precision ranges from $0.1 \mathrm{ppbv}$ in the middle stratosphere to $0.35 \mathrm{ppbv}$ around the stratopause. Vertical resolution is 3$4 \mathrm{~km}$ below $12 \mathrm{hPa}$ and $7-10 \mathrm{~km}$ above. Meaningful data are obtained below $0.1 \mathrm{hPa}(60 \mathrm{~km})$.

\section{$2.8 \mathrm{~N}_{2} \mathrm{O}_{5}$}

$\mathrm{N}_{2} \mathrm{O}_{5}$ data versions used here are $\mathrm{V} 3 \mathrm{O} \_\mathrm{N} 2 \mathrm{O}_{-}{ }_{3}$ and V3O_N2O5_10 (see Table 1), all based on the retrieval setup described in Mengistu Tsidu et al. (2004). Differences between both versions are of minor nature and do not affect noticeably the data characteristics. $\mathrm{N}_{2} \mathrm{O}_{5}$ increases related to the proton event are visible in Fig. 2 in the second half of November around $2-0.5 \mathrm{hPa}$, consistent with previous findings (López-Puertas et al., 2005b; Orsolini et al., 2005). The single measurement precision ranges from $0.05 \mathrm{ppbv}$ to $0.15 \mathrm{ppbv}$ in the middle stratosphere. Vertical resolution is $5-7 \mathrm{~km}$ below $2 \mathrm{hPa}$ and $9-10 \mathrm{~km}$ above. Meaningful data are obtained below approximately $0.3 \mathrm{hPa}(52 \mathrm{~km})$.

\section{$2.9 \mathrm{HNO}_{4}$}

We use version V3O_HNO4_12 (see Table 1) which differs from the original retrieval setup described in Stiller et al. (2007) by the application of a weaker regularization in the middle stratosphere, where most pronounced SPE effects are expected. Unfortunately, this version is sensitive to systematic oscillations in the radiance baseline related to an imperfect gain calibration of the instrument (see also Stiller et al., 2008). In consequence, retrieved $\mathrm{HNO}_{4}$ profiles are systematically biased during each gain calibration period (typically a few days) with a randomly changing magnitude from one calibration period to another. The variable bias is noticeable in the temporal evolution of the observed $\mathrm{HNO}_{4}$ distributions at $60-90^{\circ} \mathrm{N}$ (see Fig. 2) as sharp increases/decreases in the upper stratosphere, coincident with the onsets of new gain calibration periods (i.e. 28 October, 10 November, and 24 November). Therefore, we restrict our analysis of SPErelated $\mathrm{HNO}_{4}$ increases in Sect. 6 to data observed during one particular gain calibration period, 28 October-5 November, covering the onset of the proton forcing which led to short-term $\mathrm{HNO}_{4}$ increases of the order of $0.15 \mathrm{ppbv}$ (hardly visible in Fig. 2). The single measurement precision ranges from 0.03 ppbv to $0.15 \mathrm{ppbv}$ around the stratopause. Vertical resolution is $6-10 \mathrm{~km}$ below $5 \mathrm{hPa}$ and around $10 \mathrm{~km}$ above. Meaningful data are obtained below approximately $0.2 \mathrm{hPa}$ $(55 \mathrm{~km})$.

\section{$2.10 \quad \mathrm{O}_{3}$}

We use version V3O_O3_9 (see Table 1), available for the whole time period. Retrieval setup and characteristics are similar to those described in Steck et al. (2007), except for a slightly different selection of spectral intervals (microwindows) and the inclusion of pre-fitted horizontal temperature gradients. A pronounced $\mathrm{O}_{3}$ depletion during the intense proton forcing as already reported in López-Puertas et al. (2005a) is visible above the stratopause at $60-90^{\circ} \mathrm{N}$, competing with seasonal mesospheric $\mathrm{O}_{3}$ buildup in the following weeks (see Fig. 3). Also, the previously reported $\mathrm{NO}_{\mathrm{x}}$-induced losses at lower altitudes are seen on a midterm scale. The single measurement precision ranges from $0.1 \mathrm{ppmv}$ around the stratopause to $0.25 \mathrm{ppbv}$ above and below. Vertical resolution is $3-4 \mathrm{~km}$ below $1 \mathrm{hPa}$ and $5-7 \mathrm{~km}$ above. Meaningful data are obtained in the whole vertical range of interest $(25-70 \mathrm{~km})$.

\section{$2.11 \mathrm{H}_{2} \mathrm{O}_{2}$}

We use version $\mathrm{V} 3 \mathrm{O} \_\mathrm{H} 2 \mathrm{O} 2 \_4$, available for the whole time period (see Table 1) which is based on the retrieval setup described in Versick (2010). $\mathrm{H}_{2} \mathrm{O}_{2}$ increases up to $0.15 \mathrm{ppbv}$ have been observed at $60-90^{\circ} \mathrm{N}$ during the intense proton forcing on 29 October- 4 November in the upper stratosphere around $0.2 \mathrm{hPa}$ (see Fig. 3). The single measurement precision in the middle stratosphere ranges from 0.1 to $0.2 \mathrm{ppbv}$, being thus of the order of the observed enhancements. In consequence, averaging is required for the analysis. Vertical resolutions larger than $10 \mathrm{~km}$ indicate that no relevant information on the vertical distribution of the middle/upper stratospheric enhancements can be extracted from the measurements. Meaningful data are obtained below approximately $0.2 \mathrm{hPa}(55 \mathrm{~km})$.

\section{$2.12 \mathrm{ClO}$}

$\mathrm{ClO}$ data versions used here are V3O_CLO_10 and V3O_CLO_11 (see Table 1), all based on the retrieval setup described in Glatthor et al. (2004). Differences between both versions are of minor nature and do not affect noticeably the data characteristics. As in the case of $\mathrm{HNO}_{4}, \mathrm{ClO}$ data is affected by systematic oscillations in the radiance baseline related to an imperfect gain calibration of the instrument, however, to a lesser degree than in the case of $\mathrm{HNO}_{4}$. The single measurement precision ranges from $0.2 \mathrm{ppbv}$ in the lower stratosphere to $0.7 \mathrm{ppbv}$ around $2 \mathrm{hPa}$, being thus higher than $100 \%$ at the $\mathrm{ClO}$ peak height (see Fig. 3). In consequence, averaging is required for its analysis. Vertical resolution is 6-10 km below $2 \mathrm{hPa}$ and $15-20 \mathrm{~km}$ above. Meaningful data are obtained below approximately $0.5 \mathrm{hPa}(40 \mathrm{~km})$.

\subsection{HOCl}

$\mathrm{HOCl}$ data versions used here are V3O_HOCL_3 and V3O_HOCL_4 (see Table 1), all based on the retrieval setup described in von Clarmann et al. (2006). Differences between both versions are of minor nature and do not affect noticeably the data characteristics. $\mathrm{HOCl}$ increases of around 

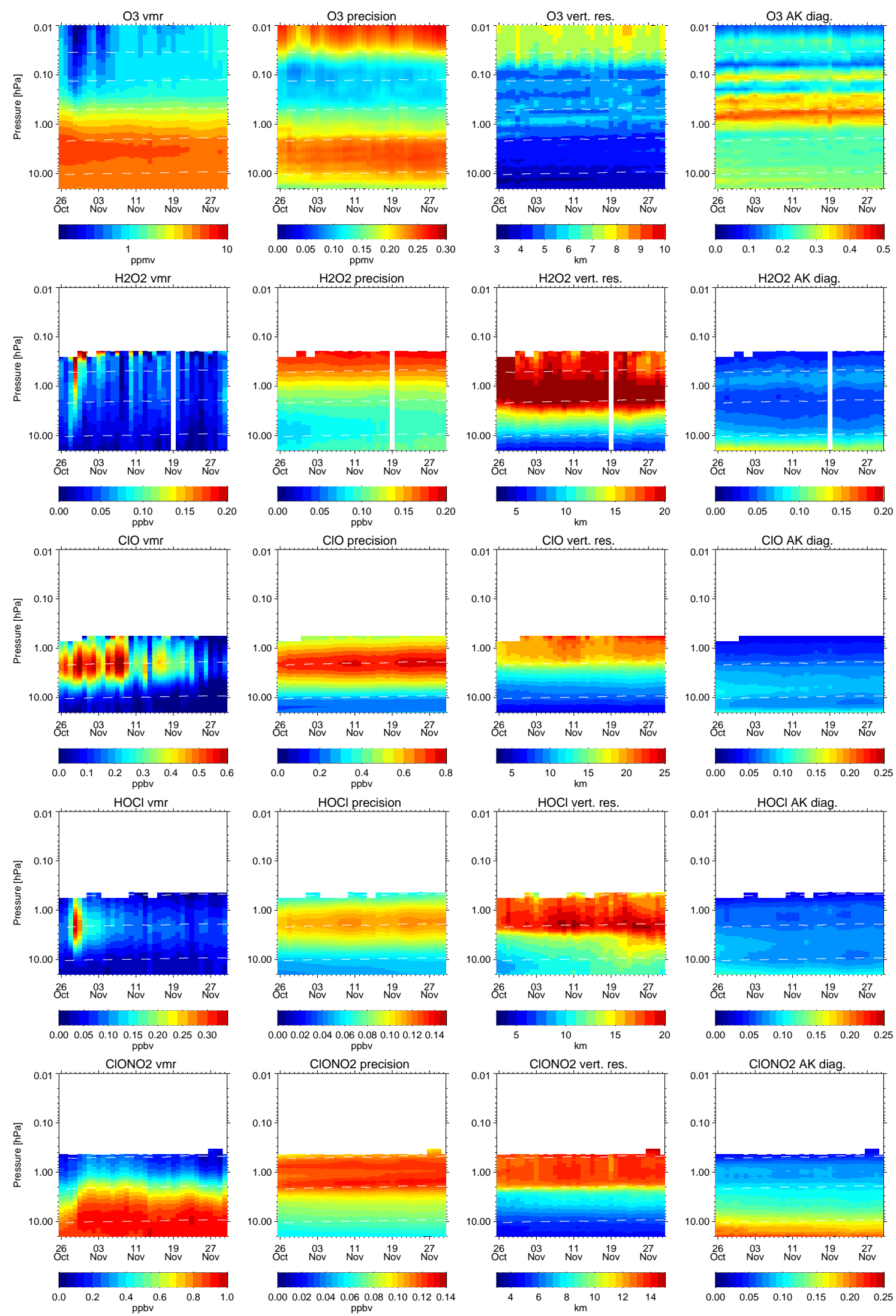

Fig. 3. Same as Fig. 2, but for $\mathrm{O}_{3}, \mathrm{H}_{2} \mathrm{O}_{2}, \mathrm{ClO}, \mathrm{HOCl}$, and $\mathrm{ClONO}_{2}$. 
0.3 ppbv show up in Fig. 3 immediately after the main proton forcing at the beginning of November, consistent with previous findings (von Clarmann et al., 2005). The single measurement precision ranges from 0.05 to $0.1 \mathrm{ppbv}$ around $2 \mathrm{hPa}$. Vertical resolution $8-12 \mathrm{~km}$ below $2 \mathrm{hPa}$ and coarser than $15 \mathrm{~km}$ above. Meaningful data is obtained below approximately $0.5 \mathrm{hPa}(40 \mathrm{~km})$.

\section{$2.14 \mathrm{ClONO}_{2}$}

$\mathrm{ClONO}_{2}$ data versions used here are V3O_CLONO2_11 and V3O_CLONO2_12 (see Table 1), all based on the retrieval setup described in Höpfner et al. (2007). Differences between both versions are of minor nature and do not affect noticeably the data characteristics. $\mathrm{ClONO}_{2}$ increases of around $0.5 \mathrm{ppbv}$ are visible in Fig. 3 after the main proton forcing above $5 \mathrm{hPa}$ and last until the end of November. This is consistent with previous findings based on data version V1_CLONO2_1 (López-Puertas et al., 2005b) in qualitative terms, however, the peak height of the increases is slightly higher $(\sim 5 \mathrm{~km})$ in the newer data versions included here. This difference is mainly related to a change of the heightdependent regularization strength in order to allow for more sensitivity at lower and higher altitudes. The single measurement precision ranges from 0.06 to $0.12 \mathrm{ppbv}$, increasing with altitude. Vertical resolution is $5-8 \mathrm{~km}$ below $2 \mathrm{hPa}$ and $12-14 \mathrm{~km}$ above. Meaningful data is obtained below approximately $0.5 \mathrm{hPa}(40 \mathrm{~km})$.

\section{Ionization rates}

The model intercomparison is based on ionization rates calculated with Atmospheric Ionization Module OSnabrück (AIMOS). The reason is to avoid different model results due to different ionization rates as to better understand the differences in the dynamical and chemistry schemes of the models under assessment. AIMOS calculates ionization rates due to precipitating solar and magnetospheric particles. The altitude range of calculated ionization rates is defined by the energy range of the particles considered, which is specific to the satellite instruments used. The data used here and their altitude coverage are listed in Table 2 . Given by the altitude range of this study, the focus lies on solar particles. As particle precipitation strongly depends on the geomagnetic field, the model accounts for different spatial precipitation zones. A detailed description of AIMOS can be found in Wissing and Kallenrode (2009).

AIMOS is composed of two parts. One describes the spatial particle flux on top of the atmosphere while the second calculates the resulting ionization rate. Both parts will be discussed in the following.
Table 2. AIMOS particle energy ranges and the corresponding pressure and altitude levels. As the upper altitude border for protons and electrons lies in the thermosphere, it varies by solar activity. The first number indicates solar minimum conditions while the second number represents solar maximum.

\begin{tabular}{cccc}
\hline Species & Energy & $\begin{array}{c}\text { Pressure } \\
(\mathrm{hPa})\end{array}$ & $\begin{array}{c}\text { Approx. altitude } \\
(\mathrm{km})\end{array}$ \\
\hline protons & $154 \mathrm{eV}-500 \mathrm{MeV}$ & $10^{-7}-100$ & $18-240 / 440$ \\
electrons & $154 \mathrm{eV}-5 \mathrm{MeV}$ & $10^{-7}-1$ & $48-240 / 440$ \\
\hline
\end{tabular}

\subsection{Spatial particle flux}

The particle flux on top of the atmosphere is measured by the TED and MEPED instruments on POES 15/16 as well as the SEM instrument on GOES 10. As all particle measurements are in-situ, the main challenge is to derive a global coverage at any time. Inside an empirically determined polar cap where particle precipitation is homogeneous, the high energy particle flux from GOES and the mean flux values from polar cap crossings of the POES satellites are used. Outside the polar cap, particle precipitation depends on geomagnetic latitude, geomagnetic activity and local time. Therefore, mean precipitation maps for the POES TED and MEPED channels, based on a 4 year data set, have been produced, sorted by the geomagnetic Kp-index and local time. These mean precipitation maps represent the spatial distribution, including, e.g. the movement of the auroral oval. According to the recent Kp-level, the mean precipitation maps are selected and scaled to recent POES particle flux.

In summary, the first part of the model describes the incoming particle flux at every grid point. The spatial resolution is 96 zonal cells, divided into 48 meridional sections. Regions of similar particle flux are combined as, e.g. the polar cap. Given by the scaling of the mean precipitation maps, the temporal resolution is limited by the POES orbit and has been set to $2 \mathrm{~h}$.

\subsection{Modeling ionization rates}

The second part of AIMOS is the atmospheric particle detector model, which simulates particle interactions based on the GEANT4-Simulation Toolkit (Agostinelli et al., 2003). GEANT4 provides Monte-Carlo based algorithms to model energy deposition/ionization of protons and electrons. The atmospheric detector model is divided into 67 logarithmically equidistant pressure levels, ranging from sea level to $1.7 \times 10^{-5} \mathrm{~Pa}$. Since the atmospheric parameters (density, altitude, composition and temperature) depend on latitude, season and solar activity, model versions for $80^{\circ} \mathrm{N}, 60^{\circ} \mathrm{N}$, $60^{\circ} \mathrm{S}$ and $80^{\circ} \mathrm{S}, 3$ different F10.7 flux values and 4 different months are used. These parameters are adopted from the HAMMONIA (Schmidt et al., 2006) and MSIS (Picone et al., 

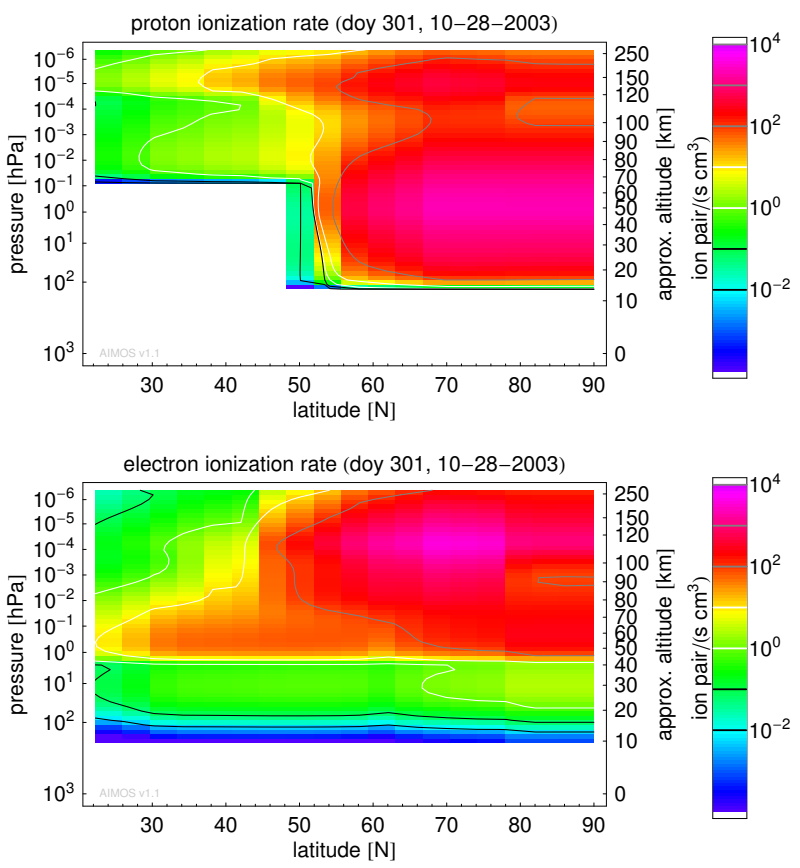

Fig. 4. Altitude-latitude sections of AIMOS ion pair production rates for protons (top) and electrons (bottom) on 28 October 2003.

2002) models. The ionization rates for mono-energetic and isotropic particle ensembles are determined. As a final step, the mono-energetic ionization rates are combined with multiple power-law fits of the particle flux at various regions. The latitudinal distribution of the proton and electron contributions to the modeled ionization rates is shown in Fig. 4 for 28 October 2003.

Figure 5 shows the temporal evolution of the resulting ion pair production rates averaged over $40-90^{\circ} \mathrm{N}$ during the period of interest. Prior to the main event, a X1.1 flare on 23 October was accompanied by a coronal mass ejection (CME), affecting moderately the Earth atmosphere on the evening of 26 October (Dst: $-72 \mathrm{nT}$ ). The main event was caused by a series of three consecutive flares (X1.2, X17 and X10) from 26 October to 29 October, accompanied by strong precipitation of energetic particles as well as interplanetary shocks causing high geomagnetic disturbance (Dst: $-42 \mathrm{nT}$, $-363 \mathrm{nT}$ and $-401 \mathrm{nT}$ ) when they arrived at $1 \mathrm{AU}$ after 20 to $32 \mathrm{~h}$. This "Halloween" SPE provoked two very strong increases in the ion pair production rates on 28-30 October and led to significant atmospheric ionization down to the middle stratosphere around $10 \mathrm{hPa}$. Modeled peak rates at $0.1 \mathrm{hPa}$ were in the order of several thousand ion pairs per $\mathrm{cm}^{-3}$. The second, less intense event was a consequence of a X8.3 flare in the evening of 2 November. The following shock arrived at Earth on 4 November, leading to geomagnetic disturbance (Dst: $-68 \mathrm{nT}$ ) and moderate ionization restricted to higher altitudes. The most intensive flare (and fastest CME) during this period (and solar cycle 23 in total) reaches class

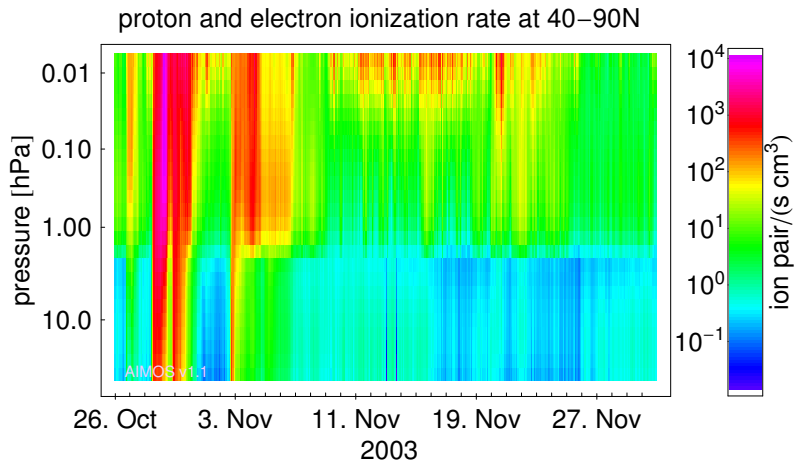

Fig. 5. Temporal evolution of area-weighted averages $\left(40-90^{\circ} \mathrm{N}\right)$ of AIMOS ion pair production rates for protons and electrons during the period of interest. Electron ionization rate below $1 \mathrm{hPa}$ is induced by bremsstrahlung only.

X28 on 4 November. However, as it was moving orthogonal to the Sun-Earth line, the impact to the Earth's atmosphere was small (Dst: $-27 \mathrm{nT}$ ) as indicated by the little red peak in the evening of 6 November. The last major forcing during this period was the large storm on 20 November (Dst: $-472 \mathrm{nT}$ ) originating from a CME on 18 November. A more detailed description of the October-November 2003 SPE period is given in Gopalswamy et al. (2005).

The ionization rates should provide a similar forcing for all models, therefore the original data set has been adopted to every model grid. The data set and the adoption routine for a used specific grid is available at http://aimos.physik.uos.de.

\section{Description of participating models}

\subsection{Bremen 2d model (B2dM)}

The Bremen two-dimensional model is based on the twodimensional transport, chemistry and radiation model formerly described in Sinnhuber et al. (2009) and Chipperfield and Feng (2003). It uses the dynamical core of the so-called "two-and a half-dimensional" model THIN AIR (Kinnersley, 1998), which calculates temperature, pressure, and horizontal transport on isentropic surfaces, interactively with the model chemistry. The model covers the altitude range from the surface to $\sim 100 \mathrm{~km}$ in 29 isentropic surfaces, providing a vertical spacing of about $3.5 \mathrm{~km}$. The horizontal resolution is about 9.5 degree. Stratospheric dynamics are forced by the amplitudes of waves 1 to 3 of the Montgomery potential from meteorological analyses with a repeating annual cycle for the period of May 1980 to April 1981. There is no quasi biennial oscillation (QBO) in the model, i.e. the modeled tropical stratospheric wind is always in a weak easterly state. In this sense, the Bremen $2 \mathrm{~d}$ model is a two-dimensional chemistry-climate model which is forced to repeat a very similar scenario by the repeating annual cycle of the Montgomery potential. 
The chemistry is based on the SLIMCAT chemistry (Chipperfield and Jones, 1999), but adapted for the use in the mesosphere in several ways: (1) above $\sim 50 \mathrm{~km}$, no family approach is used; (2) $\mathrm{H}_{2} \mathrm{O}$ and $\mathrm{CO}_{2}$ are treated as short-lived species explicitly, and $\mathrm{H}_{2}$ is varied as well, to provide a realistic description of mesospheric $\mathrm{HO}_{\mathrm{x}}$ and CO. (3) $\mathrm{NO}_{\mathrm{x}}$ and $\mathrm{HO}_{\mathrm{x}}$ production by atmospheric ionization is parameterized based on Porter et al. (1976) and Solomon et al. (1981), i.e. $1.25 \mathrm{NO}_{\mathrm{x}}$ are produced, of which $45 \%$ are produced as $\mathrm{N}$, and $55 \%$ as $\mathrm{NO}$, and up to $2 \mathrm{HO}_{\mathrm{x}}$ are produced per ion pair depending on pressure and ionization rate, equally distributed to $\mathrm{H}$ and $\mathrm{OH}$. Ionization due to Galactic Cosmic Rays in the stratosphere has been included based on Heaps (1978); the additional ionization due to solar and magnetospheric particles is considered by introducing atmospheric ionization rates of protons and electrons provided by the AIMOS model (see Sect. 3).

All reaction and photolysis rates are taken from Sander et al. (2006). The Bremen $2 \mathrm{~d}$ model has been used in the past to investigate the impact of large solar proton events on the composition of the middle atmosphere (Sinnhuber et al., 2003a; Rohen et al., 2005; Winkler et al., 2008). For the HEPPA intercomparison, the two-dimensional model has been combined with a one-dimensional model sharing the same description of chemistry in the following way:

25 model runs with the two-dimensional model are carried out at different longitudes, to take into account the tilt of the geomagnetic poles. The B2dM runs started in 1959. Tropospheric trace gases (FCKWs, halons, and green-house gases) were prescribed into the lowest model box from WMO (2010). For every MIPAS measurement used in the intercomparison, a one-dimensional model run is initialized with output of the 2-dimensional model runs interpolated to the geo-location of the measurement, at local noon of the day before the measurement took place. One-dimensional model runs are then carried out until the time of the measurement, providing model output at the exact time and geo-location of the measurement.

\subsection{Bremen 3d Chemistry and Transport model (B3dCTM)}

The Bremen three-dimensional Chemistry and Transport Model is a combination of the Bremen transport model (Sinnhuber et al., 2003b) and the chemistry code of the Bremen 2d model (Sinnhuber et al., 2003a; Winkler et al., 2008), which is based on the SLIMCAT model (Chipperfield and Jones, 1999).

The model has 28 isentropic levels ranging from 330 to $3402 \mathrm{~K}$ (approx. 10-60 km) and has a horizontal resolution of $3.75^{\circ} \times 2.5^{\circ}$. Output is provided hourly. The vertical transport across the isentropes is calculated through diabatic heating and cooling rates. These rates are calculated using the radiation scheme MIDRAD (Shine, 1987). The horizontal transport is driven by external wind fields. Advection is calculated by using the second order moments scheme by Prather (1986). Meteorological data, such as horizontal wind speeds and temperatures, are taken from ECMWF ERA Interim (Simmons et al., 2006). Concentrations at the lower model box are kept constant from the initialization. No transport over the lower and upper vertical boundary into and out of the model boxes is considered. The model run calculated with B3DCTM was initialized at the beginning of January 2003.

The model calculates the behavior of 58 chemical species, using a family approach for short-lived species $\left(\mathrm{HO}_{\mathrm{x}}, \mathrm{NO}_{\mathrm{x}}\right.$, $\mathrm{O}_{\mathrm{x}}, \mathrm{ClO}_{\mathrm{x}}, \mathrm{BrO}_{\mathrm{x}}$, and $\mathrm{CHO}_{\mathrm{x}}$ ). It includes about 180 gas phase, photochemical, and heterogeneous reactions and uses the recent set of recommendations for kinetic and photochemical data established by the Jet Propulsion Laboratory (Sander et al., 2006).

To account for ion chemistry reactions within the neutral code, the production of $\mathrm{NO}_{\mathrm{x}}$ and $\mathrm{HO}_{\mathrm{x}}$ is parameterized as suggested by Porter et al. (1976) and Solomon and Crutzen (1981). Hence $1.25 \mathrm{~N}$ atoms and about $2 \mathrm{HO}_{\mathrm{x}}$ are produced per ion pair. Atmospheric ionization due to solar and magnetospheric particles is considered by introducing atmospheric ionization rates of protons and electrons provided by the AIMOS model (see Sect. 3).

\subsection{CAO}

The Central Aerological Observatory (CAO) model consists of a CTM and a 3-D dynamical core with a horizontal resolution of $10^{\circ} \times 10^{\circ}$ and vertical resolution of $2 \mathrm{~km}$. The radiative scheme used in the dynamical core below $60 \mathrm{~km}$ is based on parameterizations described in Chou and Suarez (1994, 1999). Above, parameterizations from Kutepov and Fomichev (1993); Fomichev et al. (1998); Kockarts (1980); Strobel (1978) are applied. The CTM calculates the concentrations of 30 minor components, involved in 70 chemical and 35 photochemical reactions, in the range $0-90 \mathrm{~km}$. Output is provided hourly. The reaction rate constants, absorption cross-sections, solar radiation intensity, and quantum outputs were assigned in the tabulated form according to Sander et al. (2003). The annual and daily variations of the solar zenith angle at a given point and its dependence on the height above the Earth's surface were taken into account. For zenith angle higher than $75^{\circ}$, Chapman's functions have been used in accordance with Swinder and Gardner (1967). Photolysis rates have been recalculated every hour during the integration of the model. A family approach (Turco and Whitten, 1974) has been used for solving the chemical equations, including $\mathrm{O}_{\mathrm{x}}\left(\mathrm{O}_{3}+\mathrm{O}+\mathrm{O}\left({ }^{1} \mathrm{D}\right)\right), \mathrm{NO}_{\mathrm{y}}$ $\left(\mathrm{N}+\mathrm{NO}+\mathrm{NO}_{2}+\mathrm{NO}_{3}+2 \mathrm{~N}_{2} \mathrm{O}_{5}+\mathrm{HNO}_{3}+\mathrm{HNO}_{4}+\mathrm{ClONO}_{2}\right)$, $\mathrm{Cl}_{\mathrm{y}}(\mathrm{Cl}+\mathrm{ClO}+\mathrm{OClO}+\mathrm{ClOO}+\mathrm{HOCl}+\mathrm{HCl})$, and hydrogen compounds $\left(\mathrm{H}+\mathrm{OH}+\mathrm{HO}_{2}+2 \mathrm{H}_{2} \mathrm{O}_{2}\right)$. Other long-lived species $\left(\mathrm{N}_{2} \mathrm{O}, \mathrm{CCl}_{4}, \mathrm{CFCl}_{3}, \mathrm{CF}_{2} \mathrm{Cl}_{2}, \mathrm{CH}_{3} \mathrm{Cl}_{3}, \mathrm{CH}_{4}, \mathrm{H}_{2} \mathrm{O}\right.$, $\mathrm{H}_{2}$ and $\mathrm{CO}_{2}$ ) were included also in simulations. The $\mathrm{CAO}$ model applies additionally to electron and proton-induced 
Table 3. Summarized description of the models involved in this study.

\begin{tabular}{|c|c|c|c|c|c|c|c|c|}
\hline Model & Type & $\begin{array}{l}\text { Vertical } \\
\text { domain }\end{array}$ & $\begin{array}{r}\text { Vert. range } \\
(\mathrm{km})\end{array}$ & $\begin{array}{l}\text { Horizontal } \\
\text { resolution }\end{array}$ & $\begin{array}{r}\text { Vert. res. } \\
(\mathrm{km})\end{array}$ & $\begin{array}{l}\text { Meteorological data } \\
\text { nudging }\end{array}$ & $\begin{array}{l}\text { Family } \\
\text { approach }^{\mathrm{a}}\end{array}$ & $\begin{array}{l}\text { Kinetic } \\
\text { data }^{b}\end{array}$ \\
\hline $\mathrm{B} 2 \mathrm{dM}$ & CTM/GCM -2D & isentropic & $\sim 0-100$ & $9.5^{\circ}$ & $\sim 3.5$ & GCM & $<50 \mathrm{~km}$ & S06 \\
\hline $\mathrm{CAO}$ & CTM/GCM & altitude & 0-90 & $10^{\circ} \times 10^{\circ}$ & 2 & GCM & yes & S03 \\
\hline FinROSE & CTM & hybrid & $\sim 0-65$ & $10^{\circ} \times 5^{\circ}$ & $\sim 2$ & ECMWF ERA Interim & yes & S06 \\
\hline HAMMONIA & $\mathrm{CCM}$ & pressure & $\sim 0-200$ & $4^{\circ} \times 4^{\circ}$ & $\sim 3.5$ & ECMWF below $179 \mathrm{hPa}$ & no & S06 \\
\hline SOCOL(i) & $\mathrm{CCM}$ & hybrid & $\sim 0-80$ & $3.75^{\circ} \times 3.75^{\circ}$ & $\sim 2$ & free-running & no & S00 \\
\hline WACCM & $\mathrm{CCM}$ & pressure & $\sim 0-135$ & $1.9^{\circ} \times 2.5^{\circ}$ & $\sim 1.5$ & MERRA below $50 \mathrm{~km}$ & no & S06 \\
\hline
\end{tabular}

${ }^{\text {a }}$ See model descriptions in Sect. 4 for details. ${ }^{b}$ S00: Sander et al. (2000), S03: Sander et al. (2003), S06: Sander et al. (2006).

ionization also ionization rates caused by alpha-particles provided by the AIMOS model (Wissing and Kallenrode, 2009).

The vertical profiles of molecular oxygen and air density were fixed during photochemical calculations. Heterogeneous removal of $\mathrm{H}_{2} \mathrm{O}_{2}, \mathrm{HNO}_{3}, \mathrm{HCl}$, and $\mathrm{HNO}_{4}$ was included in the troposphere. Fixed mixing ratios for longlived and "chemical families" components at lower and upper boundaries were assumed during the calculations in order to formulate the boundary conditions. Corresponding mixing ratio values were taken from Park et al. (1999). An accurate, non-diffuse method for three-dimensional advection of trace species suggested by Prather (1986) was used to solve the continuity equation for each transported species ("families" and long-lived species). The chemical constituents were initialized with profiles obtained from a one-dimensional model (Krivolutsky et al., 2001). Wind components used for transport by advection were obtained from the simulation with the 3-D dynamical model for each day of the year. The simulation was started in January 2003. Daily averaged global zonal, meridional, vertical wind components, and temperature have then been used in the CTM runs. More details concerning the chemical 3-D model can be found in Krivolutsky and Vyushkova (2002). This model was used to study the response in composition and dynamics after the July 2000 SPE (Krivolutsky et al., 2006). The CAO simulation included in this study covers the period 26 October-4 November.

\subsection{FinROSE}

FinROSE is a global 3-D chemistry transport model (Damski et al., 2007a). The model dynamics are from external sources except the vertical wind, which is calculated inside the model using the continuity equation. In this study FinROSE has 35 vertical levels $(0-65 \mathrm{~km})$, a horizontal resolution of $10^{\circ} \times 5^{\circ}$ and uses ECMWF Interim analyses (Simmons et al., 2006) for dynamics. Output is provided every $3 \mathrm{~h}$. The model produces distributions of 40 species and includes about 120 ho- mogeneous reactions and 30 photodissociation processes, using a family approach for short-lived species $\left(\mathrm{HO}_{\mathrm{x}}, \mathrm{NO}_{\mathrm{x}}, \mathrm{O}_{\mathrm{x}}\right.$, $\mathrm{ClO}_{\mathrm{x}}, \mathrm{BrO}_{\mathrm{x}}, \mathrm{Cl}_{\mathrm{x}}$, and $\mathrm{Br}_{\mathrm{x}}$. Chemical kinetic data, reaction rate coefficients and absorption cross-sections are taken from look-up-tables based on the Jet Propulsion Laboratory compilation by Sander et al. (2006). Photodissociation frequencies are calculated using a radiative transfer model (Kylling et al., 1997). The model also includes formation and sedimentation of polar stratospheric clouds (PSCs) and reactions on PSCs. Tropospheric abundances are given as boundary conditions and long-lived trace gases are relaxed towards long time trends. The spin-up period used for this model run was 1 month. The FinROSE model applies additionally to electron and proton-induced ionization also ionization rates caused by alpha-particles provided by the AIMOS model (Wissing and Kallenrode, 2009).

\subsection{HAMMONIA}

The Hamburg Model of the Neutral and Ionized Atmosphere (HAMMONIA) is a 3-dimensional GCM and chemistry model covering an altitude range from the surface up to $1.7 \times 10^{-7} \mathrm{hPa}$. A detailed description of the model is given by Schmidt et al. (2006). Simulations of particle precipitation effects use a modified version of HAMMONIA. It treats 54 photochemical, 139 bi- and termolecular, 5 ionelectron recombination, and 12 ion-neutral reactions involving 50 neutral and 6 charged $\left(\mathrm{O}^{+}, \mathrm{O}_{2}^{+}, \mathrm{N}^{+}, \mathrm{N}_{2}^{+}, \mathrm{NO}^{+}, \mathrm{e}^{-}\right)$ components. Neutral bi- and termolecular reactions and the corresponding rate coefficients are taken from Sander et al. (2006). Photochemistry involves 7 ionizing and dissociating reactions through solar irradiance of wavelengths shorter than Lyman-alpha using a parametrization of Solomon and Qian (2005) and observed solar spectral irradiance. Additionally, 6 ionizing, dissociating, and exciting reactions represent the direct influence of precipitating primary and secondary particles on thermospheric chemistry. Corresponding reaction rates are calculated using the particle induced 
ionization rates and branching ratios given by Roble and Ridley (1987) and Rusch et al. (1981). Below $10^{-3} \mathrm{hPa}$, particle impact on chemistry is represented by the production of $\mathrm{N}\left({ }^{2} \mathrm{D}\right), \mathrm{N}\left({ }^{4} \mathrm{~S}\right)$ and $\mathrm{HO}_{\mathrm{x}}$. Here, HAMMONIA uses parametrizations of Jackman et al. (2005a) based on formulations of Porter et al. (1976) and Solomon et al. (1981). The simulations use 67 pressure levels. Linear terms of dynamics are calculated using triangular truncation at wavenumber 31 (T31), while nonlinear terms of dynamics and spatially dependent physical and chemical quantities are computed on a Gaussian grid of approximately $3.75 \times 3.75^{\circ}$. Output is provided every $2 \mathrm{~h}$. Up to $179 \mathrm{hPa}$, the model is relaxed to ECMWF analyzed temperature, divergence, vorticity, and surface pressure. The HAMMONIA simulation starts on 1st March 2003 using ionization rates for the entire time period.

\subsection{KASIMA}

The KASIMA model is a 3-D mechanistic model of the middle atmosphere including full middle atmosphere chemistry (Kouker et al., 1999). The model can be coupled to specific meteorological situations by using analyzed lower boundary conditions and nudging terms for vorticity, divergence and temperature. Here we use the version as described by Reddmann et al. (2010). It has a horizontal resolution of about $5.6^{\circ} \times 5.6^{\circ}$ with 63 pressure levels between 7 and $120 \mathrm{~km}$ and a vertical resolution in the lower stratosphere of $750 \mathrm{~m}$, gradually increasing to $3.8 \mathrm{~km}$ at the upper boundary. The frequency of output is every $6 \mathrm{~h}$. The model is nudged to ECMWF analyses below $1 \mathrm{hPa}$. A numerical time step of 12 min was used in the experiments. The chemistry uses JPL 2002 data (Sander et al., 2003) and is calculated up to $90 \mathrm{~km}$, above which only transport is applied. The chemical fields of long-lived tracers have been initialized from a multi-annual run starting in the year 1960. For the HEPPA experiments, the transport scheme has been revised to allow transport of the members of chemical families $\mathrm{NO}_{\mathrm{x}}$ and $\mathrm{HO}_{\mathrm{x}}$ individually in the mesosphere. In addition, the ozone heating rate is calculated interactively. The rate constants of the gas phase and heterogeneous reactions are taken from Sander et al. (2003). For the production of $\mathrm{HO}_{\mathrm{x}}$ the parameterization of Solomon et al. (1981) is used, for the production of $\mathrm{NO}_{\mathrm{x}}, 0.7 \mathrm{NO}$ molecules are produced per ion pair and $0.55 \mathrm{~N}$ atoms in ground state, including reactions of $\mathrm{N}+\mathrm{O}_{2}$, $\mathrm{N}+\mathrm{NO}, \mathrm{N}+\mathrm{NO}_{2}$. The $\mathrm{HNO}_{3}$ production from proton hydrates (de Zafra and Smyshlyaev, 2001) has been modied to be dependent on actual ionization rates.

\subsection{EMAC}

The ECHAM5/MESSy Atmospheric Chemistry (EMAC) model is a numerical chemistry and climate simulation system that includes sub-models describing tropospheric and middle atmosphere processes and their interaction with oceans, land and human influences (Jöckel et al., 2006).
It uses the Modular Earth Submodel System (MESSy, see Jöckel et al., 2005) to link multi-institutional computer codes. The core atmospheric model is the 5th generation European Centre Hamburg general circulation model (ECHAM5, Roeckner et al., 2006). Here, EMAC (ECHAM5 version 5.3.02, MESSy version $1.8^{+}$) was applied in the T42L90MA-resolution, i.e. with a spherical truncation of T42 (corresponding to a quadratic Gaussian grid of approximately 2.8 by $2.8^{\circ}$ in latitude and longitude) with 90 vertical hybrid pressure levels up to $0.01 \mathrm{hPa}$. The frequency of output is every $2 \mathrm{~h}$. The model is weakly nudged at $200-700 \mathrm{hPa}$ to ECMWF reanalysis data. The chemistry submodel includes 104 chemical species and 250 homogeneous and heterogeneous reactions based on Sander et al. (2006). The simulation was initialized from a free-running simulation which was started in 1958. For more details on the setup used here refer to Baumgaertner et al. (2010).

\subsection{SOCOL and SOCOLi}

SOCOL (modeling tool for SOlar Climate Ozone Links studies) is a combination of the GCM MA-ECHAM4 and the chemistry-transport model MEZON. It is a spectral model with T30 horizontal truncation resulting in a grid spacing of about 3.75; in the vertical direction the model has 39 levels in a hybrid sigma-pressure coordinate system spanning the model atmosphere from the surface to $0.01 \mathrm{hPa}$. Time step for dynamical and physical processes is $15 \mathrm{~min}$ and $2 \mathrm{~h}$ for radiative transfer calculations and chemical reactions. The original version of the chemistry-climate model SOCOL was described by Egorova et al. (2005), and updated version in Schraner et al. (2008). For the HEPPA comparison, two versions of SOCOL have been used. One is with parameterized production of odd nitrogen, where for the $\mathrm{NO}_{\mathrm{x}}$ sources, the fact that $1.25 \mathrm{NO}$ molecules were produced was taken into account (Porter et al., 1976), for the $\mathrm{HO}_{\mathrm{x}}$ sources, the table given by Solomon et al. (1981) has been used. The other version (SOCOLi ) includes the chemistry of ionized species. SOCOLi is described in Egorova et al. (2011). As sources for ionization the model uses galactic cosmic rays (Heaps, 1978), energetic electron precipitation, solar proton events and observed solar irradiance. SOCOLi takes into account 580 reactions involving 43 neutral of the oxygen, hydrogen, nitrogen, carbon, chlorine and bromine groups, electrons, 31 positive and 17 negative charge species including clusters of $\mathrm{O}^{+}, \mathrm{H}^{+}$and $\mathrm{NO}^{+}$. The rate constants of the gas phase and heterogeneous reactions are taken from Sander et al. (2000). The experiment runs with SOCOL and SOCOLi were initialized in September 2003 from the restart files of SPARC CCMVal2 REF-B1 run started in 1960 (Morgenstern et al., 2010). SOCOL and SOCOLi models apply additionally to electron and proton-induced ionization also ionization rates caused by alpha-particles provided by AIMOS model (Wissing and Kallenrode, 2009). This choice is based on the assumption that AIMOS describes all physical processes 
relevant to particle precipitation during the event. Output is provided at the local time and location of the MIPAS overpass.

\subsection{WACCM}

The fourth version of the Whole Atmosphere Community Climate Model (WACCM4) is part of the Community Earth System Model (http://www.cesm.ucar.edu/). It is a coupled chemistry climate model with horizontal resolution of $1.9^{\circ}$ latitude by $2.5^{\circ}$ longitude. For this study WACCM4 has 88 vertical levels and is forced with meteorological fields from the Modern Era Retrospective-analysis for Research and Applications (MERRA, http://gmao.gsfc.nasa.gov/research/ merra/). MERRA is a NASA reanalysis for the satellite era using the Goddard Earth Observing System Data Assimilation System Version 5 (Rienecker et al., 2008). The forcing is achieved by relaxing horizontal winds and temperatures with a time constant of approximately $50 \mathrm{~h}$ from the surface to $40 \mathrm{~km}$. Above that level the forcing is reduced linearly, so that the model is free-running between $50 \mathrm{~km}$ and the model top at approximately $135 \mathrm{~km}\left(4.5 \times 10^{-6} \mathrm{hPa}\right)$. Heating rates and photolysis are calculated using observed daily solar spectral irradiance and geomagnetic activity effects in the auroral region are parameterized in terms of the $\mathrm{Kp}$ index (Marsh et al., 2007). A description of simulations of the effects of solar proton events using an earlier free-running version of WACCM and comparison with measurements is given in Jackman et al. (2008, 2009). The standard WACCM chemistry is described and evaluated extensively in WMO (2010). Reaction rates are from Sander et al. (2006). For these simulations we have modified the $\mathrm{N}+\mathrm{NO}_{2}$ reaction to include two additional pathways as described in Funke et al. (2008). It should be noted that both WACCM and HAMMONIA use the same chemical solver based on the MOZART3 chemistry (Kinnison et al., 2007), include the same set of ionized species, and use the parameterized EUV ionization rates from Solomon and Qian (2005). For these simulations the latter parameterization has been extended to include the photoionization of $\mathrm{CO}_{2}$ in the EUV. Proton and electron ionization rates, used in the nominal simulation, are taken from AIMOS, however above $5 \times 10^{-4} \mathrm{hPa}(\sim 100 \mathrm{~km})$ ionization from electrons is instead calculated by the WACCM parameterized aurora. An additional simulation using proton ionization, only, has also been performed (in the following denoted as WACCMp). The $\mathrm{HO}_{\mathrm{x}}$ production per ion pair is included in WACCM using a lookup table from Jackman et al. (2005b, Table 1), which is based on the work of Solomon et al. (1981). It is assumed that $1.25 \mathrm{~N}$ atoms are produced per ion pair and divide the $\mathrm{N}$ atom production between ground state, $\mathrm{N}\left({ }^{4} \mathrm{~S}\right)$, at 0.55 per ion pair and excited state, $\mathrm{N}\left({ }^{2} \mathrm{D}\right)$, at 0.7 per ion pair (Jackman et al., 2005b; Porter et al., 1976). In this study, the "spin-up" period was one year. The nudged simulation was started 1 January 2003, from an initial condition file based on a free running tran- sient simulation performed for the SPARC CCMVal2 exercise that covered the second half of the 20th Century ("REF $1 \mathrm{~B}$ " scenario). WACCM constituent and temperature profiles were saved at the model grid point and time-step (model time-step is $30 \mathrm{~min}$ ) closest to each of the MIPAS observation locations.

\section{Intercomparison method}

In order to reduce errors related to the different sampling of the MIPAS observations and gridded model data (i.e. B3dCTM, CAO, FinROSE, HAMMONIA, KASIMA, and EMAC), we have linearly interpolated the model results to the MIPAS measurement locations and times, as well as to the corresponding pressure levels of the vertical retrieval grid of the species under consideration. This approach has the further advantage that diurnal variations of particular species are implicitly taken into account. Comparison of MIPAS measurements and model results requires the transformation of modeled profiles to MIPAS altitude resolution. Based on the formalism by Rodgers (2000), we calculate the model profiles adjusted to MIPAS resolution $\boldsymbol{x}_{\text {adj }}$ as

$\boldsymbol{x}_{\mathrm{adj}}=\boldsymbol{A} \boldsymbol{x}_{\mathrm{mod}}+(\boldsymbol{I}-\boldsymbol{A}) \boldsymbol{x}_{\mathrm{a}}$,

where $\boldsymbol{A}$ is the MIPAS averaging kernel matrix, $\boldsymbol{x}_{\text {mod }}$ is the original model profile, $\boldsymbol{I}$ is unity, and $\boldsymbol{x}_{\mathrm{a}}$ is the a priori information used in the MIPAS retrievals. This adjustment procedure yields species profiles that MIPAS would see if it were to sound the model atmosphere. Assuming that the altitude resolution of the models is much finer than that of the MIPAS retrievals, the comparison of $\boldsymbol{x}_{\text {adj }}$ and MIPAS measurements is not affected by any smoothing error.

This procedure has been applied to each model result resampled at the corresponding measurement location. As an example, Fig. 6 compares $\mathrm{HOCl}$ zonal mean distributions at $40-90^{\circ} \mathrm{N}$, averaged over the period 29 October to 4 November 2003, as observed by MIPAS and as modeled by WACCM with and without application of averaging kernels. In the former case, the vertical distribution is broader and slightly shifted towards lower altitudes compared to the original model data, similar to the retrieved MIPAS profiles. Also, the absolute vmr peak values are smaller than without application of the averaging kernel. It should be noted that the apparent better agreement of the maximum vmr values between MIPAS and the unconvolved WACCM simulations are related to the fact that background $\mathrm{HOCl}$ vmrs are underestimated in the model. The relative vmr increase related to the SPE is in better agreement when comparing observed and convolved model data (see also Sect. 6). 

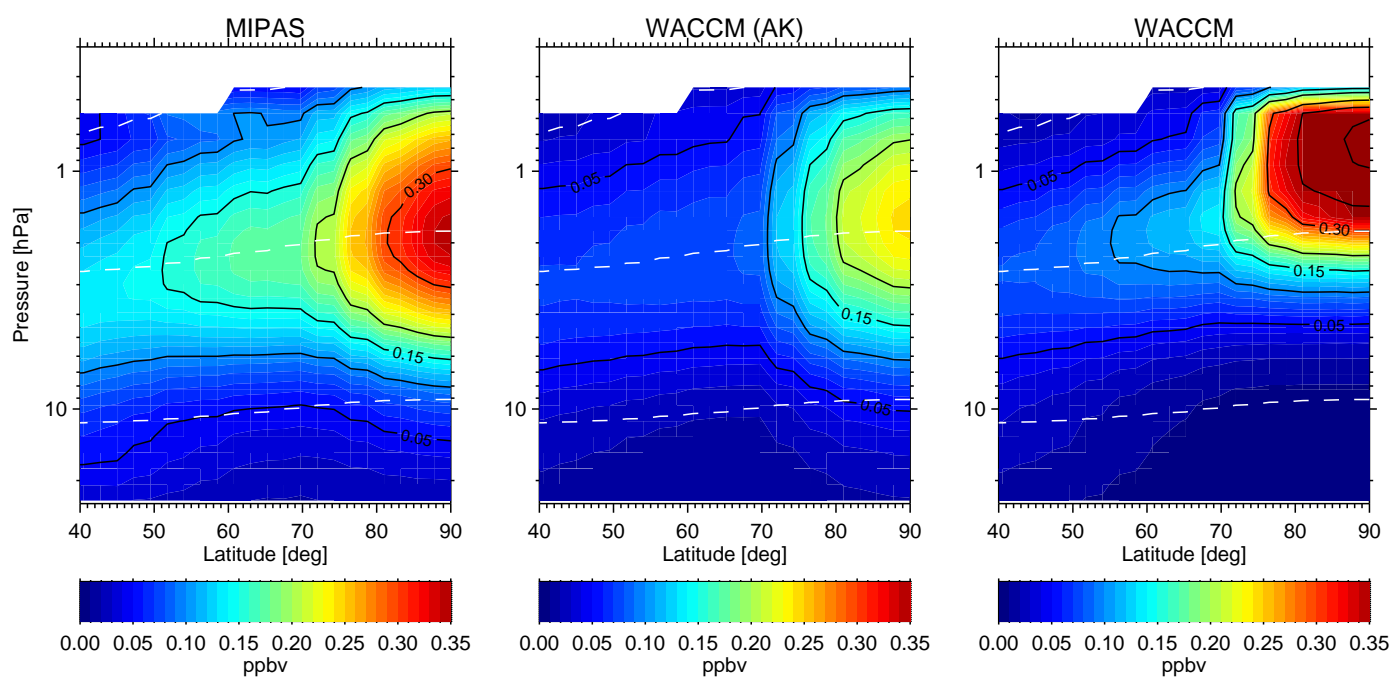

Fig. 6. Effect of application of averaging kernels (AKs) to the model data on the example of MIPAS and WACCM4 HOCl zonal mean distributions $\left(40-90^{\circ} \mathrm{N}\right)$ averaged over the period 29 October to 4 November 2003. Left: MIPAS, middle: WACCM4 with MIPAS averaging kernels applied, right: WACCM4, original model results.

\section{Results and discussion}

\subsection{Meteorological background conditions}

Meteorological background conditions, particularly the thermal structure and the prevailing dynamics, can have an important impact on the magnitude and spatial distribution of SPE-induced composition changes. Temperature differences between models and observed data have, on the one hand, a significant impact on SPE-related chemistry due to involvement of highly temperature-dependent reactions (i.e. $\mathrm{N}+\mathrm{O}_{2}$ or $\mathrm{NO}_{2}+\mathrm{O}_{3}$ ). On the other hand, meridional transport and mixing, depending largely on the development stage of the early winter polar vortex, control the redistribution of air masses between polar night and illuminated regions and hence, the efficiency of photochemical losses. Also, the strength of polar winter descent plays an important role in the vertical redistribution of some species on the time scale of the intercomparison period.

Figure 7 shows the MIPAS temperature zonal mean distribution at $40-90^{\circ} \mathrm{N}$ averaged over the period of the main proton forcing, 29 October to 4 November 2003, and the corresponding differences between the models and the observations. It is evident that models which are driven or strongly forced by assimilated meteorological data up to the upper stratosphere (i.e. B3dCTM, FinROSE, KASIMA, and WACCM) reproduce reasonably well the observed temperatures below approximately $1 \mathrm{hPa}$. On the other hand, free-running models (B2dM and SOCOLi) and those which are nudged to meteorological in the troposphere only (i.e. HAMMONIA) tend to overestimate the observations inside the polar vortex by more than $15 \mathrm{~K}$ around approximately $1 \mathrm{hPa}$ or slightly below, while polar mesospheric temperatures are considerably underestimated by these models (more than $25 \mathrm{~K}$ in the case of SOCOLi). This behavior is related to a lower polar stratopause height compared to the observations. Slightly too high stratopause temperatures are found in EMAC, CAO, B3dCTM, FinROSE, and WACCM simulations. These models also tend to have a higher stratopause compared to the observations, particularly in the case of WACCM. The KASIMA model yields generally good agreement with the observations in the polar regions, however, overestimates stratopause temperatures in the $50-60^{\circ} \mathrm{N}$ region.

The temporal evolution of observed polar temperatures $\left(70-90^{\circ} \mathrm{N}\right)$ and the corresponding differences between model and observations are shown in Fig. 8. No significant trend in either, observations or model data, can be observed during the period of interest, while short-term temperature fluctuations of more than $10 \mathrm{~K}$ compared to the observations, most likely related to differences in the planetary wave activity, show up particularly in the case of the free-running or weakly nudged models (B2dM, CAO, HAMMONIA, and SOCOLi).

Differences in the magnitude of meridional redistribution between models and observations have been assessed by comparing $\mathrm{CH}_{4}$ zonal mean distributions provided by all models except CAO. Since the global stratospheric $\mathrm{CH}_{4}$ abundances differ noticeably among the models, we used the relative meridional $\mathrm{CH}_{4}$ anomaly as indicator for meridional redistribution rather than absolute vmrs. The relative meridional anomaly is defined as percentage deviation from the $40-90^{\circ} \mathrm{N}$ average at each vertical level. Figure 9 shows the observed and modeled meridional $\mathrm{CH}_{4}$ anomalies at 40 $90^{\circ} \mathrm{N}$ averaged over the whole period. A pronounced gradient in the observed anomalies around $60^{\circ} \mathrm{N}$ indicates the 

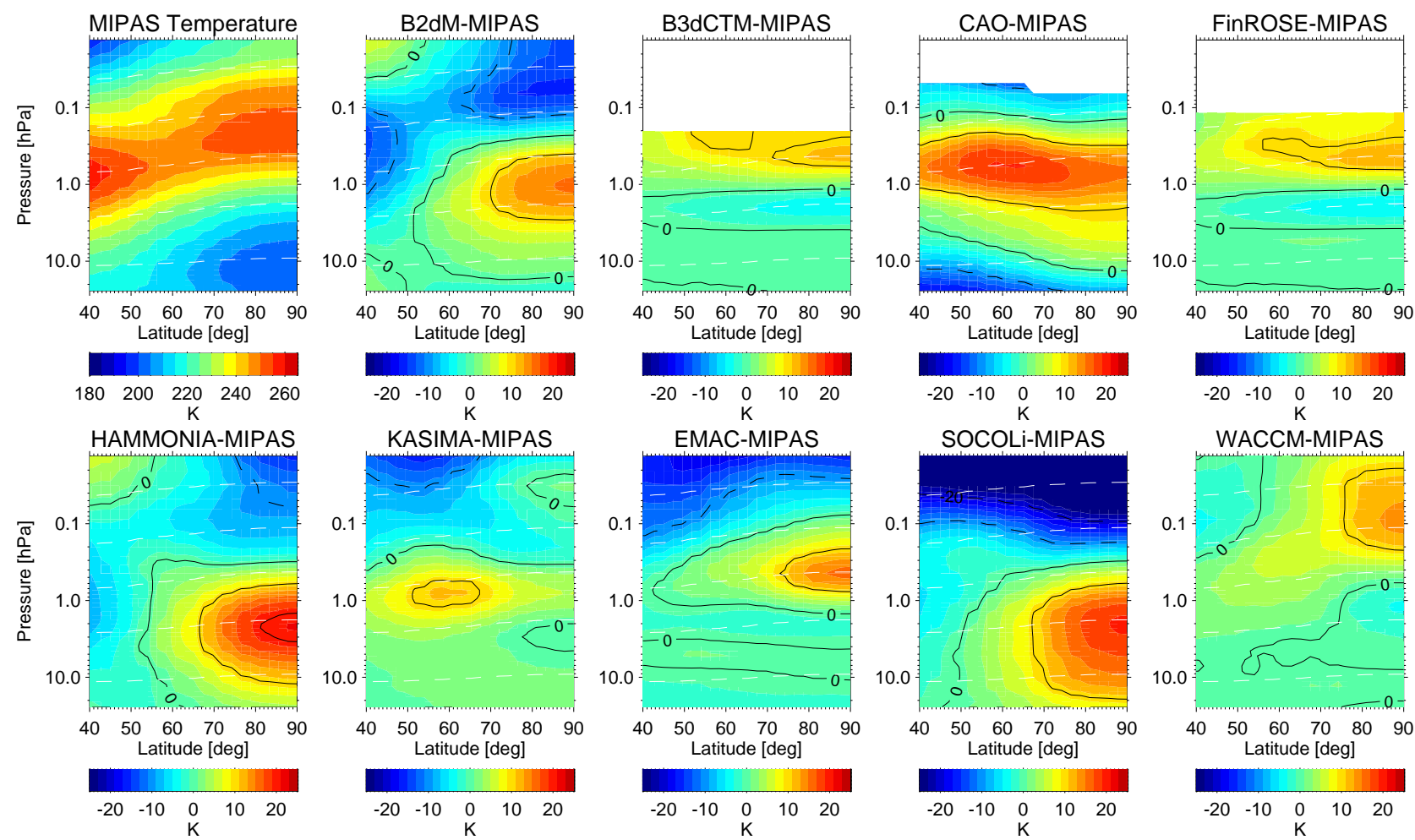

Fig. 7. Observed and modeled temperature zonal mean distributions at 40-90 $\mathrm{N}$ averaged over the period 29 October to 4 November 2003.

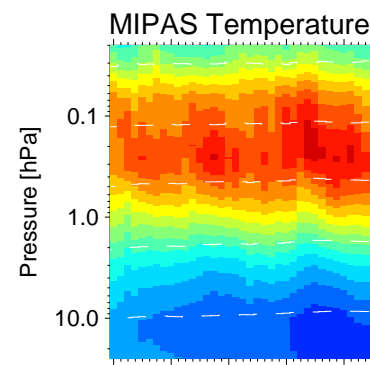

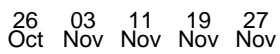

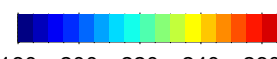

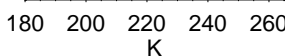

HAMMONIA-MIPAS

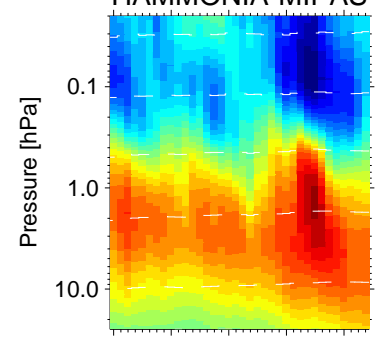

$\begin{array}{lll}26 & 3 & 11 \\ \text { Oct Nov Nov Nov Nov }\end{array}$

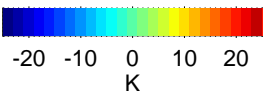

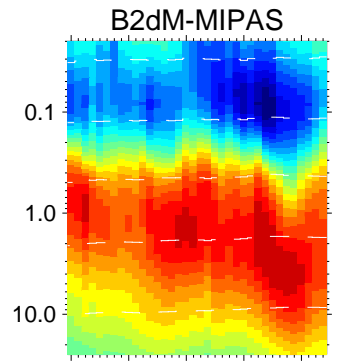

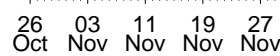

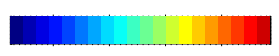

$\begin{array}{llll}-20 & -10 \\ \mathrm{~K} & & & 10\end{array}$

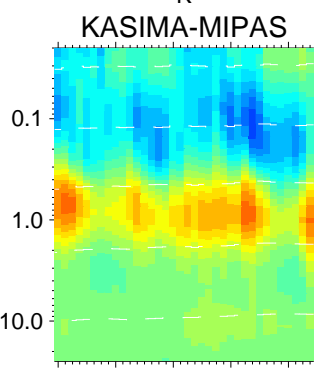

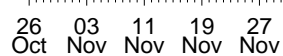

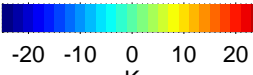

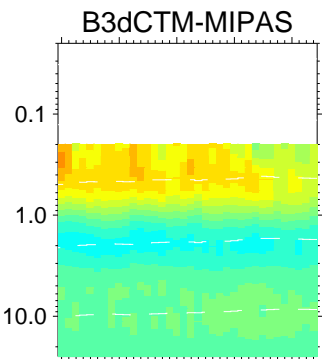

$\begin{array}{lllll}26 & 03 & 11 & 19 & 27 \\ \text { Oct } & \text { Nov } & \text { Nov } & \text { Nov } & \text { Nov }\end{array}$
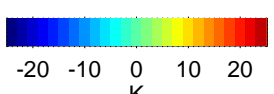

EMAC-MIPAS

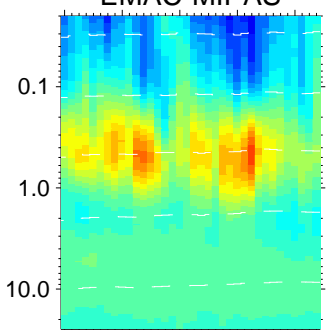

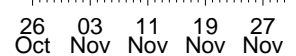

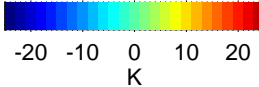

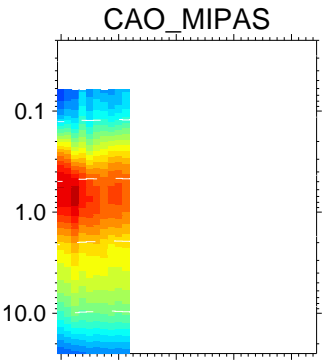

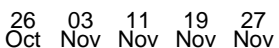
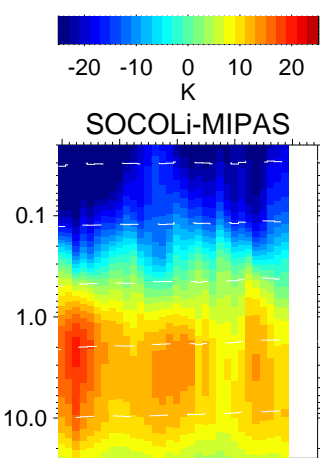

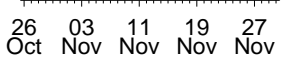

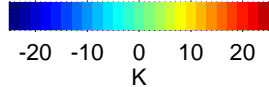

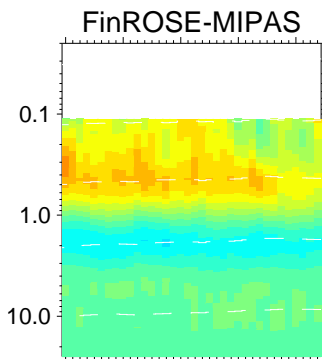

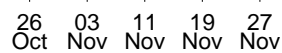

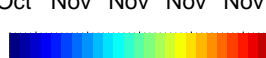
$\begin{array}{lllll}-20 & -10 & 0 & 10 & 20\end{array}$ WACCM-MIPAS

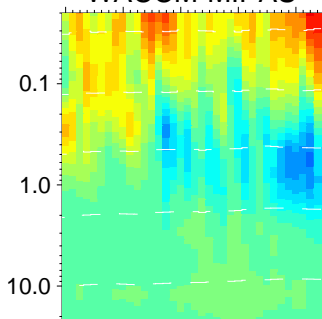

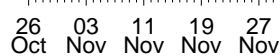

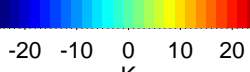

Fig. 8. Temporal evolution of MIPAS temperature and model - MIPAS differences averaged over $70-90^{\circ} \mathrm{N}$. 

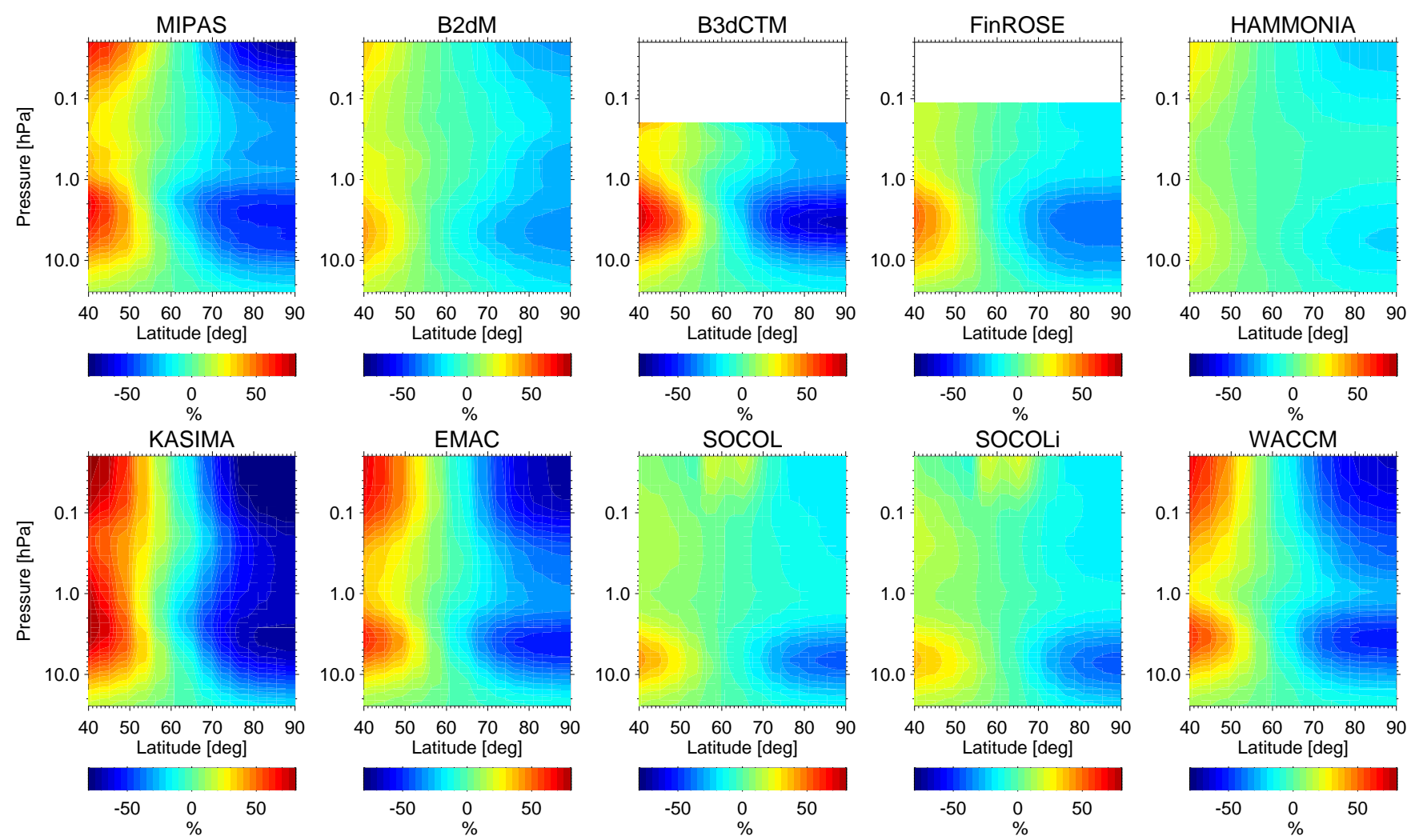

Fig. 9. Relative meridional $\mathrm{CH}_{4}$ anomalies in MIPAS observations and model simulations at $40-90^{\circ} \mathrm{N}$ averaged over the whole time period.

early winter vortex boundary. In general, the vortex boundary position is well reproduced by all models, although there are significant differences in the overall $\mathrm{CH}_{4}$ change from mid-latitudes to the pole between the models. Strongest latitudinal gradients (i.e. weakest redistribution) were found in the KASIMA simulations, while smallest gradients (i.e. strongest redistribution) are visible in HAMMONIA. The reason for the underestimation of meridional redistribution in KASIMA is not fully understood, particularly because other ECMWF-driven models have simulated considerably stronger mixing. The too strong mixing in HAMMONIA is most probably related to wave- 1 activity, being present in the whole time period. The vertical distribution of the observed $\mathrm{CH}_{4}$ meridional anomaly shows a broadening in the stratopause region $(1-0.1 \mathrm{hPa})$. Spatial $\mathrm{CH}_{4}$ distributions at these vertical levels (not shown) indicate that this broadening is related to a weakened transport barrier at the vortex top rather than to increased planetary wave activity in the mesosphere. This behavior is reproduced by the models in general although there are differences with respect to the altitude and magnitude of the broadening region. In B2dM, it is shifted slightly upwards while the opposite is observed in EMAC, SOCOL, and SOCOLi simulations. In these latter models, meridional redistribution seems also to be slightly overestimated around the stratopause. It should be noted that our analysis of $\mathrm{CH}_{4}$ meridional anomalies does not allow to dis- tinguish between meridional redistribution by eddy diffusion and large-scale transport by planetary waves, the latter being of higher importance for the redistribution of air masses between polar night and illuminated regions.

The variability of the polar vortex strength has been assessed by comparing the temporal evolution of the relative change of $\mathrm{CH}_{4}$ abundances with respect to 26 October averaged over $70-90^{\circ} \mathrm{N}$ (see Fig. 10). The observed evolution indicates a vortex intensification and descent in the lower and middle stratosphere while a $\mathrm{CH}_{4}$ increase above $0.3 \mathrm{hPa}$, particularly during the proton forcing at the beginning of November, hints at an increase of meridional mixing in the mesosphere. This general behavior is partly reproduced by the models but important differences with respect to the vertical structure and magnitude exist. These differences have to be taken into account when analyzing the temporal evolution of SPE-induced composition changes (see next sections).

Carbon monoxide is an ideal tracer for upper stratospheric and mesospheric dynamics. Particularly, it allows to identify air masses which have descended from the upper mesosphere and contain enhanced $\mathrm{NO}_{\mathrm{x}}$ related to energetic electron precipitation (EEP). Since polar winter descent of $\mathrm{NO}_{\mathrm{x}}$ generated by EEP prior to the SPE event is not resolved by all models, and since we focus here on SPE-related effects, observed $\mathrm{NO}_{\mathrm{x}}$ enhancements due to descending upper mesospheric air masses perturb our analysis and should hence be excluded. 


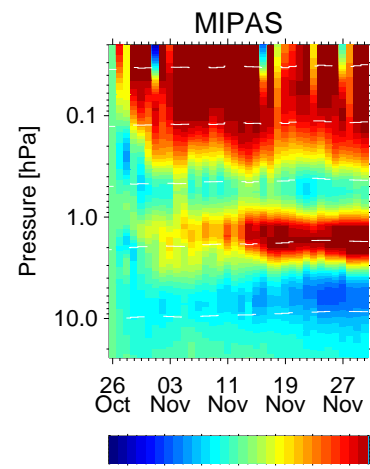

$-60-40-20 \quad 0 \quad 204060$ KASIMA

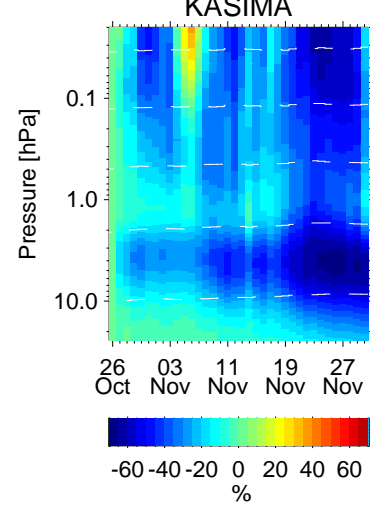

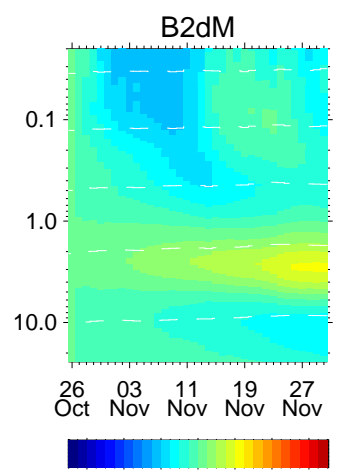

$-60-40-20 \quad 0 \quad 2040 \quad 60$

EMAC

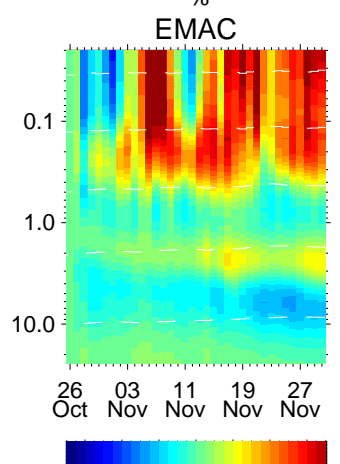

$-60-40-20 \quad 0 \quad 204060$

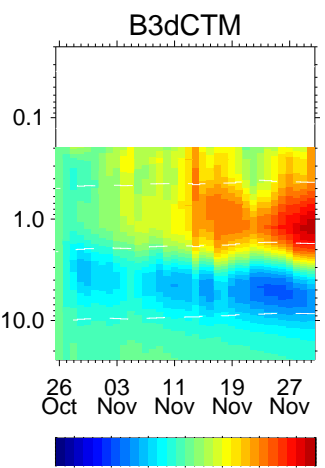

$-60-40-20 \quad 0 \quad 204060$ SOCOL
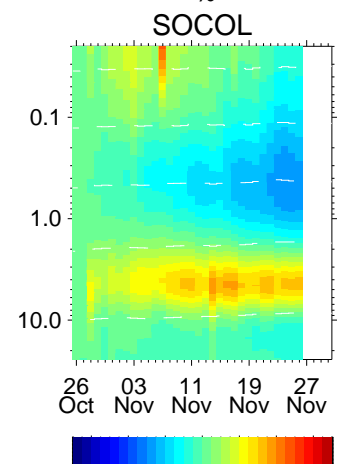

$-60-40-20 \underset{\%}{0} 204060$

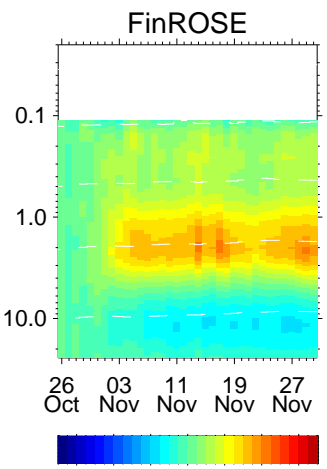

$-60-40-20 \quad 0 \quad 204060$ SOCOLi

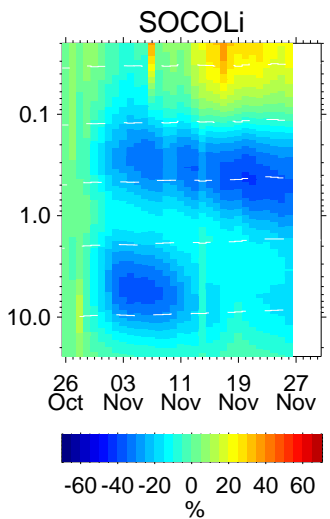

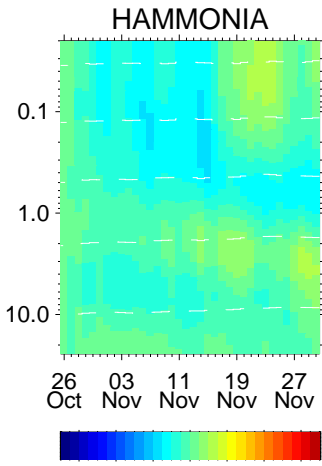

$-60-40-20 \quad 0 \quad 204060$

WACCM

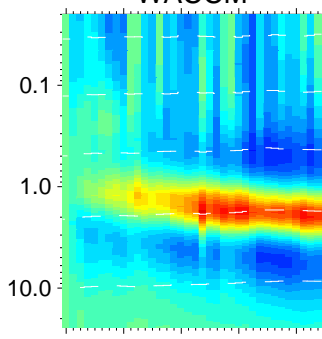

26 Öct Nov Nov Nov Nov

$-60-40-20 \quad 0 \quad 204060$

Fig. 10. Temporal evolution of $\mathrm{CH}_{4}$ changes with respect to 26 October 2003 in MIPAS observations and model simulations averaged over $70-90^{\circ} \mathrm{N}$.

MIPAS CO observations provide an excellent criterion for identification of EEP-related enhancements (see Sect. 6.2).

$\mathrm{CO}$ distributions also allow for the characterization of descent and vortex perturbations by large-scale wave activity and isentropic mixing across the vortex boundary in the upper stratosphere and mesosphere. Figure 11 shows the observed and modeled temporal evolution of $\mathrm{CO}$ abundances averaged over $70-90^{\circ} \mathrm{N}$. In general, the continuous decrease in altitude of $\mathrm{CO} \mathrm{vmr}$ isolines in the upper stratosphere, related to polar winter descent, agrees well in models and data. Around $1 \mathrm{hPa}$, polar air masses descended approximately $5 \mathrm{~km}$ in both models and observations during the time period under investigation.

A higher variability is found in the mesosphere. Observed $\mathrm{CO}$ abundances decreased around the beginning of November, at the same time when $\mathrm{CH}_{4}$ increased significantly (see Fig. 10). A pronounced CO increase occurred around 20 November, hinting at enhanced descent and vortex intensification. Modeled CO distributions show a different temporal evolution in the mesosphere, although some similarities can be found. For instance, EMAC, KASIMA and WACCM reproduce the $\mathrm{CO}$ increase in late November, however, with a smaller magnitude and slightly shifted in time. A $\mathrm{CO}$ decrease around $0.1 \mathrm{hPa}$ at the beginning of November, as observed by MIPAS, is also visible in SOCOL, SOCOLi, and - to a lesser extent - in WACCM simulations.
In contrast to the observations, these modeled decreases occur nearly instantaneously on 31 October, suggesting that the simulated $\mathrm{CO}$ changes might be related to the proton event rather than dynamical modulations. Indeed, $\mathrm{CO}$ is removed by the reaction with $\mathrm{OH}$, which is strongly enhanced during the SPE at nighttime. The isolation of a possible SPEinduced chemical CO loss from dynamical effects is difficult in both observations and simulations. Nevertheless, we have analyzed the observed $\mathrm{CO}$ abundances at fixed $\mathrm{CH}_{4} \mathrm{lev}$ els in the vertical range of $0.2-0.05 \mathrm{hPa}$ in order to exclude $\mathrm{CO}$ variations related to isentropic mixing or meridional redistribution. $\mathrm{CO}$ abundances observed simultaneously with $\mathrm{CH}_{4}$ vmrs of less than $40 \mathrm{ppbv}$ decreased by approximately 1 ppmv from 29 October to 1 November, thus suggesting a chemical removal of the order of $10 \%$ which could be related to enhanced $\mathrm{OH}$. The $\mathrm{CO}$ decreases found in the WACCM simulations have a similar magnitude, while SOCOL and SOCOLi simulations show a CO decrease around $30 \%$.

\subsection{Enhancements of $\mathrm{NO}_{\mathrm{y}}$ and $\mathrm{N}_{2} \mathrm{O}$}

The most important impact of proton precipitation on the middle atmosphere is the immediate formation of $\mathrm{NO}_{\mathrm{x}}$ $\left(=\mathrm{NO}+\mathrm{NO}_{2}\right)$ via dissociation of molecular nitrogen by ionization and subsequent recombination with oxygen. Due to its relatively long chemical lifetime in the stratosphere, 

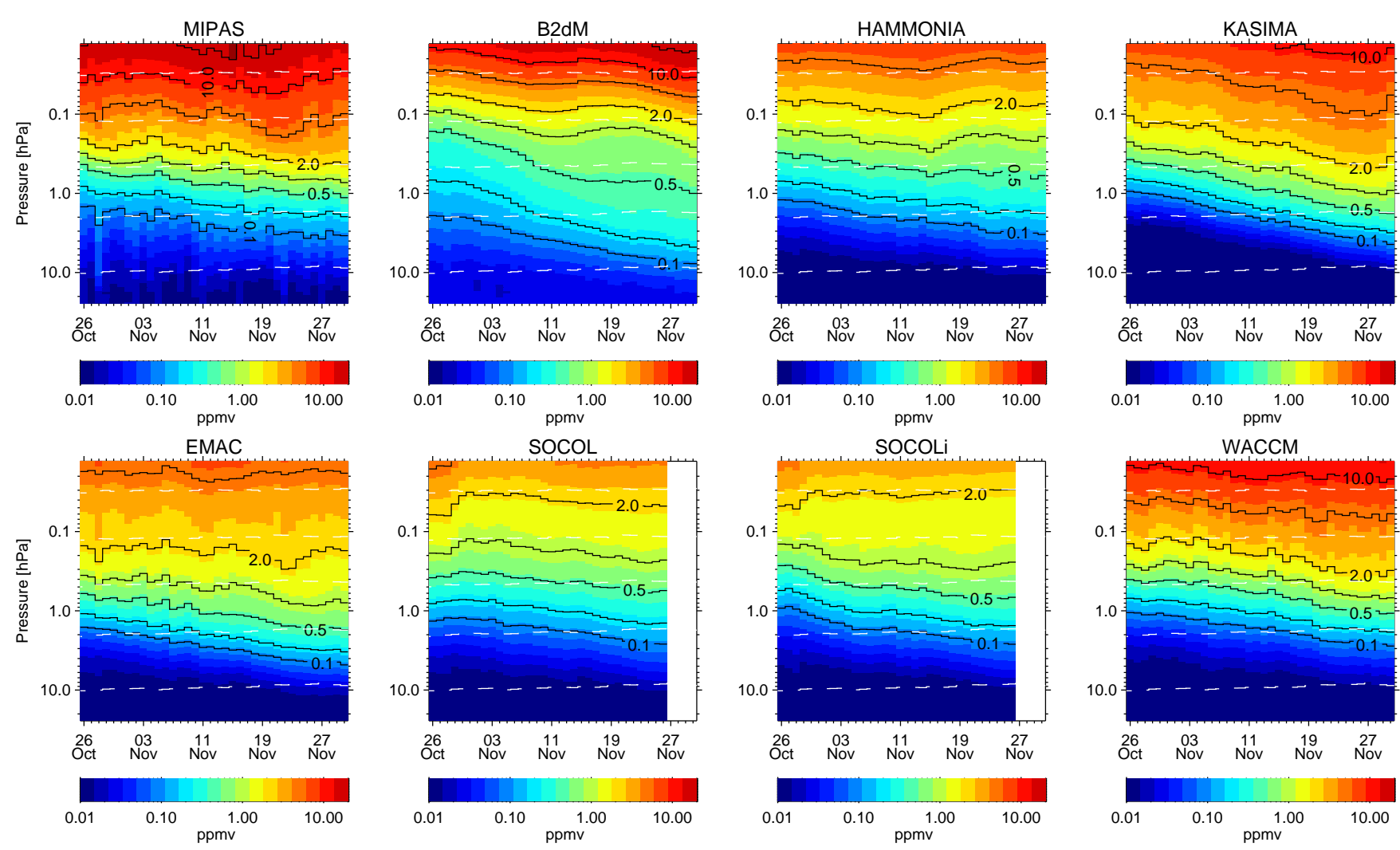

Fig. 11. Temporal evolution of CO abundances in MIPAS observations and model simulations averaged over $70-90^{\circ} \mathrm{N}$. The $0.1,0.2,0.5,1$, $2,5,10$, and 20 ppmv contours are shown by solid lines.

SPE-induced $\mathrm{NO}_{\mathrm{x}}$ enhancements have a strong potential to deplete ozone on a mid- to long-term scale via catalytic cycles. A fraction of excess $\mathrm{NO}_{\mathrm{x}}$ produced by proton forcing is subsequently buffered into $\mathrm{NO}_{\mathrm{y}}$ reservoir species (i.e. $\mathrm{N}_{2} \mathrm{O}_{5}, \mathrm{HNO}_{3}$, and $\mathrm{ClONO}_{2}$ ) by a series of chemical processes (see next section) at different time scales. In general, the $\mathrm{NO}_{\mathrm{x}}$ deactivation is very slow in the upper stratosphere. At lower altitudes, however, observed $\mathrm{HNO}_{3}$ and $\mathrm{ClONO}_{2}$ increases immediately after the onset of the proton forcing during the Halloween event indicate a much faster conversion. In order to assess the agreement of observed and modeled SPE-related odd nitrogen enhancements, we have thus compared, at first instance, total $\mathrm{NO}_{\mathrm{y}}\left(=\mathrm{NO}+\mathrm{NO}_{2}+\mathrm{HNO}_{3}+2 \mathrm{~N}_{2} \mathrm{O}_{5}+\mathrm{ClONO}_{2}+\mathrm{HNO}_{4}\right)$ rather than $\mathrm{NO}_{\mathrm{x}}$. Since meridional redistribution is an issue (see discussion in the previous subsection), we have separately analyzed area-weighted averages of $\mathrm{NO}_{\mathrm{y}}$ enhancements with respect to 26 October within $70-90^{\circ} \mathrm{N}$ and 40 $90^{\circ} \mathrm{N}$, the latter area covering entirely the source region.

As a first step, we analyze the instantaneous $\mathrm{NO}_{\mathrm{y}}$ enhancements during the main proton forcing around 29 October1 November. Figure 12 shows the observed and modeled $\mathrm{NO}_{\mathrm{y}}$ enhancements during this period, ranging from a few ppbv in the middle stratosphere to several $100 \mathrm{ppbv}$ in the mesosphere. As expected from the latitudinal distribution of
SPE-induced ionization (see Fig. 4), higher $\mathrm{NO}_{\mathrm{y}}$ enhancements are found at $70-90^{\circ} \mathrm{N}$ compared to $40-90^{\circ} \mathrm{N}$. The agreement between the observations and the multi-model average, the latter providing a measure of the overall ability of current atmospheric models to reproduce SPE-related $\mathrm{NO}_{\mathrm{y}}$ increases, is reasonable, exhibiting differences below $50 \%$ in the whole altitude range. There is, however, a systematic overestimation of the models around $1 \mathrm{hPa}$, being more pronounced over the pole. Above $0.3 \mathrm{hPa}$, the models tend to underestimate observed $\mathrm{NO}_{\mathrm{y}}$ enhancements at $40-90^{\circ} \mathrm{N}$, while they agree on average with the observations in the polar region.

The $\mathrm{NO}_{\mathrm{y}}$ underestimation of the models above $0.3 \mathrm{hPa}$ in the sunlit $40-90^{\circ} \mathrm{N}$ region could be related to an overestimation of $\mathrm{NO}$ photolysis, the principal $\mathrm{NO}_{\mathrm{y}}$ loss mechanism in the illuminated mesosphere. It has been pointed out by Minschwaner and Siskind (1993) that absorption of solar irradiance by thermospheric NO, being significantly enhanced during SPEs, has an important impact on the photolysis rates of nitric oxide in the middle atmosphere. An overestimation of NO photolysis is also supported by the fact that modeled $\mathrm{NO}_{\mathrm{y}}$ enhancements agree on average with the observations in the polar region $\left(70-90^{\circ} \mathrm{N}\right)$ where photochemical losses of NO are small. 

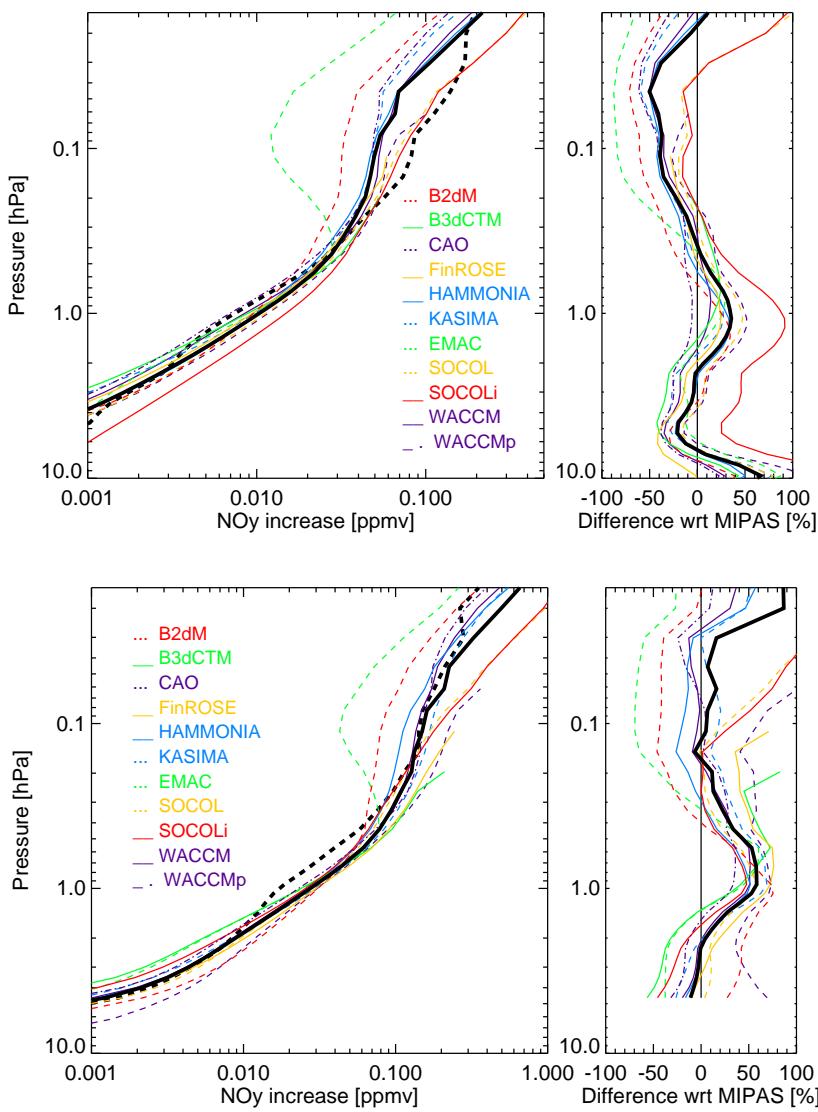

Fig. 12. Area-weighted averages of observed and modeled $\mathrm{NO}_{\mathrm{y}}$ enhancements for $40-90^{\circ} \mathrm{N}$ (top) and $70-90^{\circ} \mathrm{N}$ (bottom) during 30 October-1 November with respect to 26 October (left) and relative deviations of modeled averages from the MIPAS observations (right). Thick solid and dashed lines represent the multi-model mean and MIPAS observations, respectively. WACCMp denotes the WACCM simulation including proton ionization only (excluded from the multi-model mean).

The systematic behavior of the $\mathrm{NO}_{\mathrm{y}}$ overestimation around $1 \mathrm{hPa}$ suggests that these differences are related - at least partly - to the simulated ionization rate profile. In this pressure range, uncertainties in the modeling of electron precipitation at $300 \mathrm{keV}$ to $5 \mathrm{MeV}$, contributing to the total ionization by approximately $15 \%$, represent an important error source in the AIMOS calculations. As the highest electron channel on POES does not provide data up to $5 \mathrm{MeV}$, the energy spectrum was extended according to Klassen et al. (2005). In addition, the energy range of the highest electron channel mep0e3 is not known for sure (private communication, Janet Green, NOAA) and it might be smaller than the published $300 \mathrm{keV}-2.5 \mathrm{MeV}$ (Evans and Greer, 2000). A smaller energy range would also result in increased $\mathrm{NO}_{\mathrm{y}}$ production within $40-90^{\circ} \mathrm{N}$ at $0.1 \mathrm{hPa}$ in agreement with the observations. A possible overestimation of electron ionization alone, however, cannot explain the mismatch between modeled and observed $\mathrm{NO}_{\mathrm{y}}$ increases of up to $50 \%$. Around
$1 \mathrm{hPa}$, the WACCM simulation without electrons (WAC$\mathrm{CMp}$ ) yields $20 \%$ less enhanced $\mathrm{NO}_{\mathrm{y}}$ than the nominal simulation, including protons and electrons. Even when assuming that electrons do not contribute to the SPE-induced ionization at stratospheric altitudes, only about half of the differences between modeled and observed enhancements could be explained. Additional ionization by alpha particles, included in CAO, FinROSE, SOCOL, and SOCOLi contributes only by approximately $5 \%$ to the total ionization within $40-90^{\circ} \mathrm{N}$, hence increasing the SPE-related $\mathrm{NO}_{\mathrm{y}}$ enhancements only marginally. Other possible error sources in the ionization rate calculation are related to uncertainties of the GOES proton flux observations and to the spatial interpolation scheme for particle fluxes from the POES satellites. Also, uncertainties of atmospheric parameters (density, altitude, composition, and temperature) used in the AIMOS calculations could produce errors in the ionization rates. These parameters, taken from HAMMONIA and MSIS calculations, might differ from the actual atmospheric conditions during the Halloween SPE. Apart from possible deficiencies in the ionization rate calculation, also differences of the true and modeled atmospheric background state and/or dynamical conditions could contribute to the encountered model overestimation of $\mathrm{NO}_{\mathrm{y}}$ enhancements. However, such differences are likely to produce a spread in the modeled $\mathrm{NO}_{\mathrm{y}}$ increases rather than a systematic bias compared to the observations.

Indeed, such a spread of up to $100 \%$ among the modeled $\mathrm{NO}_{\mathrm{y}}$ enhancements can be observed, particularly in the 40 $90^{\circ} \mathrm{N}$ region. $\mathrm{NO}_{\mathrm{y}}$ enhancements are most strongly overestimated (up to $100 \%$ ) by SOCOLi, SOCOL, and CAO in the stratosphere around $1 \mathrm{hPa}$. In the mesosphere, smallest $\mathrm{NO}_{\mathrm{y}}$ increases are obtained by B2dM and EMAC (up to $80 \%$ less than observed), while SOCOL and SOCOLi simulations agree well with the MIPAS observations.

In order to investigate possible reasons for the dispersion among the model results, a more detailed look into the $\mathrm{NO}_{\mathrm{x}}$ production mechanism is required. Generally, it is assumed that each ion pair produces 1.25 atomic nitrogen atoms, distributed between the electronic ground state $\mathrm{N}\left({ }^{4} \mathrm{~S}\right)$ and the excited $\mathrm{N}\left({ }^{2} \mathrm{D}\right)$ state with a branching ratio of 0.45 and 0.55 , respectively (Jackman et al., 2005b). The value of 1.25 atomic nitrogen atoms per ion pair has been adapted by all models involved in this study, except for EMAC and SOCOLi. In the latter model, $\mathrm{N}$ production is implicitly modeled by means of the involved ion chemistry scheme. In EMAC, an altitude-dependent $\mathrm{N}$ production has been assumed which has been determined empirically by the adjustment of the simulations to observed $\mathrm{NO}_{2}$ and $\mathrm{N}_{2} \mathrm{O}$ abundances (Baumgaertner et al., 2010). The resulting $\mathrm{N}$ production profile is slightly higher than that used by the other models in the upper stratosphere (around $1.5 \mathrm{~N}$ per ion pair) and considerably lower in the mesosphere (less than $0.3 \mathrm{~N}$ per ion pair) which explains to a major extent the behavior of the EMAC $\mathrm{NO}_{\mathrm{y}}$ enhancements compared to other models. 
An important source of variability in the $\mathrm{NO}_{\mathrm{y}}$ production is related to the reaction paths of the produced atomic nitrogen in its ground and excited states. While the reaction of $\mathrm{N}\left({ }^{2} \mathrm{D}\right)$ with oxygen to form $\mathrm{NO}$ is very fast such that practically all $\mathrm{N}\left({ }^{2} \mathrm{D}\right)$ is immediately converted to NO below the thermosphere, the corresponding reaction of the nitrogen ground state

$\mathrm{N}\left({ }^{4} \mathrm{~S}\right)+\mathrm{O}_{2} \rightarrow \mathrm{NO}+\mathrm{O}$

is slower and highly temperature-dependent. Hence, it competes with other reactions, namely:

$\mathrm{N}\left({ }^{4} \mathrm{~S}\right)+\mathrm{NO} \rightarrow \mathrm{N}_{2}+\mathrm{O}$

$\mathrm{N}\left({ }^{4} \mathrm{~S}\right)+\mathrm{NO}_{2} \rightarrow \mathrm{N}_{2} \mathrm{O}+\mathrm{O}$,

both destroying $\mathrm{NO}_{\mathrm{x}}$. As a consequence, only a fraction of the initially produced $\mathrm{NO}_{\mathrm{x}}$ remains available after the proton forcing. This fraction depends strongly on temperature due to Reaction (R1) and to a lesser extent on the repartitioning between $\mathrm{NO}$ and $\mathrm{NO}_{2}$, driven by illumination and odd oxygen availability. In order to assess the sensitivity of the SPE-related $\mathrm{NO}_{\mathrm{x}}$ production to these parameters, we have integrated the relevant chemical equations for the period 28 October-1 November with a simple box model including AIMOS ionization rates and assuming initial atmospheric conditions as observed by MIPAS at $70-90^{\circ} \mathrm{N}$ before the SPE, as well as the $\mathrm{N}\left({ }^{4} \mathrm{~S}\right) / \mathrm{N}\left({ }^{2} \mathrm{D}\right)$ branching ratio recommended by Jackman et al. (2005b) . The modeled $\mathrm{NO}_{\mathrm{x}}$ enhancements have then been compared to a similar simulation, but setting the rate coefficient for Reactions (R2) and (R3) to zero (i.e. assuming that all initially produced NO survives). The ratio of both simulations reflects the $\mathrm{NO}_{\mathrm{x}}$ production efficiency. It is shown in Fig. 13 for nighttime and daytime conditions (solid and dotted black lines, respectively), exhibiting maximum value of $0.55-0.7$ around the stratopause and smaller values (0.15-0.4) above and below. Reduced values below the stratopause are related to the background $\mathrm{NO}_{\mathrm{x}}$ : if initial $\mathrm{NO}_{\mathrm{x}}$ abundances are set to zero, the production efficiency increases with pressure to values close to unity in the lower stratosphere (see Fig. 13, dotted green line). A temperature increase (decrease) of $20 \mathrm{~K}$ results in an enhancement (reduction) of this quantity by approximately $30-50 \%$ (see red and blue lines in Fig. 13). On the other hand, assuming a two times higher ozone abundance results in an increase of the $\mathrm{NO}_{\mathrm{x}}$ production efficiency by only a few percent.

The chemical scheme described above (including a $\mathrm{N}\left({ }^{4} \mathrm{~S}\right)$ and $\mathrm{N}\left({ }^{2} \mathrm{D}\right)$ branching ratio of 0.45 and 0.55$)$ has been employed in most of the atmospheric models included in the intercomparison, with some exceptions: B3dCTM and CAO use a family approach which implies the immediate conversion of all atomic nitrogen to NO (equivalent to a ratio of 1 in Fig. 13), explaining - at least partly - the relatively high $\mathrm{NO}_{\mathrm{y}}$ increases above $2 \mathrm{hPa}$ in these models. Also FinROSE applies a family approach, however, in this model it is implicitly assumed that all $\mathrm{N}\left({ }^{4} \mathrm{~S}\right)$ produced by ionization destroys

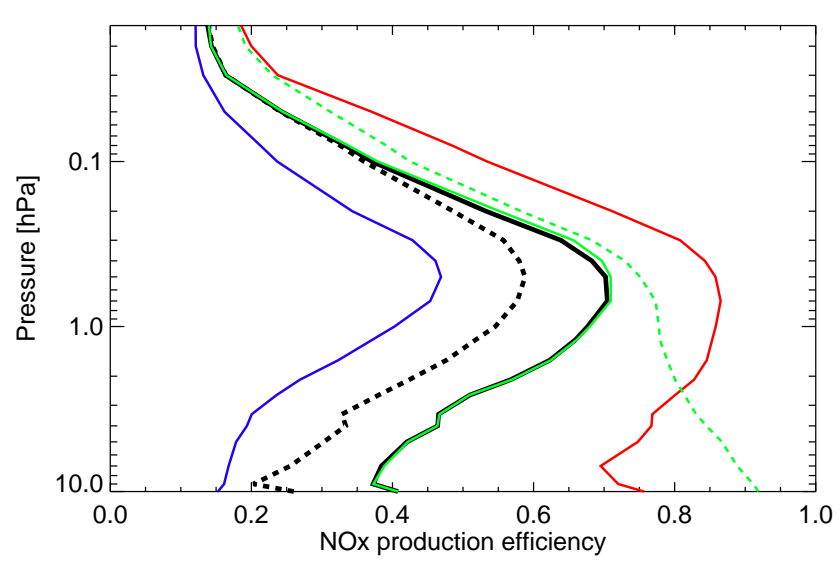

Fig. 13. $\mathrm{NO}_{\mathrm{x}}$ production efficiency (ratio of the net $\mathrm{NO}_{\mathrm{x}}$ increase and the integrated initial $\mathrm{N}$ production) during the period of the main proton forcing (28 October-1 November) from box model calculations for night- and daytime conditions (solid and dashed black lines, respectively), assuming initial atmospheric conditions as observed by MIPAS in the polar cusp region. The following variations for dark conditions are also shown: a $20 \mathrm{~K}$ temperature increase (red) and decrease (blue), a factor of 2 increase of $\mathrm{O}_{3}$ (solid green), and initial $\mathrm{NO}_{\mathrm{x}}$ abundances set to zero (dashed green).

$\mathrm{NO}$ via Reaction (R2), resulting in a net $\mathrm{NO}_{\mathrm{x}}$ production of 0.25 per ion pair (i.e. an altitude-independent production efficiency of 0.2 in Fig. 13). However, although a considerably smaller $\mathrm{NO}_{\mathrm{y}}$ production is hence expected, FinROSE model results show more excess $\mathrm{NO}_{\mathrm{y}}$ than found in the observations. EMAC uses a $\mathrm{N}\left({ }^{4} \mathrm{~S}\right)$ and $\mathrm{N}\left({ }^{2} \mathrm{D}\right)$ branching ratio of approximately 0.2 and 0.8 , respectively. Box model calculations using this atomic nitrogen branching yield weakly altitude-dependent $\mathrm{NO}_{\mathrm{x}}$ production efficiencies of $0.6-0.8$, considerably higher than the nominal efficiency of $\sim 0.2$ in the mesosphere. Therefore, the smaller atomic nitrogen production in the mesosphere applied in EMAC is partly compensated by the modified $\mathrm{N}\left({ }^{4} \mathrm{~S}\right)$ and $\mathrm{N}\left({ }^{2} \mathrm{D}\right)$ branching ratio.

As shown above, temperature differences might explain the differences of the $\mathrm{NO}_{\mathrm{y}}$ enhancements simulated by the remaining models. B2dM underestimates the observed temperatures in the mesosphere by about $15 \mathrm{~K}$, consistent with the relatively low $\mathrm{NO}_{\mathrm{y}}$ enhancements compared to the other models and observations, there. In contrast, HAMMONIA and SOCOLi simulations, exhibiting relatively low mesospheric temperatures, show much larger $\mathrm{NO}_{\mathrm{y}}$ enhancements. Stratospheric temperatures are significantly overestimated by B2dM, CAO, HAMMONA, and SOCOLi. However, only the latter model shows stratospheric $\mathrm{NO}_{\mathrm{y}}$ enhancements well above the model average. Thus, temperature differences among the models cannot be the only reason for the spread encountered in the modeled $\mathrm{NO}_{\mathrm{y}}$ enhancements.

Therefore, we have looked at the spatial $\mathrm{NO}_{\mathrm{y}}$ distribution in order to investigate if the spread in the modeled $\mathrm{NO}_{\mathrm{y}}$ could also be related to dynamical effects. Figure 14 shows the observed and modeled $\mathrm{NO}_{\mathrm{y}}$ distributions in the upper 

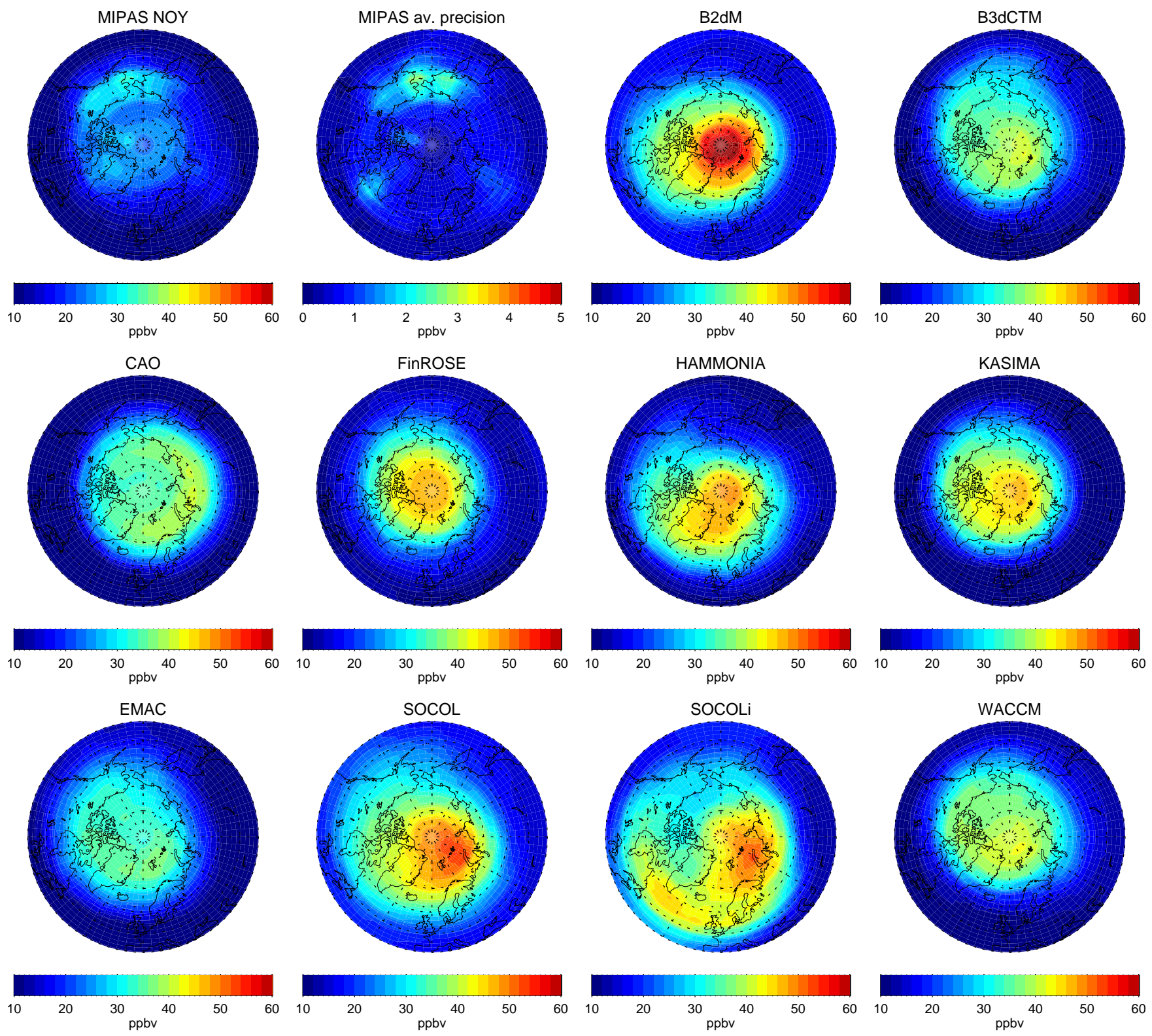

Fig. 14. Spatial distributions of observed and modeled $\mathrm{NO}_{\mathrm{y}}$ at $1 \mathrm{hPa}$ averaged over the period of the main proton forcing during 30 October1 November. The average precision of MIPAS observations is also shown (upper second panel from the left).

stratosphere $(1 \mathrm{hPa})$ averaged over the period 30 October1 November. The spatial extension of the modeled $\mathrm{NO}_{\mathrm{y}}$ enhancements exhibits pronounced differences. In some cases, $\mathrm{NO}_{\mathrm{y}}$ enhancements are confined to the polar region northward of $70^{\circ} \mathrm{N}$ (i.e. B2dM, KASIMA, FinROSE) while in other cases they extend even to regions equatorwards of $50^{\circ} \mathrm{N}$ (i.e. SOCOL and SOCOLi). Taking into account that the spatial extension of the source region is the same in all models, these differences must be related to transport acting on a very short time scale. As discussed above, SOCOLi shows higher $\mathrm{NO}_{\mathrm{y}}$ averages than other models with similar stratospheric temperatures (i.e. HAMMONIA, B2dM). The spatial $\mathrm{NO}_{\mathrm{y}}$ distribution of SOCOLi at $1 \mathrm{hPa}$ indicates strong wave activity resulting in a deformation of the pole-centered shape of the $\mathrm{NO}_{\mathrm{y}}$ distribution. Thus, it cannot be excluded that tropical $\mathrm{NO}_{\mathrm{y}}$, transported into the $40-90^{\circ} \mathrm{N}$ region, contributed to the large $\mathrm{NO}_{\mathrm{y}}$ enhancements identified in this simulation. Further, the fast transport of SPE-generated $\mathrm{NO}_{\mathrm{y}}$ out of the source region in the SOCOLi simulations might result in a higher net $\mathrm{NO}_{\mathrm{y}}$ production since $\mathrm{NO}_{\mathrm{x}}$ destruction by reactions with atomic nitrogen (Reactions R2 and R3) is then less efficient. On the other hand, B2dM shows the most pole-centered $\mathrm{NO}_{\mathrm{y}}$ distribution among the models. As a consequence, $\mathrm{NO}_{\mathrm{y}}$ enhancements in the $70-90^{\circ} \mathrm{N}$ region reach 

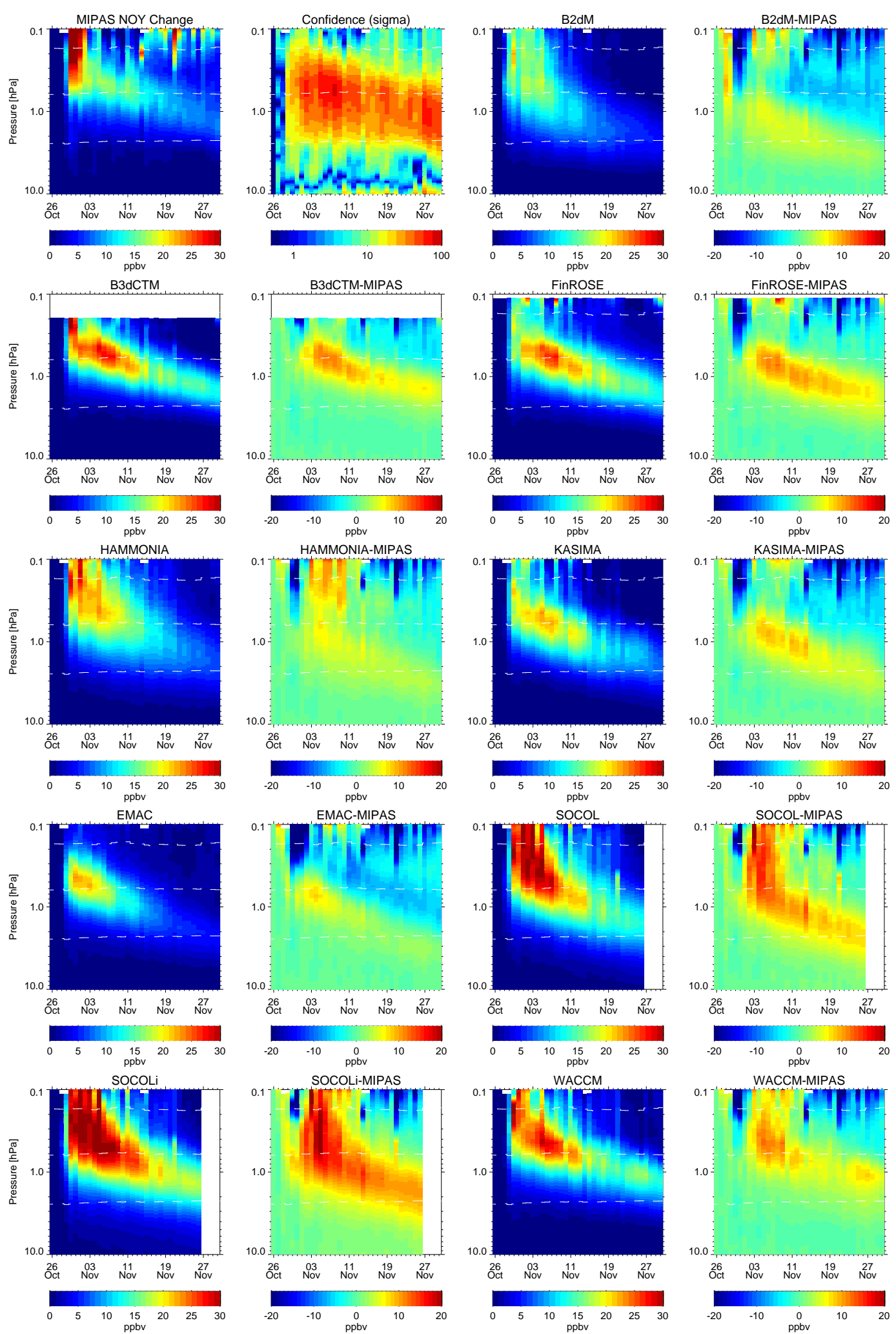

Fig. 15. Temporal evolution of area-weighted averages of $\mathrm{NO}_{\mathrm{y}}$ changes with respect to 26 October 2003 in MIPAS observations and model simulations at $40-90^{\circ} \mathrm{N}$, as well as differences between modeled and observed averages. The significance of observed $\mathrm{NO}_{\mathrm{y}}$ changes (in units of $\sigma$ ) is shown in the upper second panel (from the left). Note that observations exhibiting CO abundances higher than 1 ppmv have been omitted in the averaging in order to exclude the contributions from descended $\mathrm{NO}_{\mathrm{x}}$ produced by EEP at higher altitudes before the Halloween stroms. See text for further details. 

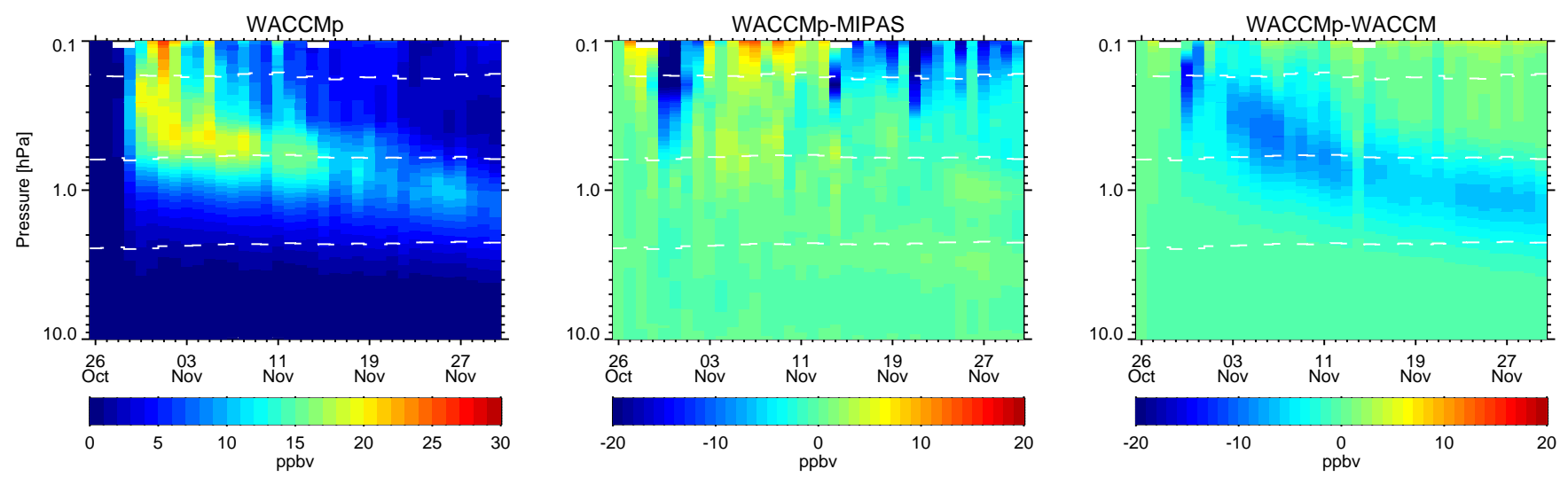

Fig. 16. As Fig. 15, but showing area-weighted averages for WACCMp (proton ionization, only, left), differences between WACCMp and MIPAS (middle), and differences between WACCMp and WACCM (right).

highest values of up to $60 \mathrm{ppbv}$ (twice as much as observed), although the $40-90^{\circ} \mathrm{N}$ average (see Fig. 12) is below the multi-model mean at this pressure level. This behavior is related to the very strong but small vortex in this particular model, probably as a result of its relatively poor horizontal resolution. The high dispersion in the latitudinal extent of the modeled $\mathrm{NO}_{\mathrm{y}}$ distributions, showing up already two days after the onset of the main proton forcing, is rather unexpected and highlights the importance of transport processes on a very short timescale.

During the following month, the SPE-induced $\mathrm{NO}_{\mathrm{y}}$ enhancements were transported downwards with the meridional circulation, forming a $\mathrm{NO}_{\mathrm{y}}$ layer around $45 \mathrm{~km}$ at the end of November (López-Puertas et al., 2005a). At the same time, $\mathrm{NO}_{\mathrm{x}}$, generated by continuous EEP in the lower thermosphere before the Halloween storm, reached the upper stratosphere and began to merge with the upper part of the SPE-induced layer (see also Fig. 1). This behavior is not reproduced by the simulations since low and mid-energy EEP is not included in the majority of the models. In order to facilitate the comparison of observed and modeled SPE-induced $\mathrm{NO}_{\mathrm{y}}$ enhancements in the following month after the proton forcing, we have excluded those parts of all observed and modeled $\mathrm{NO}_{\mathrm{y}}$ profiles where MIPAS $\mathrm{CO}$ abundances were higher than 1 ppmv. This value has been chosen such that the major fraction of EEP-induced $\mathrm{NO}_{\mathrm{y}}$ enhancements has been filtered out without removing too many MIPAS locations, particularly at higher altitudes.

Figure 15 shows the temporal evolution of the observed and modeled $\mathrm{NO}_{\mathrm{y}}$ enhancements (related to the SPE-induced in-situ production, only) with respect to 26 October within $40-90^{\circ} \mathrm{N}$ for the following month. While the magnitude of the enhancements is generally larger than in the observations and further shows a significant spread related to the differences in the $\mathrm{NO}_{\mathrm{y}}$ production during the proton forcing (see discussion above), the observed evolution of the SPEinduced $\mathrm{NO}_{\mathrm{x}}$ layer is well reproduced by all models in terms of vertical distribution and relative vmr decrease. A more detailed look into the temporal $\mathrm{NO}_{\mathrm{y}}$ evolution of individual models shows that smaller fluctuations can be attributed to dynamical variability.

It is interesting to notice that the WACCM simulation without electron-induced ionization yields better agreement with the observations than the nominal simulation throughout the period under investigation (see Fig. 16). Additional $\mathrm{NO}_{\mathrm{y}}$ buildup related to electron-induced ionization is even more pronounced during the second event (4-5 November) below $0.4 \mathrm{hPa}$ compared to the main proton forcing (see right panel of this figure). The $\mathrm{NO}_{\mathrm{y}}$ increase caused by electrons during the second event contributes with 5-10 ppbv to the excess $\mathrm{NO}_{\mathrm{y}}$ layer, descending during the following weeks.

The meridional distributions of the observed and modeled $\mathrm{NO}_{\mathrm{y}}$ enhancements exhibit important differences towards the end of November (see Fig. 17, showing $\mathrm{NO}_{\mathrm{y}}$ distributions at $2 \mathrm{hPa}$ averaged over 20-27 November). The observed and modeled latitudinal gradients correlate well with the meridional $\mathrm{CH}_{4}$ anomalies (see Fig. 9), highlighting the important role of mixing and large-scale transport. The meridional redistribution of the SPE-induced $\mathrm{NO}_{\mathrm{y}}$ enhancements, particularly the transport out of the polar night region, has important implications for the $\mathrm{NO}_{\mathrm{y}}$ repartitioning which is to a major part driven by photochemistry (see next subsection).

An interesting detail of the observed evolution of SPEinduced $\mathrm{NO}_{\mathrm{y}}$ enhancements (Fig. 15, upper left panel) is the appearance of several "spikes" at mesospheric altitudes, which are temporally correlated with peaks in the ionization related to high energy $(>300 \mathrm{keV})$ electron precipitation, the most pronounced event occurring on 21 November. Ionization by high energy electrons is included in the models which, however, do not reproduce such sudden $\mathrm{NO}_{\mathrm{y}}$ increases. It is therefore unlikely the observed mesospheric $\mathrm{NO}_{\text {y }}$ peaks are related to in situ production by EEP associated with the Halloween event. Instead, they could be related to residual contributions of descending $\mathrm{NO}_{\mathrm{x}}$ from the 

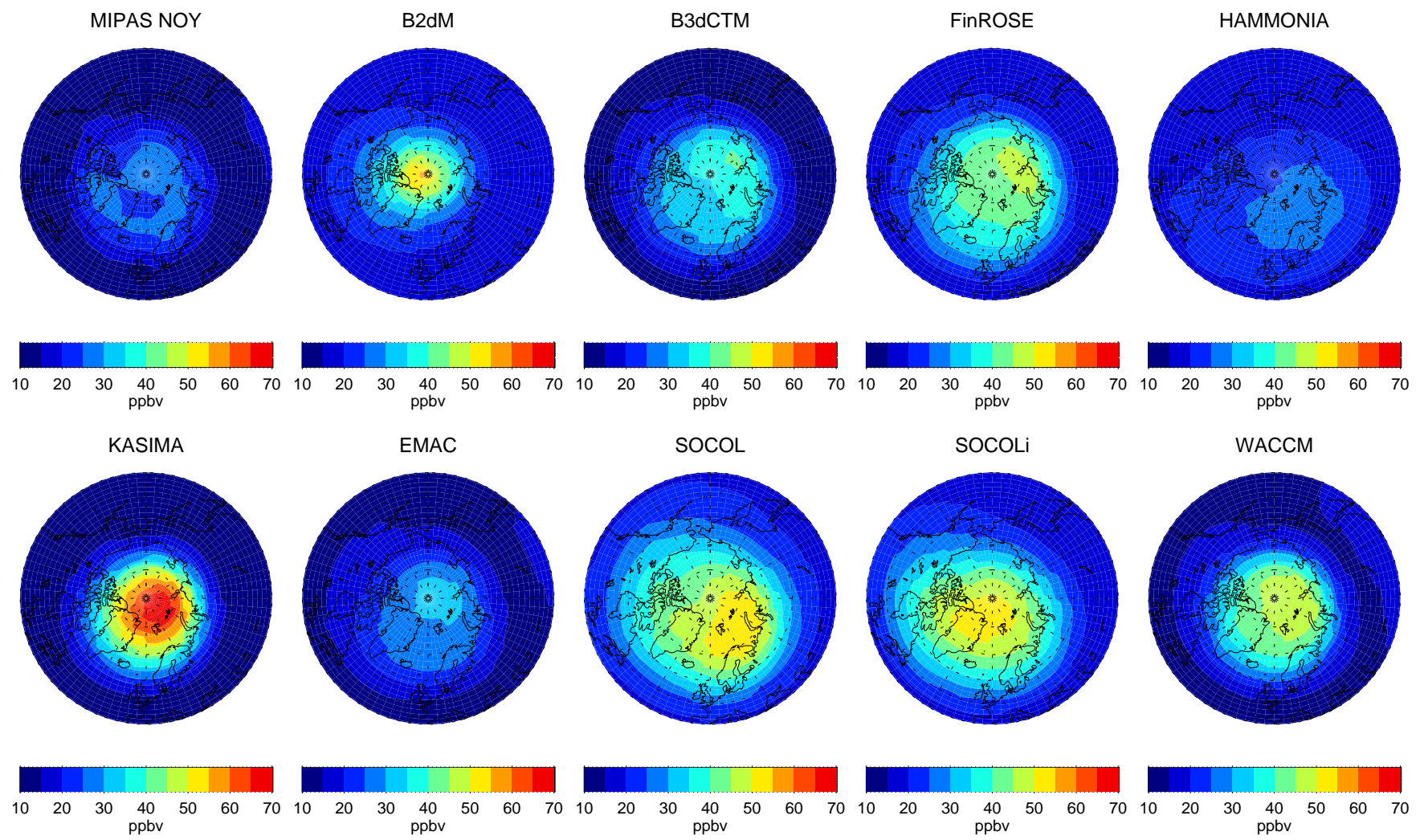

Fig. 17. Spatial distributions of observed and modeled $\mathrm{NO}_{\mathrm{y}}$ at $2 \mathrm{hPa}$ averaged of the period 20-27 November.

upper mesosphere which have not completely been filtered out. It should be noted that the observed CO temporal evolution (see Fig. 11) indicates particularly strong descent around 20 November.

A fraction of the $\mathrm{NO}_{\mathrm{x}}$ deactivation by reaction with atomic nitrogen during the proton forcing discussed above occurred via Reaction (R3), giving rise to the buildup of $\mathrm{N}_{2} \mathrm{O}$. Upper stratospheric and mesospheric nitrous oxide increases up to 7 ppbv have been observed by MIPAS during the Halloween SPE and have been attributed to this reaction channel (Funke et al., 2008). Reasonable agreement with CMAM model calculations has been obtained by assuming that only half of the products of Reaction ( $\mathrm{R} 3$ ) is $\mathrm{N}_{2} \mathrm{O}$ and $\mathrm{O}$, while the other half is $\mathrm{N}_{2}$ and $\mathrm{O}_{2}$. Figure 18 shows the observed and modeled $\mathrm{N}_{2} \mathrm{O}$ zonal mean enhancements averaged over the period of the main proton forcing (29-31 October). Except for FinROSE and B2dM, which do not include the reaction channel $\mathrm{R} 3, \mathrm{~N}_{2} \mathrm{O}$ increases are simulated by all models. The observed enhancements, however, are generally overestimated by a factor 2 to 10, except for EMAC which shows smaller $\mathrm{N}_{2} \mathrm{O}$ increases than observed by MIPAS. In the latter model, this can be clearly attributed to the modified $\mathrm{N}\left({ }^{4} \mathrm{~S}\right)$ and $\mathrm{N}\left({ }^{2} \mathrm{D}\right)$ branching ratio (see discussion above). Except for WACCM, the remaining models do not include the additional reaction channel of (R3), responsible for the formation of $\mathrm{N}_{2}$ and $\mathrm{O}_{2}$, which has been included in the CMAM simulations (Funke et al., 2008). But even when taking into account a reduction by a factor of 2 of the simulated enhancements, these models tend to overestimate the observations and further show a significant spread among the individual results. As in the case of $\mathrm{NO}_{\mathrm{y}}$, also the total SPE-induced $\mathrm{N}_{2} \mathrm{O}$ production depends on temperature, $\mathrm{NO}_{\mathrm{x}}$ partitioning, and dynamical redistribution. However, a dominant relationship of none of these quantities with the differences of the magnitudes of the modeled $\mathrm{N}_{2} \mathrm{O}$ increases can be established.

\subsection{Repartitioning of nitrogen species}

After having assessed the observed and modeled total $\mathrm{NO}_{\mathrm{y}}$ and $\mathrm{N}_{2} \mathrm{O}$ enhancements generated by the Halloween event, we analyze in this subsection the repartitioning of initially produced nitric oxide into other $\mathrm{NO}_{y}$ species in the aftermath of the SPE.

\subsection{1 $\mathrm{NO}_{\mathrm{x}}$}

The conversion of the excess NO generated by the proton forcing into $\mathrm{NO}_{2}$ acts on a very short timescale (seconds to minutes) and is controlled at dark conditions by the reactions

$$
\begin{aligned}
& \mathrm{NO}+\mathrm{O}_{3} \rightarrow \mathrm{NO}_{2}+\mathrm{O}_{2} \\
& \mathrm{NO}_{2}+\mathrm{O} \rightarrow \mathrm{NO}+\mathrm{O}_{2},
\end{aligned}
$$



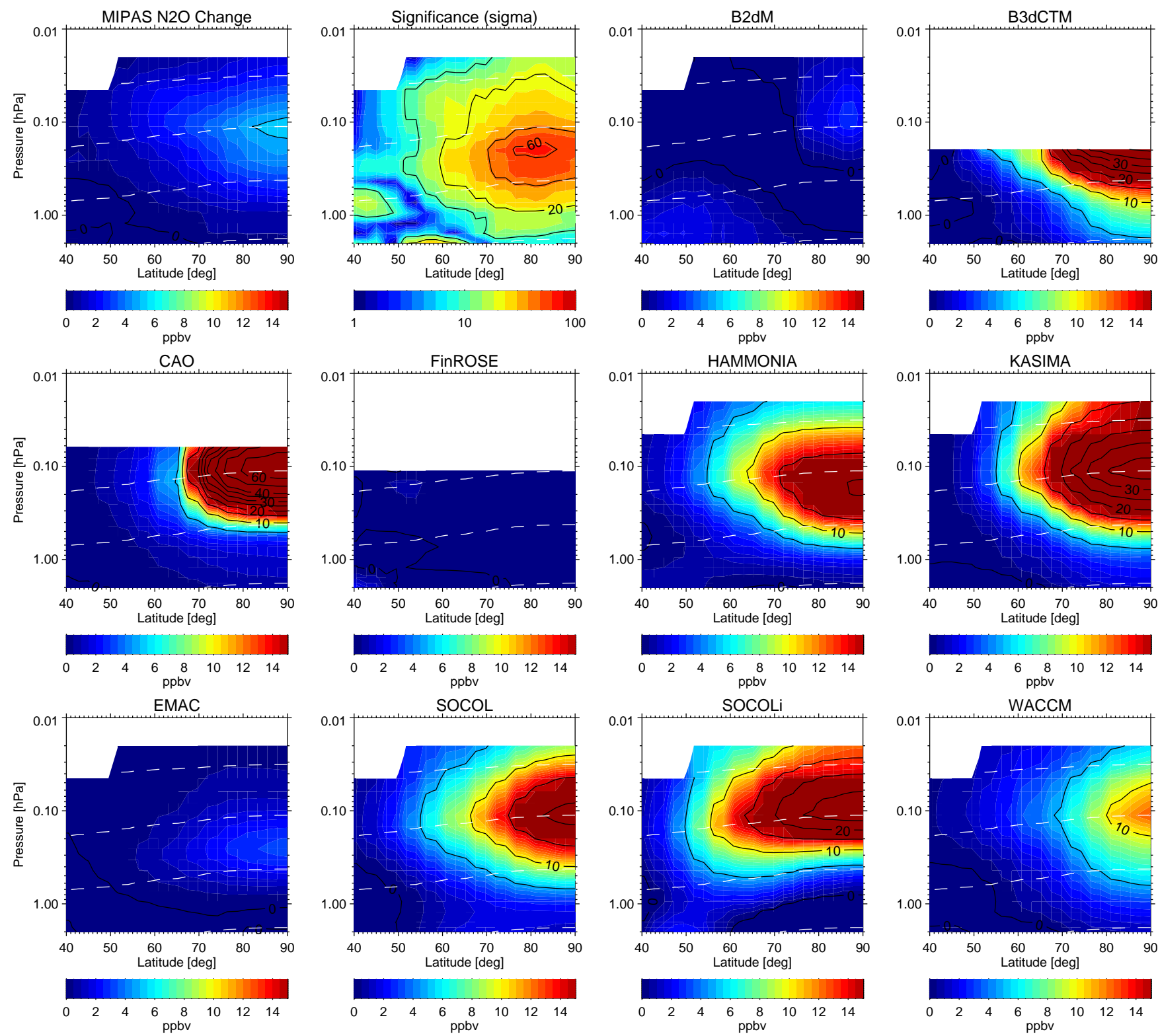

Fig. 18. Zonal mean $\mathrm{N}_{2} \mathrm{O}$ changes with respect to 26 October 2003 in MIPAS observations and model simulations averaged over the period 29-31 October. The significance of observed $\mathrm{N}_{2} \mathrm{O}$ changes (in units of $\sigma$ ) is shown in the upper second panel (from the left).

giving rise to a $\mathrm{NO}_{2} / \mathrm{NO}_{\mathrm{x}}$ ratio close to one in the stratosphere, but decreasing in the mesosphere due to the availability of atomic oxygen. This decrease occurs at higher altitudes in the polar night region compared to midlatitudes. Figure 19 shows the observed and modeled nighttime $\mathrm{NO}_{2} / \mathrm{NO}_{\mathrm{x}}$ ratios averaged over the initial SPE period. The observed decrease of this ratio above $0.3 \mathrm{hPa}$ at midlatitudes and $0.1 \mathrm{hPa}$ in the polar region is generally well reproduced by the models which resolve the mesosphere, except for B2dM and EMAC, which both overestimate the polar $\mathrm{NO}_{2}$ fraction at these altitudes. The higher mesospheric $\mathrm{NO}_{2}$ abundances in these two models might be related to lower atomic oxygen con- centrations at high altitudes and/or less efficient mixing between polar night and illuminated regions. At sunlit conditions, photolysis of $\mathrm{NO}_{2}$ and higher atomic oxygen abundances shift the $\mathrm{NO}_{2} / \mathrm{NO}_{\mathrm{x}}$ ratio to lower values compared to dark conditions. Figure 20 shows the observed and modeled daytime ratios. The observed values are well reproduced by B2dM, B3dCTM, SOCOL, and SOCOLi, while other models tend to overestimate the polar upper stratospheric and mesospheric $\mathrm{NO}_{2}$ fraction close to the terminator. In the case of CAO, EMAC, FinROSE, and HAMMONIA, this behavior can be explained by cut-off solar zenith angles lower than $95^{\circ}$ applied in the photolysis rate calculation. The encountered 

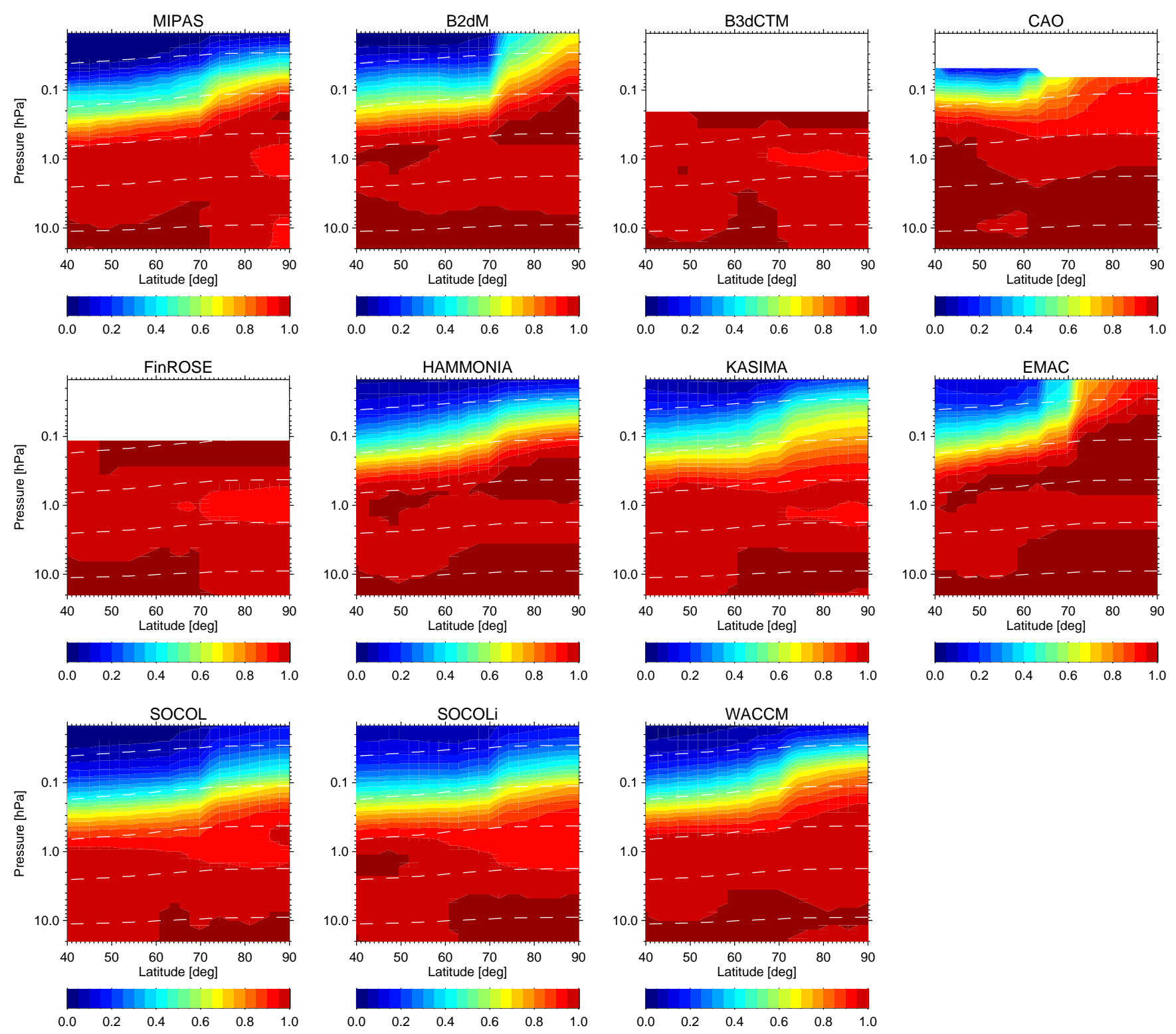

Fig. 19. Zonal mean nighttime $\mathrm{NO}_{2} / \mathrm{NO}_{\mathrm{x}}$ ratios averaged over the period 28 October-15 November in MIPAS observations and model simulations.

differences in the $\mathrm{NO}_{\mathrm{x}}$ partitioning among the models and observations highlight the difficulties in drawing conclusions on the SPE-induced total $\mathrm{NO}_{\mathrm{x}}$ enhancements from the comparison if only one of its components is considered.

\subsection{2 $\mathrm{N}_{2} \mathrm{O}_{5}$ and $\mathrm{HNO}_{3}$}

In the stratosphere, excess $\mathrm{NO}_{\mathrm{x}}$ produced by the proton forcing is slowly converted into $\mathrm{N}_{2} \mathrm{O}_{5}$ in the following weeks after the SPE by the reactions

$\mathrm{NO}_{2}+\mathrm{O}_{3} \rightarrow \mathrm{NO}_{3}+\mathrm{O}_{2}$

$\mathrm{NO}_{2}+\mathrm{NO}_{3}+\mathrm{M} \rightarrow \mathrm{N}_{2} \mathrm{O}_{5}+\mathrm{M}$.
The rate-limiting reaction of this conversion is Reaction (R6) which exhibits a strong temperature dependence. $\mathrm{N}_{2} \mathrm{O}_{5}$ enhancements around 1-2 ppbv, appearing 10-15 days after the Halloween event, have been observed by MIPAS around 70 $90^{\circ} \mathrm{N}$ and have been attributed to the repartitioning of SPEinduced excess $\mathrm{NO}_{\mathrm{x}}$ (López-Puertas et al., 2005b). This conversion is further accelerated in the course of November by the growth of the polar night region, reducing the efficiency of $\mathrm{N}_{2} \mathrm{O}_{5}$ losses by photolysis.

Figure 21 shows the observed and modeled temporal evolutions of the $\mathrm{N}_{2} \mathrm{O}_{5}$ enhancements with respect to 26 October averaged over $70-90^{\circ} \mathrm{N}$. A stratospheric $\mathrm{N}_{2} \mathrm{O}_{5}$ buildup, being most pronounced in the second half of November, is 

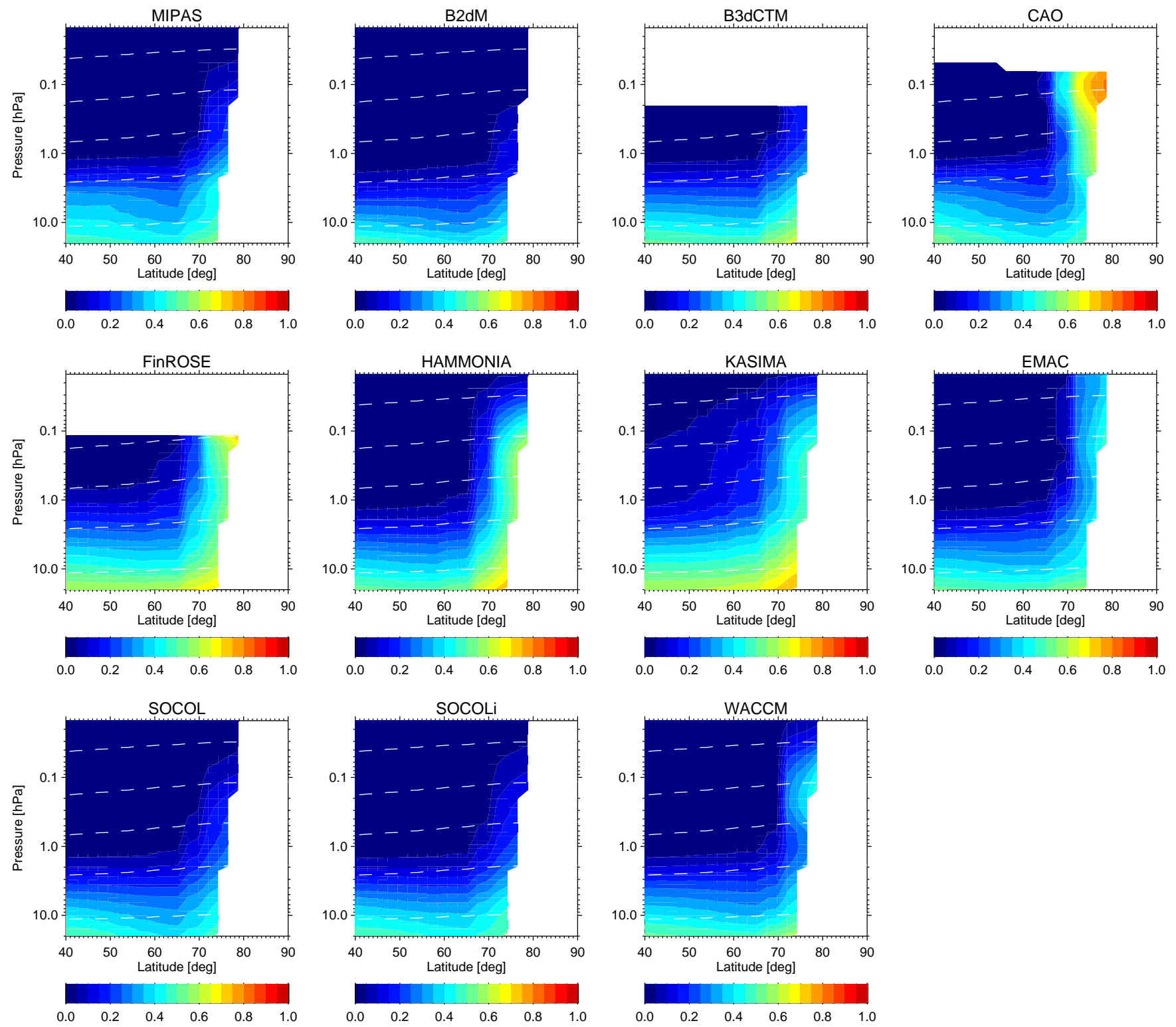

Fig. 20. Zonal mean daytime $\mathrm{NO}_{2} / \mathrm{NO}_{\mathrm{x}}$ ratios averaged over the period 28 October-15 November in MIPAS observations and model simulations.

simulated by all models, qualitatively reproducing the observed behavior. The modeled $\mathrm{N}_{2} \mathrm{O}_{5}$ increases are, however, generally overestimated (except for KASIMA) and exhibit a wide spread among the models. Taking into account that the magnitude of the $\mathrm{N}_{2} \mathrm{O}_{5}$ increase depends on various factors such as $\mathrm{NO}_{\mathrm{x}}$ availability, temperature, ozone abundances, and the efficiency of $\mathrm{N}_{2} \mathrm{O}_{5} \rightarrow \mathrm{HNO}_{3}$ conversion (see below), a large spread of the model results is expected. B2dM and EMAC, however, overestimate the observed $\mathrm{N}_{2} \mathrm{O}_{5}$ increases by factors of 4 and 6 , respectively. While in the case of $\mathrm{B} 2 \mathrm{dM}$ the extraordinarily high $\mathrm{N}_{2} \mathrm{O}_{5}$ amounts can be explained by the very pole-centered distribution of the precursor $\mathrm{NO}_{\mathrm{x}}$, implying insignificant photochemical losses in the source re- gion (see also discussion below), the reason for the unreasonably high $\mathrm{N}_{2} \mathrm{O}_{5}$ abundances of up to $12 \mathrm{ppbv}$ in the case of EMAC is still under investigation. $\mathrm{N}_{2} \mathrm{O}_{5}$ enhancements simulated by CAO until 4 November are likely to be caused by seasonal variations rather than by the SPE. The overestimated seasonal $\mathrm{N}_{2} \mathrm{O}_{5}$ buildup in this model is most likely related to the use of a family approach for $\mathrm{NO}_{\mathrm{y}}$.

Two distinct $\mathrm{HNO}_{3}$ enhancements were observed by MIPAS in the aftermath of the Halloween SPE (López-Puertas et al., 2005b). The first one, reaching vmrs around $2 \mathrm{ppbv}$, occurred immediately after the SPEs at altiudes above $40 \mathrm{~km}$ and has been initially attributed to the gas-phase reaction $\mathrm{NO}_{2}+\mathrm{OH}+\mathrm{M} \rightarrow \mathrm{HNO}_{3}+\mathrm{M}$. Verronen et al. (2008), 

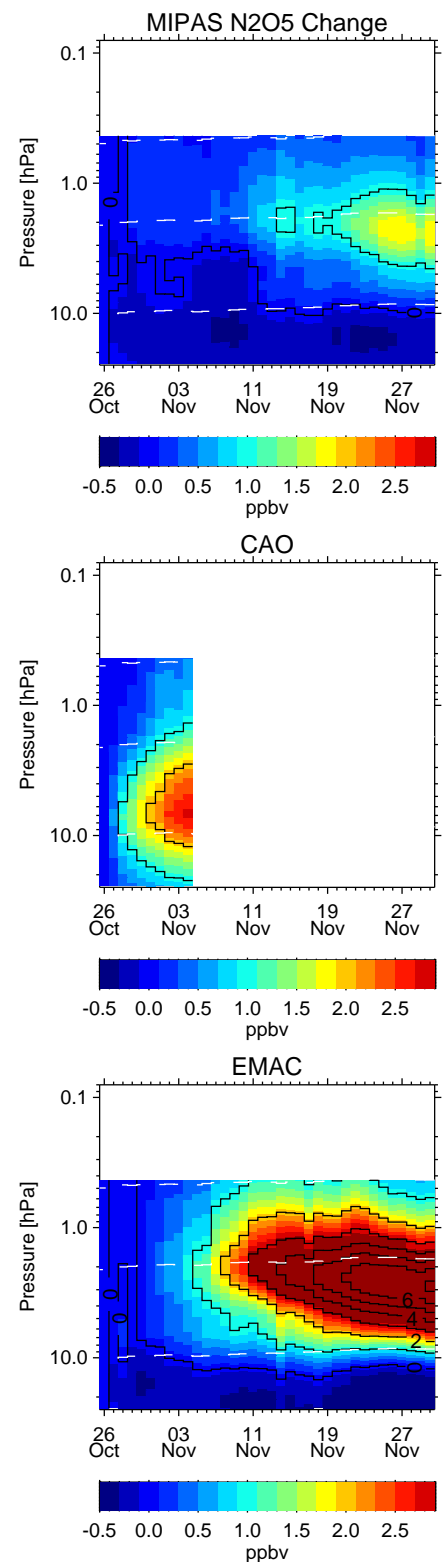
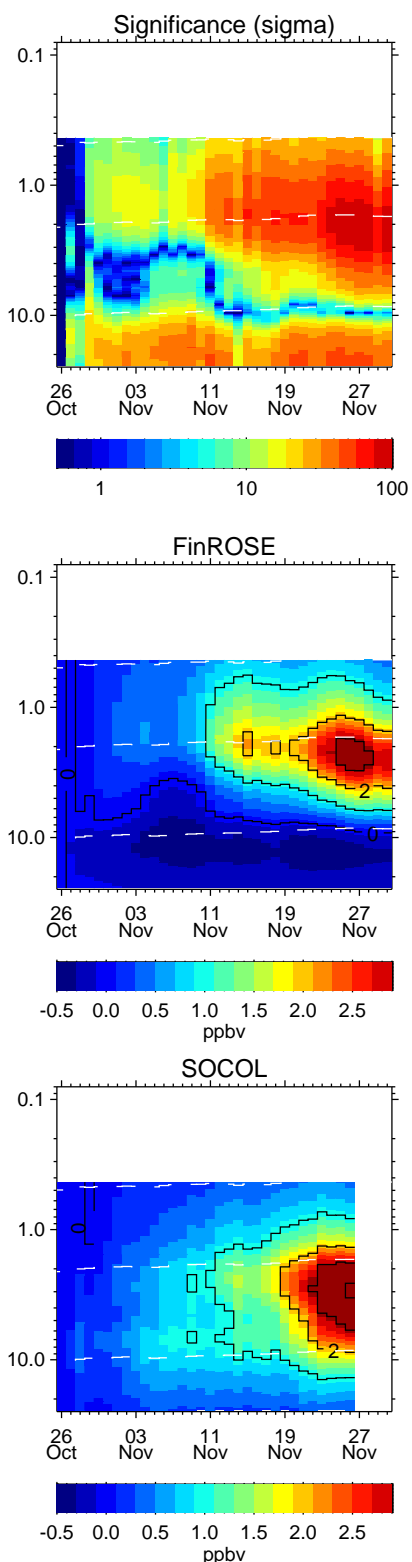
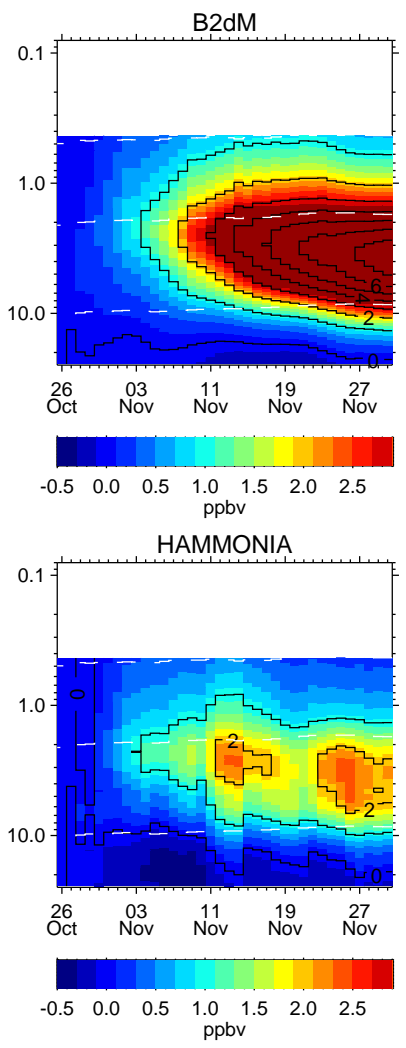

SOCOLi
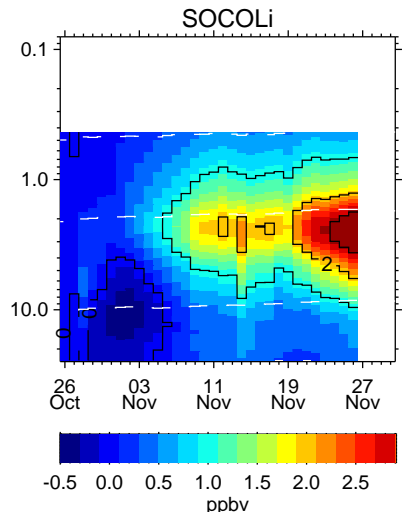
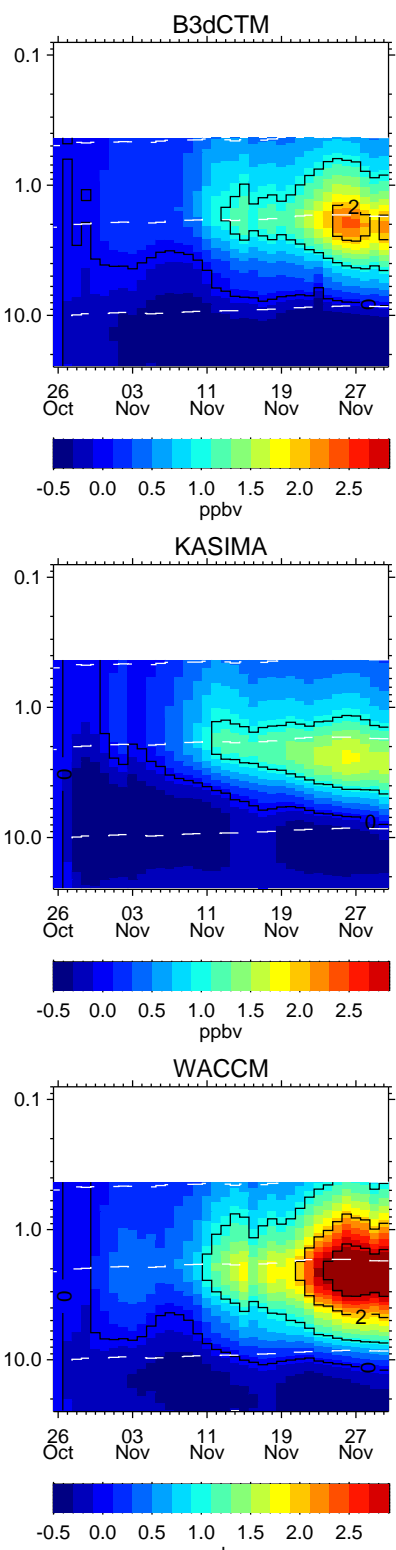

Fig. 21. Temporal evolution of area-weighted averages of $\mathrm{N}_{2} \mathrm{O}_{5}$ changes with respect to 26 October 2003 in MIPAS observations and model simulations at $70-90^{\circ} \mathrm{N}$. Solid contour lines reflect 1 ppbv steps. The significance of observed $\mathrm{N}_{2} \mathrm{O}_{5}$ changes (in units of $\sigma$ ) is shown in the upper second panel (from the left).

however, have shown that the instantaneous $\mathrm{HNO}_{3}$ increase after the proton forcing can only be reproduced by model calculations including ion-ion recombination between $\mathrm{NO}_{3}{ }^{-}$ and $\mathrm{H}^{+}$cluster ions. The second enhancement of $1-5 \mathrm{ppbv}$ started around 10 November and lasted until the end of December. Also in this case, attempts to reproduce the magnitude of the observed increases by model calculations including gas phase chemistry only, have failed (Jackman et al., 2008).

Figure 22 shows the observed and modeled temporal evolutions of the $\mathrm{HNO}_{3}$ enhancements with respect to 26 Octo- ber averaged over $70-90^{\circ} \mathrm{N}$. Consistent with previous findings, the first instantaneous enhancement is considerably underestimated by all models, except FinROSE, which includes the ion chemistry proposed by Verronen et al. (2008). This model, however, overestimates the observed increases by up to a factor of 3 . The overestimation below $50 \mathrm{~km}$ is surprising, given that 1-D simulations with the Sodankylä Ion and Neutral Chemistry (SIC) model which includes the ion-ion recombination were found to be in good agreement with the same MIPAS dataset at these altitudes. It should be noted, however, that different ionization rates have been used in the 

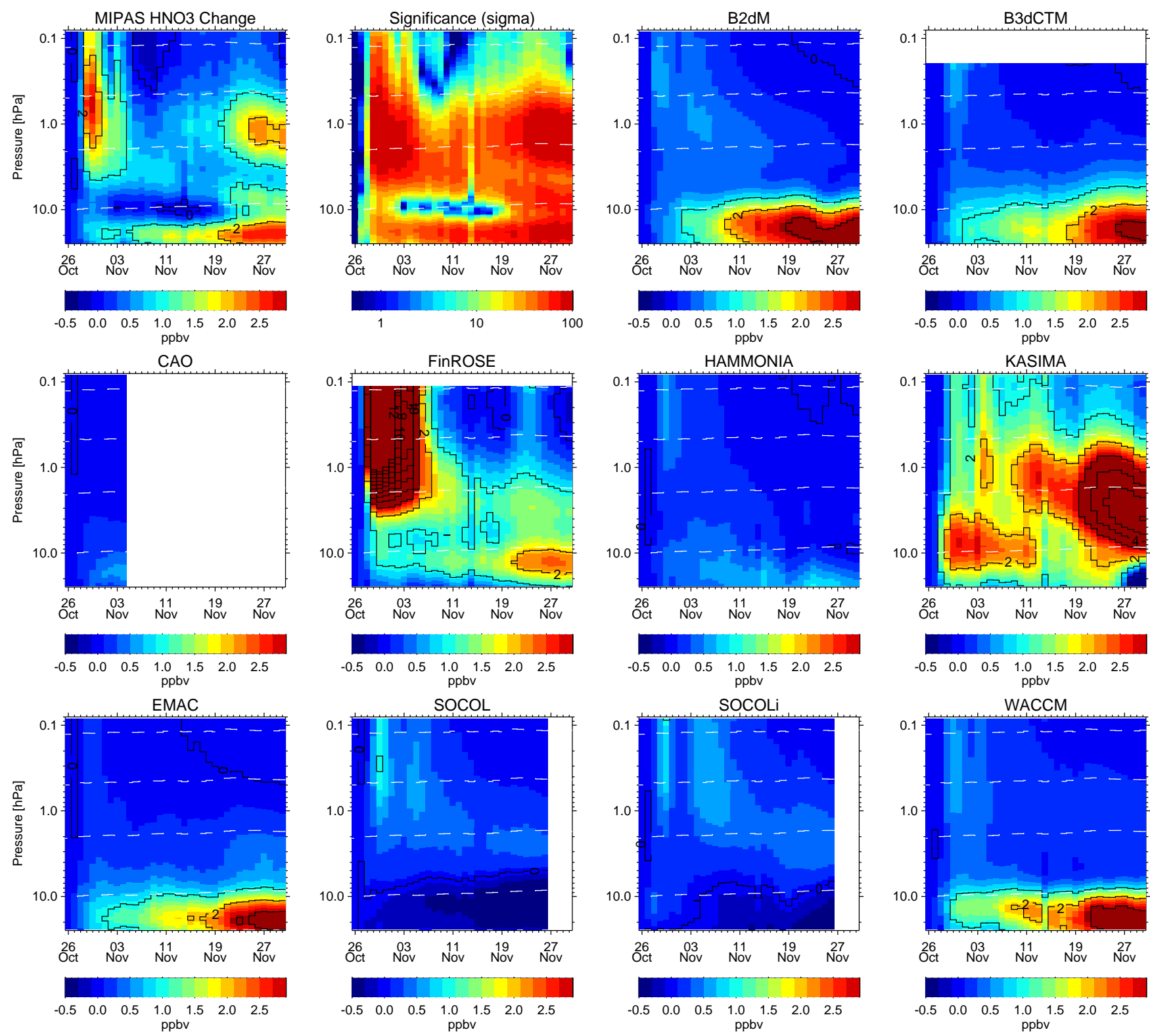

Fig. 22. Temporal evolution of area-weighted averages of $\mathrm{HNO}_{3}$ changes with respect to 26 October 2003 in MIPAS observations and model simulations at $70-90^{\circ} \mathrm{N}$. Solid contour lines reflect 1 ppbv steps. The significance of observed $\mathrm{HNO}_{3}$ changes (in units of $\sigma$ ) is shown in the upper second panel (from the left).

SIC calculations of Verronen et al. (2008), and - probably even more important - that FinROSE uses a parameterization of the ion-ion recombination included in the full ion chemistry scheme of the SIC model.

The second enhancement, occurring around 15 November at $1-2 \mathrm{hPa}$, is only reproduced by KASIMA. In this case, however, the observed increases are overestimated by a factor of 3. Contrary to other models, KASIMA simulations account for $\mathrm{HNO}_{3}$ formation via water cluster ions (Böhringer et al., 1983) combined with heterogeneous reactions on sulfate aerosols by means of a parameterization provided by de Zafra and Smyshlyaev (2001). At lower altitudes (i.e. below $10 \mathrm{hPa}$ ), midterm $\mathrm{HNO}_{3}$ increases are visible in the observations, as well as in the B2dM, B3dCTM, EMAC, FinROSE, and WACCM model results. These increases are not related to the SPE and can be explained by seasonal variations.

In order to assess the repartitioning of the main $\mathrm{NO}_{\mathrm{y}}$ species towards the end of November in a more quantitative way, we have analyzed their relative contributions to the total $\mathrm{NO}_{\mathrm{y}}$. This is necessary because of the encountered differences in the total amount of SPE-induced excess $\mathrm{NO}_{\mathrm{y}}$ among 

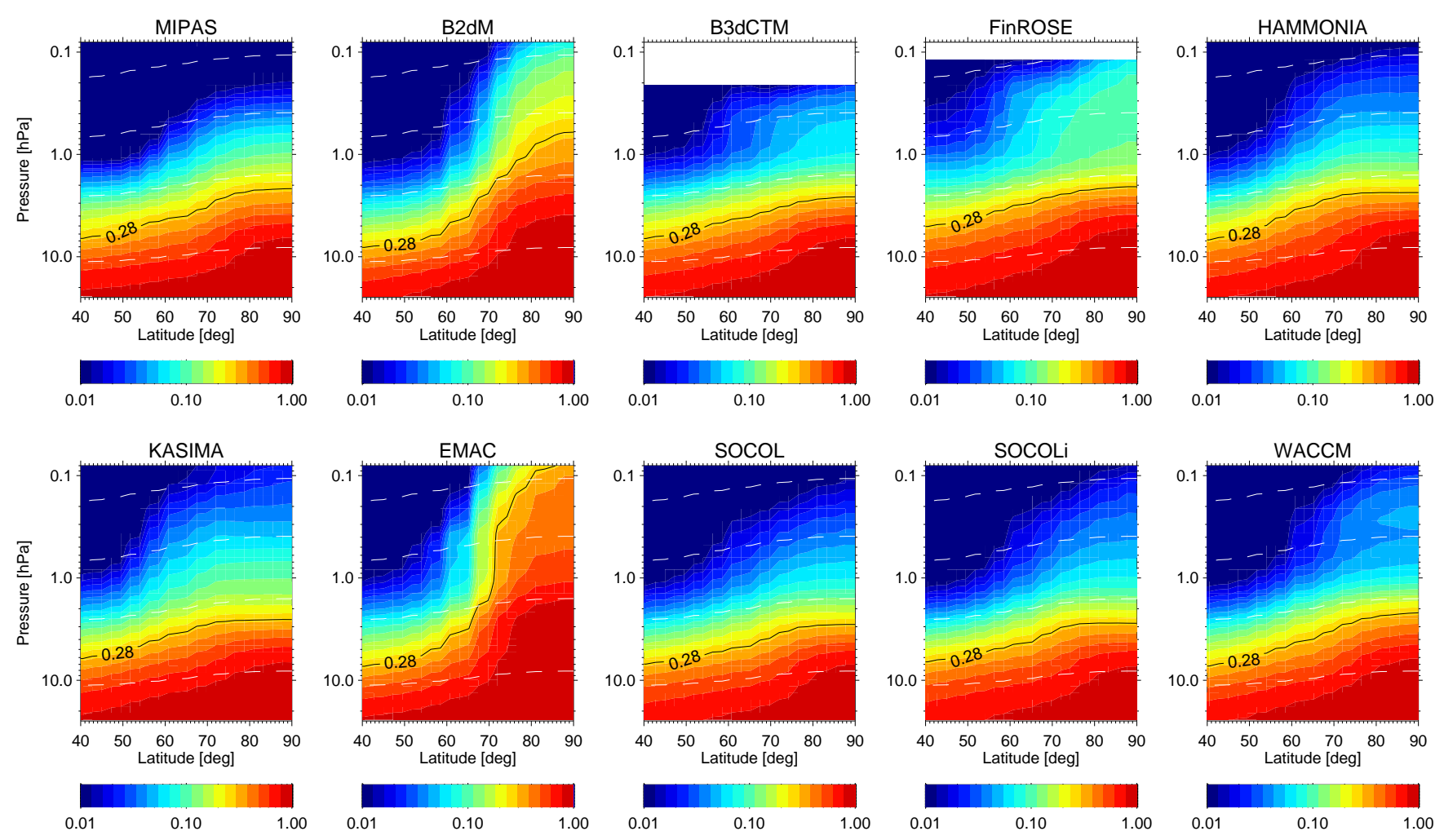

Fig. 23. Zonal mean $\left(2 \mathrm{~N}_{2} \mathrm{O}_{5}+\mathrm{HNO}_{3}\right) / \mathrm{NO}_{\text {y }}$ ratios averaged over the period $15-30$ November in MIPAS observations and model simulations. The MIPAS ratio of 0.28 , encountered at altitude of the maximum of the SPE-induced $\mathrm{NO}_{\mathrm{y}}$ layer, is indicated by a black line.

the different models and the observations. Due to the observed conversion of $\mathrm{N}_{2} \mathrm{O}_{5}$ into $\mathrm{HNO}_{3}$, we have looked, as a first step, at the relative contribution of the sum of both reservoir species to $\mathrm{NO}_{\mathrm{y}}$. Observed and simulated zonal mean $\left(2 \mathrm{~N}_{2} \mathrm{O}_{5}+\mathrm{HNO}_{3}\right) / \mathrm{NO}_{\mathrm{y}}$ ratios, averaged over the period $15-$ 30 November, are shown in Fig. 23. The observed ratio of 0.28 at the peak height $(\sim 0.2 \mathrm{hPa}$, see Fig. 15$)$ of the $\mathrm{NO}_{\mathrm{y}}$ enhancements in late November (indicated by a black line in Fig. 23) is very well reproduced by all models, except B2dM and EMAC. As discussed above, the disagreement found in these models is produced by too efficient buildup of $\mathrm{N}_{2} \mathrm{O}_{5}$ (see Fig. 21). The differences of the $\left(2 \mathrm{~N}_{2} \mathrm{O}_{5}+\mathrm{HNO}_{3}\right) / \mathrm{NO}_{\mathrm{y}}$ ratio in the observations and the $\mathrm{B} 2 \mathrm{dM}$ simulations are, however, much less pronounced than those encountered in the absolute $\mathrm{N}_{2} \mathrm{O}_{5}$ abundances: while $\mathrm{B} 2 \mathrm{dM} \mathrm{N}_{2} \mathrm{O}_{5}$ exceeds the observed amounts by a factor of 4 , the modeled $2 \mathrm{~N}_{2} \mathrm{O}_{5}+\mathrm{HNO}_{3}$ contribution to $\mathrm{NO}_{\mathrm{y}}$ at its peak height is around $40 \%$, exceeding the observed contribution by only a factor of 0.5 . The $\mathrm{N}_{2} \mathrm{O}_{5}$ overestimation in this model is hence mainly related to the higher amounts and more pole-centered distribution of the precursor $\mathrm{NO}_{2}$. In contrast to $\mathrm{B} 2 \mathrm{dM}$, EMAC simulations obtain more than $90 \%$ of the available $\mathrm{NO}_{\mathrm{y}}$ at its peak altitude in the form of $\mathrm{N}_{2} \mathrm{O}_{5}$. This contribution decreases with altitude, but still exceeds $30 \%$ in the mesosphere. Other models show, in some cases, a minor overestimation of the reservoir species fraction which can be partly explained by differences in the modeled temperatures and ozone abundances, controlling the efficiency of Reaction (R6).

The repartitioning between $\mathrm{HNO}_{3}$ and $\mathrm{N}_{2} \mathrm{O}_{5}$ has been assessed by comparing the observed and modeled zonal mean $\mathrm{HNO}_{3} /\left(2 \mathrm{~N}_{2} \mathrm{O}_{5}+\mathrm{HNO}_{3}\right)$ ratios averaged over the period $15-$ 30 November (Fig. 24). As expected, the observed ratio is strongly underestimated above approximately $10 \mathrm{hPa}$ by all models, except KASIMA. The qualtitative agreement of KASIMA simulations and MIPAS observations is very good, particularly regarding the vertical shape of this ratio. The modeled ratio, however, exhibits a positive bias of 0.2 with respect to the observations, most pronounced in the polar region. We conclude that the $\mathrm{HNO}_{3}$ formation via water cluster ions and/or heterogeneous reactions on sulfate aerosols, both included in KASIMA by means of the parameterization of de Zafra and Smyshlyaev (2001), is the responsible mechanism for the observed $\mathrm{HNO}_{3}$ enhancements in late November. However, some further work is required to adjust the parameterization quantitatively to the measurements.

\subsubsection{Minor $\mathrm{NO}_{\mathrm{y}}$ species}

Also minor $\mathrm{NO}_{\mathrm{y}}$ species were found to be enhanced in the aftermath of the Halloween SPE due to the repartitioning of initially produced $\mathrm{NO}_{\mathrm{x}}$. López-Puertas et al. (2005b) reported 

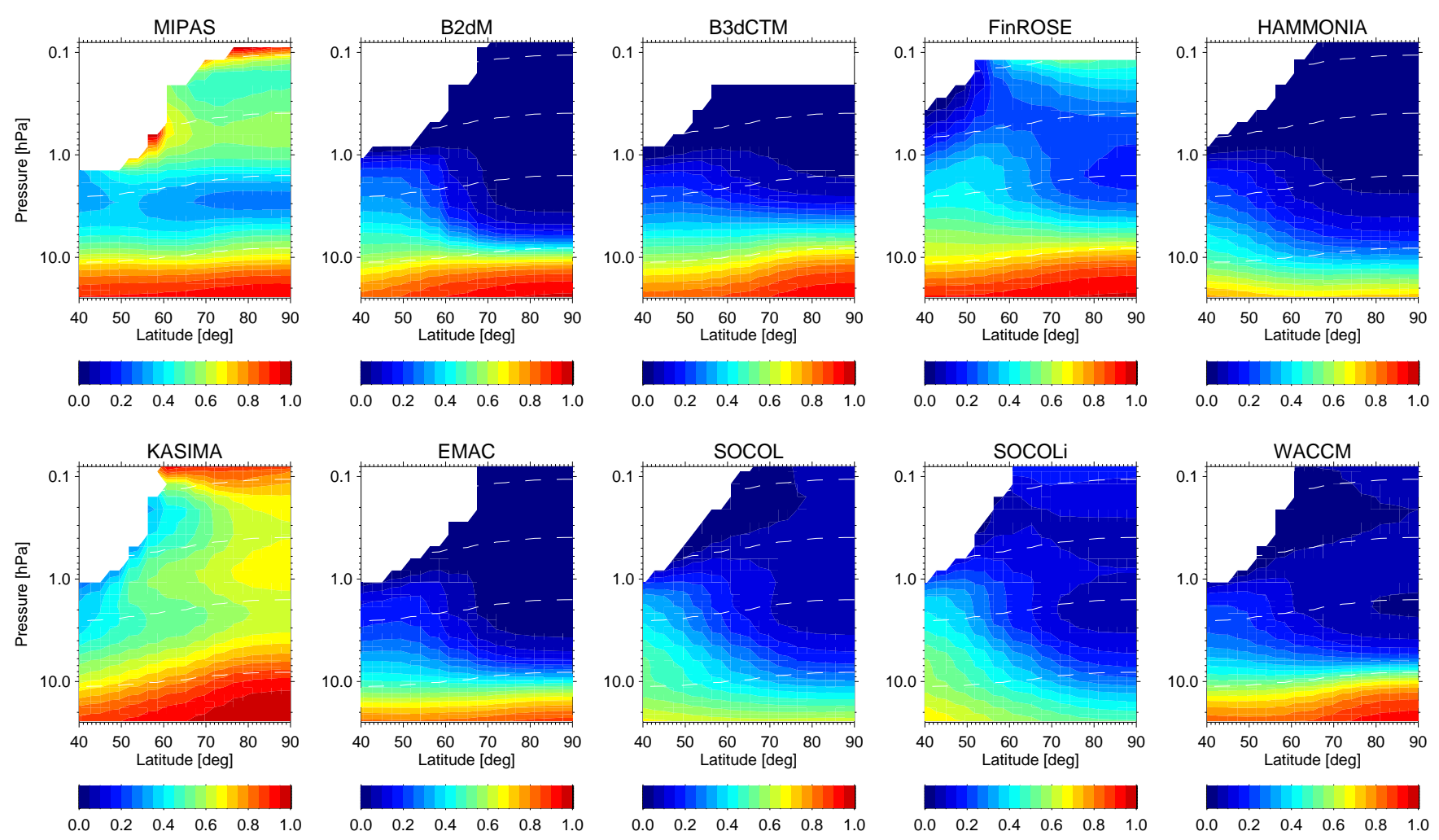

Fig. 24. Zonal mean $\mathrm{HNO}_{3} /\left(2 \mathrm{~N}_{2} \mathrm{O}_{5}+\mathrm{HNO}_{3}\right)$ ratios averaged over the period 15-30 November in MIPAS observations and model simulations. Regions with observed vmrs of $2 \mathrm{~N}_{2} \mathrm{O}_{5}+\mathrm{HNO}_{3}$ smaller than $0.1 \mathrm{ppbv}$ have been omitted.

$\mathrm{ClONO}_{2}$ enhancements up to $0.4 \mathrm{ppbv}$ a few days after the proton forcing from MIPAS observations. These observations are compared to the model simulations in Sect. 6.6, together with observations of other chlorine species. MIPAS has also observed enhanced $\mathrm{HNO}_{4}$ during the first days of the Halloween SPE which have not been reported so far. These increases can be attributed to the termolecular reaction

$\mathrm{HO}_{2}+\mathrm{NO}_{2}+\mathrm{M} \rightarrow \mathrm{HNO}_{4}+\mathrm{M}$.

Since at the altitude of the $\mathrm{HNO}_{4}$ enhancements (around 2$3 \mathrm{hPa}$ ) SPE-related increases of the precursor $\mathrm{NO}_{2}$ are relatively small $(\sim 2 \mathrm{ppbv})$ compared to the background $\mathrm{NO}_{2}$ abundance, the observed $\mathrm{HNO}_{4}$ changes are mainly driven by enhanced $\mathrm{HO}_{2}$ abundances, and hence, represent an indicator of SPE-generated $\mathrm{HO}_{\mathrm{x}}$ in the middle stratosphere. At dark conditions, $\mathrm{HO}_{\mathrm{x}}$ is in steady state even during a SPE, and its abundance is hence directly proportional to atmospheric ionization. Stratospheric $\mathrm{HNO}_{4}$ is destroyed during the day by photolysis and by reaction with $\mathrm{OH}$. Nighttime losses are negligible under quiescent conditions, and even during SPEs, OH-driven $\mathrm{HNO}_{4}$ destruction is small compared to its production via Reaction (R8).

Due to problems with the gain calibration, particularly affecting this species (see discussion in Sect. 2), we restrict our analysis to data from the gain calibration period 28 October5 November. Figure 25 shows the observed and modeled zonal mean distributions of $\mathrm{HNO}_{4}$ vmrs during the first four days of the proton forcing (29 October-1 November). Model results for pre-SPE conditions (26 October) are also shown. $\mathrm{HNO}_{4}$ model output is not available from CAO, EMAC, HAMMONIA, and FinROSE. Polar upper stratospheric enhancements of up to $0.18 \mathrm{ppbv}$ are visible in the observations on 30 October, decreasing until 1 November by about $20 \%$. The $\mathrm{HNO}_{4}$ enhancements are also simulated by the models in the first days of the SPE, but are generally overestimated. The overestimation is most pronounced in the $\mathrm{B} 2 \mathrm{dM}, \mathrm{B} 3 \mathrm{dCTM}$, and WACCM simulations (a factor 2-3), while SOCOLi shows smaller $\mathrm{HNO}_{4}$ increases. The $\mathrm{HNO}_{4}$ peak height is located at somewhat lower altitudes in SOCOLi which might be related to the relatively high abundances inside the ambient $\mathrm{HNO}_{4}$ layer around $5 \mathrm{hPa}$. Both, the SPE-related and ambient peaks can not be vertically resolved and merge together after the application of MIPAS averaging kernels. The moderate decrease of $\mathrm{HNO}_{4}$ in the following days is qualitatively reproduced by all models except B2dM. In this particular model, the $\mathrm{HNO}_{4}$ enhancements are confined to the polar night region, hence experiencing less photochemical losses.

The differences in the magnitude of the $\mathrm{HNO}_{4}$ enhancements in the simulations and the observations can partially be explained by differences in the abundances of the precursor $\mathrm{NO}_{2}$. During the main proton forcing, modeled $\mathrm{NO}_{2}$ 


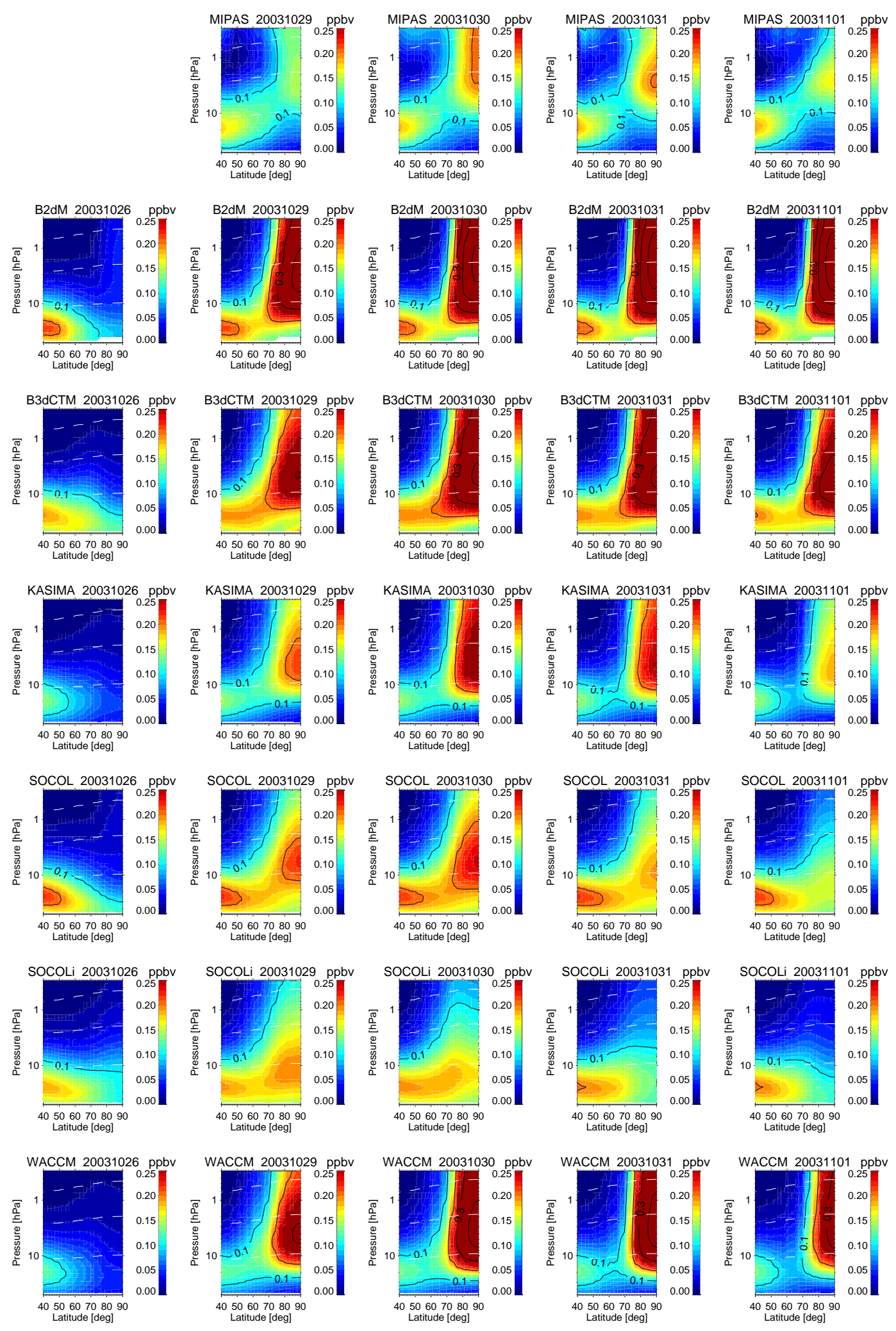

Fig. 25. Observed and modeled zonal mean $\mathrm{HNO}_{4}$ vmrs for pre-SPE conditions (26 October) and during the main proton forcing (29 October-1 November). Solid contour lines reflect 0.1 ppbv steps. Note that MIPAS observations from 26 October have been omitted due to gain calibration problems. 

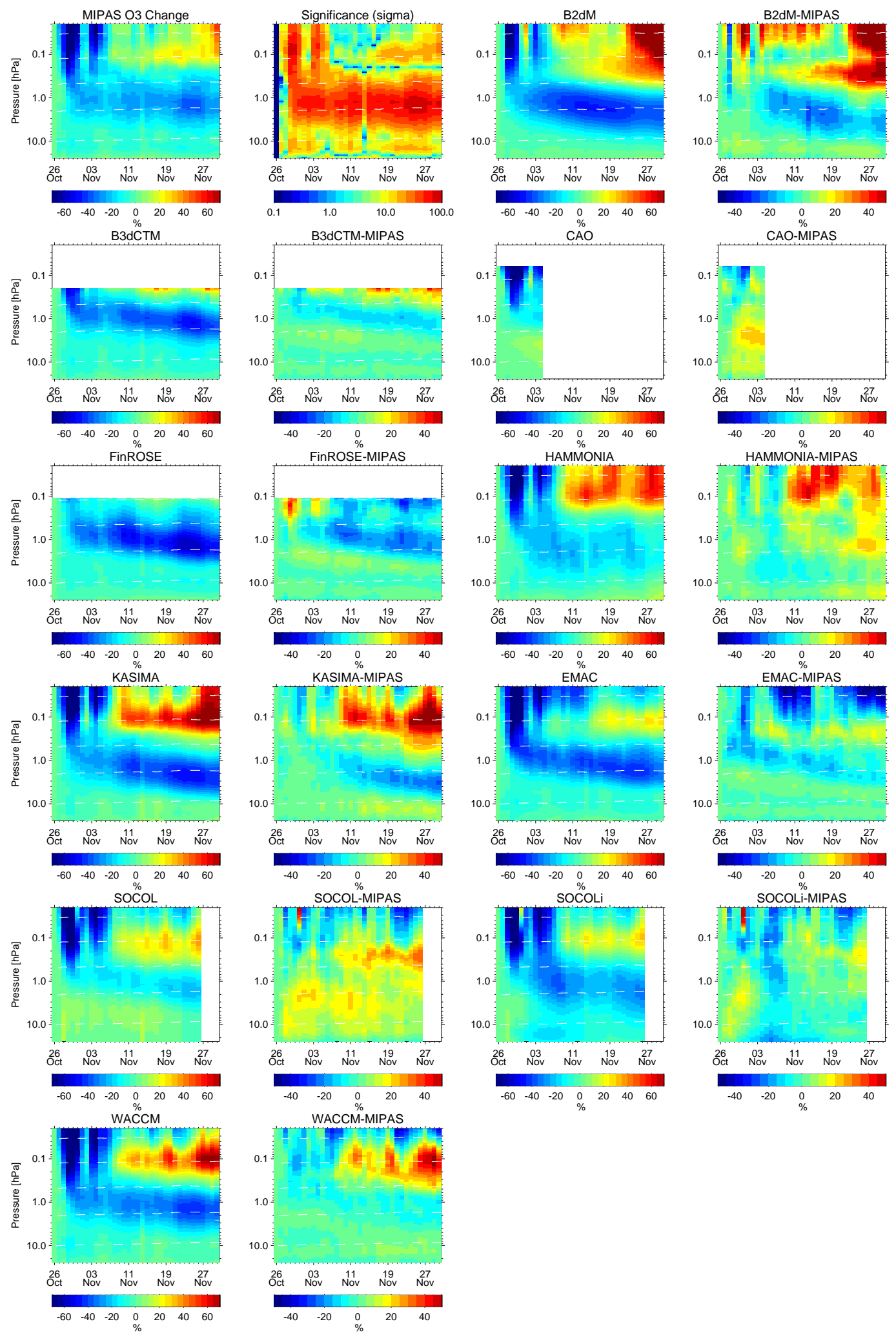

Fig. 26. Temporal evolution of area-weighted averages of relative $\mathrm{O}_{3}$ changes with respect to 26 October 2003 in MIPAS observations and model simulations at $70-90^{\circ} \mathrm{N}$, as well as differences between modeled and observed averages. The significance of observed $\mathrm{O}_{3}$ changes (in units of $\sigma$ ) is shown in the upper second panel (from the left). 


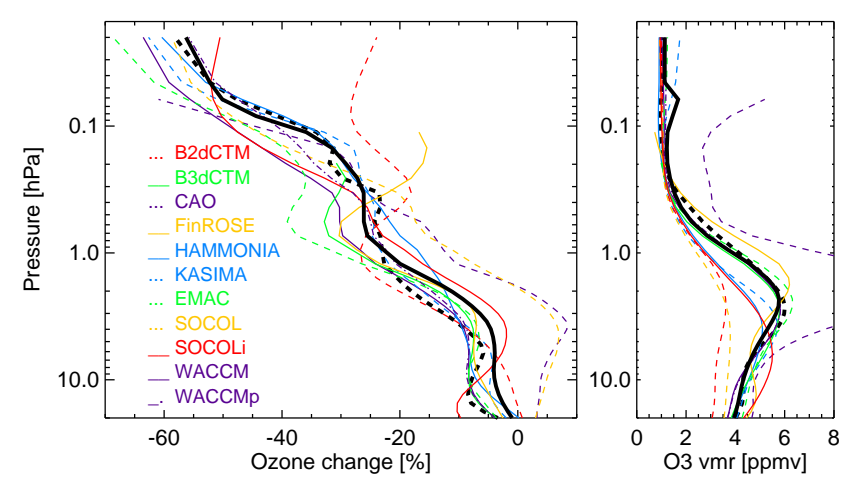

Fig. 27. Area-weighted averages $\left(70-90^{\circ} \mathrm{N}\right)$ of observed and modeled relative $\mathrm{O}_{3}$ changes during 29 October-4 November (left) with respect to the abundances on 26 October (right). Thick solid and dashed lines represent multi-model mean average and MIPAS observations, respectively. WACCMp denotes the WACCM simulation including proton ionization, only (excluded from the multimodel mean).

abundances at $70-90^{\circ} \mathrm{N}$ at the $\mathrm{HNO}_{4}$ peak height are on average $50-100 \%$ higher than the observed ones (not shown). The $\mathrm{NO}_{2}$ overestimation in the models is mainly related to a weaker degree of denoxification compared to the observations already before the SPE event. Additionally, differences in the $\mathrm{HO}_{2}$ availability might also play an important role in explaining the behavior of modeled $\mathrm{HNO}_{4}$. At the peak height of the $\mathrm{HNO}_{4}$ enhancements and in the absence of sunlight, $\mathrm{HO}_{2}$ is the dominant $\mathrm{HO}_{\mathrm{x}}$ compound in the presence of proton forcing. Since $\mathrm{HO}_{\mathrm{x}}$ production by SPE-induced ionization is not expected to differ significantly among the models, different $\mathrm{HO}_{2}$ abundances are most likely related to differences in the $\mathrm{HO}_{\mathrm{x}}$ losses. These are dominated by the cannibalistic reaction

$\mathrm{HO}_{2}+\mathrm{OH} \rightarrow \mathrm{H}_{2} \mathrm{O}+\mathrm{O}_{2}$.

In this sense, the $\mathrm{HO}_{\mathrm{x}}$ partitioning plays a crucial role in the $\mathrm{HO}_{2}$ availability at these altitudes despite the approximately 20 times smaller $\mathrm{OH}$ concentrations compared to $\mathrm{HO}_{2}$.

It might also be possible that the $\mathrm{HO}_{\mathrm{x}}$ partitioning is affected by ion chemistry. Several ion chemistry reactions are known which transfer $\mathrm{H}$ into $\mathrm{OH}^{-}$, and therefore might act as a sink of $\mathrm{HO}_{2}$; one reaction is known which transfers $\mathrm{OH}$ into $\mathrm{HO}_{2}$. While it is beyond the scope of this investigation to determine whether these reactions really significantly affect the partitioning between odd hydrogen species, it might be worthwhile to investigate this point in the future.

\subsection{Ozone loss}

One of the most important aspects of the model-data intercomparison of SPE-induced composition changes during the Halloween event is the evaluation of the ability of the models to reproduce the observed ozone destruction caused by acceleration of catalytic $\mathrm{HO}_{\mathrm{x}}$ and $\mathrm{NO}_{\mathrm{x}}$ cycles. SPE-induced ozone losses have been observed by a variety of space-borne instruments during several of the stronger events of the past two solar cycles (see Jackman et al., 2000, for a review). Two different types of ozone destruction could be distinguished: $\mathrm{HO}_{\mathrm{x}}$-related short-time losses, acting principally in the mesosphere during the event itself, and $\mathrm{NO}_{\mathrm{x}}$-related midterm losses in the stratosphere which can last up to several months in the polar winter atmosphere. Such a behavior was also observed by MIPAS in the aftermath of the Halloween event. López-Puertas et al. (2005a) reported $\mathrm{HO}_{\mathrm{x}}$-driven mesospheric ozone losses up to $70 \%$ and $\mathrm{NO}_{\mathrm{x}}$-driven stratospheric losses of around $30 \%$, the latter lasting for more than 2 weeks in the Northern Hemisphere.

Figure 26 shows the observed and modeled temporal evolutions of the relative $\mathrm{O}_{3}$ changes with respect to 26 October, averaged over $70-90^{\circ} \mathrm{N}$. The mesospheric ozone losses above $0.3 \mathrm{hPa}$, which exhibit two distinct peaks related to the proton events on 29 October and 4 November, are well reproduced by most of the models. Also the stratospheric $\mathrm{O}_{3}$ losses during the following month, peaking around $1 \mathrm{hPa}$, are qualitatively reproduced by the simulations, however, with a more pronounced spread of the model results. This is not surprising since these losses are driven by $\mathrm{NO}_{\mathrm{x}}$ which exhibits important differences between the models, particularly during the second half of November (see Sects. 6.2 and 6.3). Further, $\mathrm{NO}_{\mathrm{x}}$-induced ozone loss is driven by Reaction (R4) which is very sensitive to temperature differences. The midterm evolution in the mesosphere is characterized by ozone buildup which is related to seasonal variations (summer to winter transition), and which is generally more pronounced in the model simulations compared to the observations. This seasonal ozone buildup masks the residual ozone depletion related to the SPE.

In order to assess observed and modeled short-term ozone depletion in a more quantitative way, we have compared profiles of relative ozone changes at $70-90^{\circ} \mathrm{N}$, averaged over the period of the main proton forcing (28 October- 4 November), in Fig. 27. The agreement between observations and the multi-model average is excellent in the mesosphere, indicating a very good overall ability of the models to reproduce $\mathrm{HO}_{\mathrm{x}}$-related ozone losses under SPE conditions. Also, the models themselves agree reasonably well in this altitude range, except for $\mathrm{B} 2 \mathrm{dM}$. In the stratosphere, where $\mathrm{NO}_{\mathrm{x}}-$ related losses are dominant, the agreement between the models is worse, though the model average is very close to the observations within $5 \%$. Ozone depletion around $1 \mathrm{hPa}$ is overestimated by EMAC and B3dCTM. CAO and SOCOL results indicate a somewhat smaller ozone loss throughout the stratosphere. WACCM simulations performed with and without electron-induced ionization (WACCM and WACCMp, respectively in Fig. 27) indicate an additional ozone loss induced by electrons in the order of $5 \%$ above $2 \mathrm{hPa}$.

Figure 28 shows the corresponding zonal mean distributions. Observed mesospheric losses extend to around $60^{\circ} \mathrm{N}$ in consonance with the expected cut-off latitude of proton 

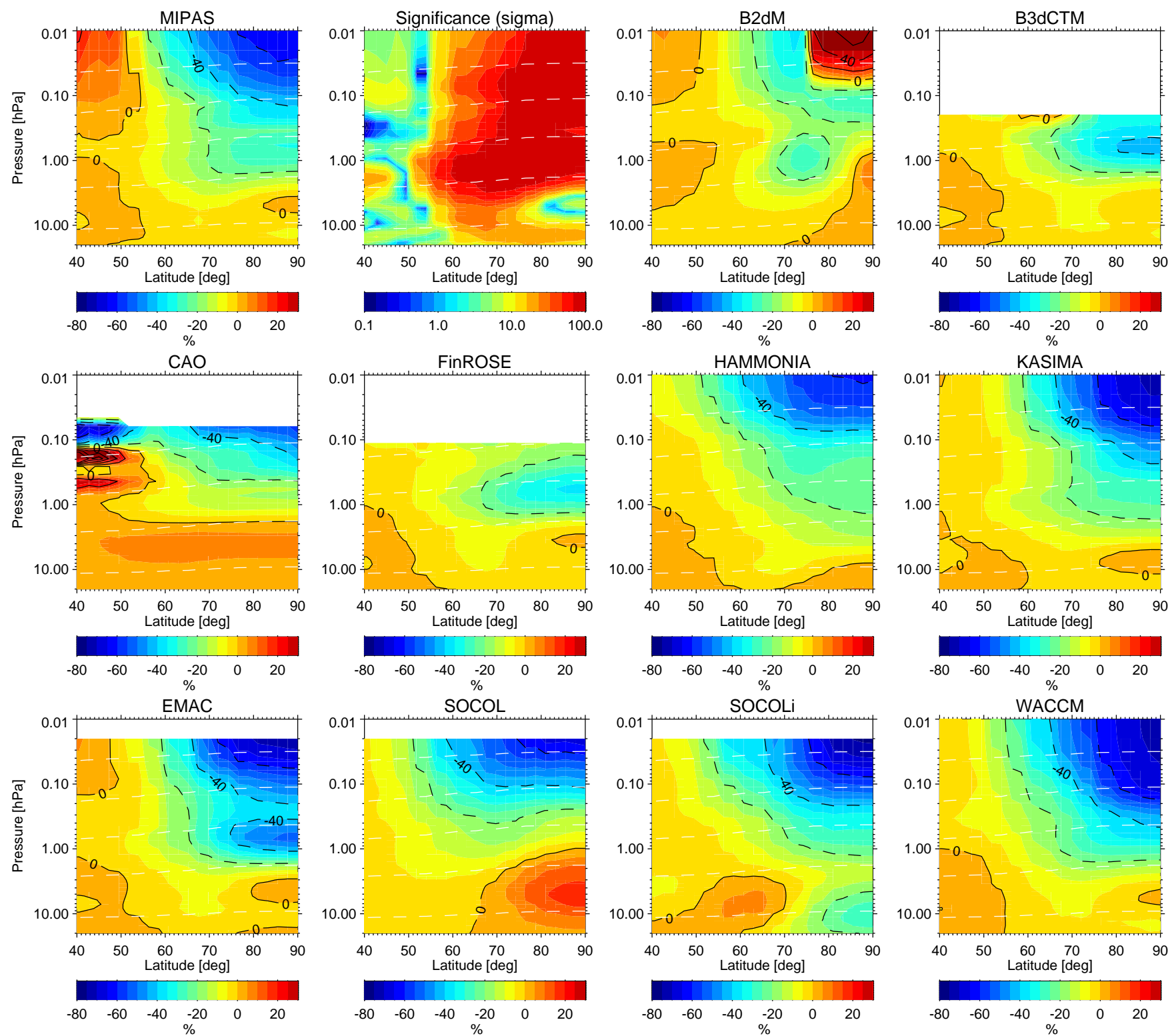

Fig. 28. Zonal mean relative $\mathrm{O}_{3}$ changes with respect to 26 October averaged over the period 28 October- 4 November in MIPAS observations and model simulations. Solid contour lines reflect $20 \%$ steps. The significance of the observations is also shown (second top panel from the left, in units of $\sigma$ ).

precipitation. This latitudinal distribution is well reproduced by the models. B2dM shows a mesospheric ozone buildup poleward of $80^{\circ} \mathrm{N}$ related to seasonal changes, which overcompensates $\mathrm{HO}_{\mathrm{x}}$-related losses at these particular latitudes. This behavior, which can be attributed to deficient meridional mixing in the polar region, give rise to the apparent underestimation of mesospheric ozone losses of B2dM in Fig. 27. Oscillations encountered in the $\mathrm{CAO}$ ozone changes above $1 \mathrm{hPa}$ at $40-50^{\circ} \mathrm{N}$ are related to the background $\mathrm{O}_{3}$ and are not caused by the SPE.
The latitudinal extension of observed and modeled stratospheric ozone losses around $1 \mathrm{hPa}$ correlates well with the area of $\mathrm{NO}_{\mathrm{x}}$ increases shown in Fig. 14. In this altitude region, ozone depletion is restricted to latitudes poleward of $70^{\circ} \mathrm{N}$. It is interesting to notice that B2dM simulations show no $\mathrm{NO}_{\mathrm{x}}$-induced ozone loss in the upper stratospheric polar night region, in contrast to the observations and other models. Indeed, the $\mathrm{NO}_{\mathrm{x}}$ catalytic cycle is expected to be inefficient at dark conditions since $\mathrm{NO}_{2}$ is not reconverted to NO. Strong mixing is hence required in order to obtain a homogeneous ozone distribution in the polar stratosphere as found 


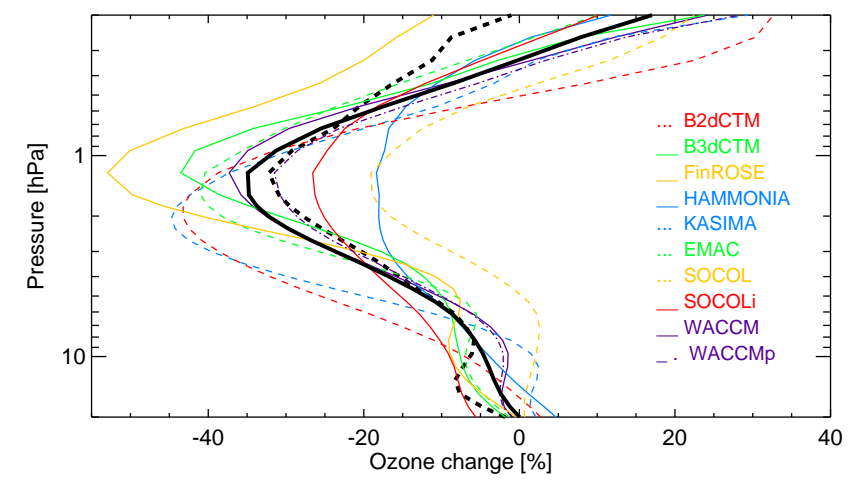

Fig. 29. Area-weighted averages $\left(70-90^{\circ} \mathrm{N}\right)$ of observed and modeled relative $\mathrm{O}_{3}$ changes with respect to 26 October during 1626 November. Thick solid and dashed lines represent model mean average and MIPAS observations, respectively. WACCMp denotes the WACCM simulation including proton ionization, only (excluded from the multi-model mean).

in the observations. Ozone increases occur in the SOCOL simulation below $1 \mathrm{hPa}$ which can be related to intrusions of mid-latitude air into the polar region, over-compensating the SPE-induced ozone losses.

Figure 29 shows profiles of stratospheric mid-term ozone changes at $70-90^{\circ} \mathrm{N}$, averaged over the period $16-$ 26 November. As expected, modeled ozone depletions have a larger spread than during the main proton forcing, ranging from 10 to $50 \%$ at the peak height. The model average, however, is in very good agreement with the observed depletion of $30 \%$ at $1-2 \mathrm{hPa}$. Only minor differences of $5 \%$ are found at its maximum.

Figure 30 shows the corresponding zonal mean distributions. Generally, the magnitude of the stratospheric ozone loss at $70-90^{\circ} \mathrm{N}$ is anti-correlated to its latitudinal extension which, in turn, is linked to the spatial distribution of the SPErelated $\mathrm{NO}_{\mathrm{x}}$ layer (see Fig. 17). Meridional redistribution is hence a key factor for explaining the differences in the modeled ozone depletions shown in Fig. 29. In particular, SOCOL simulations indicate strong meridional distribution around $1 \mathrm{hPa}$, resulting in higher polar ozone abundances than in the other models, despite the relatively high $\mathrm{NO}_{\mathrm{y}}$ availability shown in Fig. 17. There, $\mathrm{NO}_{\mathrm{x}}$-driven ozone loss is partly compensated by in-mixing of $\mathrm{O}_{3}$-rich air-masses from lower latitudes.

Observed mesospheric ozone changes in late November are characterized by a pronounced increase around the polar night terminator which is related to the buildup of the third ozone maximum (Marsh et al., 2001). This rapid buildup is responsible for the short lifetime of $\mathrm{HO}_{\mathrm{x}}$-related ozone depletion at these altitudes. Only in the polar night region, reduced ozone abundances are found until the end of November. This behavior is well reproduced by EMAC, KASIMA, WACCM and, to a lesser extent, HAMMONIA. B2dM behaves in an opposite way. A detailed investigation of the en- countered differences in the seasonal ozone buildup among the models and the observations is beyond the scope of this paper, though an interesting topic for future studies.

In summary, SPE-related short- and midterm ozone changes are well reproduced by the atmospheric models on average, though individual model results can vary significantly due to differences in dynamical and meteorological background conditions. The good agreement between models and observations in the mesosphere can be interpreted as a verification of the parameterization of $\mathrm{HO}_{\mathrm{x}}$ production by atmospheric ionization included in the models.

\subsection{Enhancements of $\mathrm{H}_{2} \mathrm{O}_{2}$}

MIPAS observed $\mathrm{H}_{2} \mathrm{O}_{2}$ increases of short duration immediately after the Halloween SPE in polar night stratosphere. $\mathrm{H}_{2} \mathrm{O}_{2}$ is formed by the reaction

$\mathrm{HO}_{2}+\mathrm{HO}_{2} \rightarrow \mathrm{H}_{2} \mathrm{O}_{2}+\mathrm{O}_{2}$

and is hence - together with $\mathrm{HNO}_{4}$ - an indicator for SPEgenerated $\mathrm{HO}_{\mathrm{x}}$ in the stratosphere. During daytime, it is photolyzed within several hours to a day, or destroyed by the reaction

$\mathrm{H}_{2} \mathrm{O}_{2}+\mathrm{OH} \rightarrow \mathrm{H}_{2} \mathrm{O}+\mathrm{HO}_{2}$.

Chemical nighttime losses are negligible at quiescent conditions. The availability of $\mathrm{OH}$ during periods of proton forcing allows for $\mathrm{H}_{2} \mathrm{O}_{2}$ destruction also at night. These losses, however, are most important above the stratopause. In the dark stratosphere, Reaction (R11) is expected to deplete $\mathrm{H}_{2} \mathrm{O}_{2}$ by less than $10 \%$. Therefore, observed $\mathrm{H}_{2} \mathrm{O}_{2}$ increases are primarily driven by the production mechanism (R10).

Model output of $\mathrm{H}_{2} \mathrm{O}_{2}$ is available from $\mathrm{B} 2 \mathrm{dM}$, B3dCTM, FinROSE, HAMMONIA, KASIMA, and WACCM. Figure 31 shows observed and modeled zonal mean $\mathrm{H}_{2} \mathrm{O}_{2}$ changes during the period of the main SPEs (28 October4 November). The observed increases of up to $0.1 \mathrm{ppbv}$ are considerably overestimated by the simulations by a factor of 4-7. This huge difference between observed and modeled $\mathrm{H}_{2} \mathrm{O}_{2}$ increases can hardly be explained by a possible overestimation of the ionization rates by a factor of $1.2-2$, as suggested from the comparison of $\mathrm{NO}_{\mathrm{y}}$ increases. Although $\mathrm{H}_{2} \mathrm{O}_{2}$ production depends quadratically on $\mathrm{HO}_{2}$, total $\mathrm{HO}_{\mathrm{x}}$ scales with the square root of the ionization rate due to Reaction (R9), being the principal chemical loss mechanism at nighttime. Thus, 4-7 times lower ionization rates would be required in order to reduce modeled $\mathrm{H}_{2} \mathrm{O}_{2}$ increases to the observed values. As already mentioned in the discussion of $\mathrm{HNO}_{4}$ enhancements, the availability of $\mathrm{HO}_{2}$ during nighttime SPE conditions is largely controlled by the $\mathrm{HO}_{\mathrm{x}}$ partitioning. At the peak height of the $\mathrm{H}_{2} \mathrm{O}_{2}$ increases (0.5$1 \mathrm{hPa}$ ), this dependence is even more pronounced than at the pressure levels of the $\mathrm{HNO}_{4}$ enhancements $(2-3 \mathrm{hPa})$ due to the increasing $\mathrm{OH}$ contribution to $\mathrm{HO}_{\mathrm{x}}$ with altitude. Thus, the disagreement of observed and simulated $\mathrm{H}_{2} \mathrm{O}_{2}$ hints at 

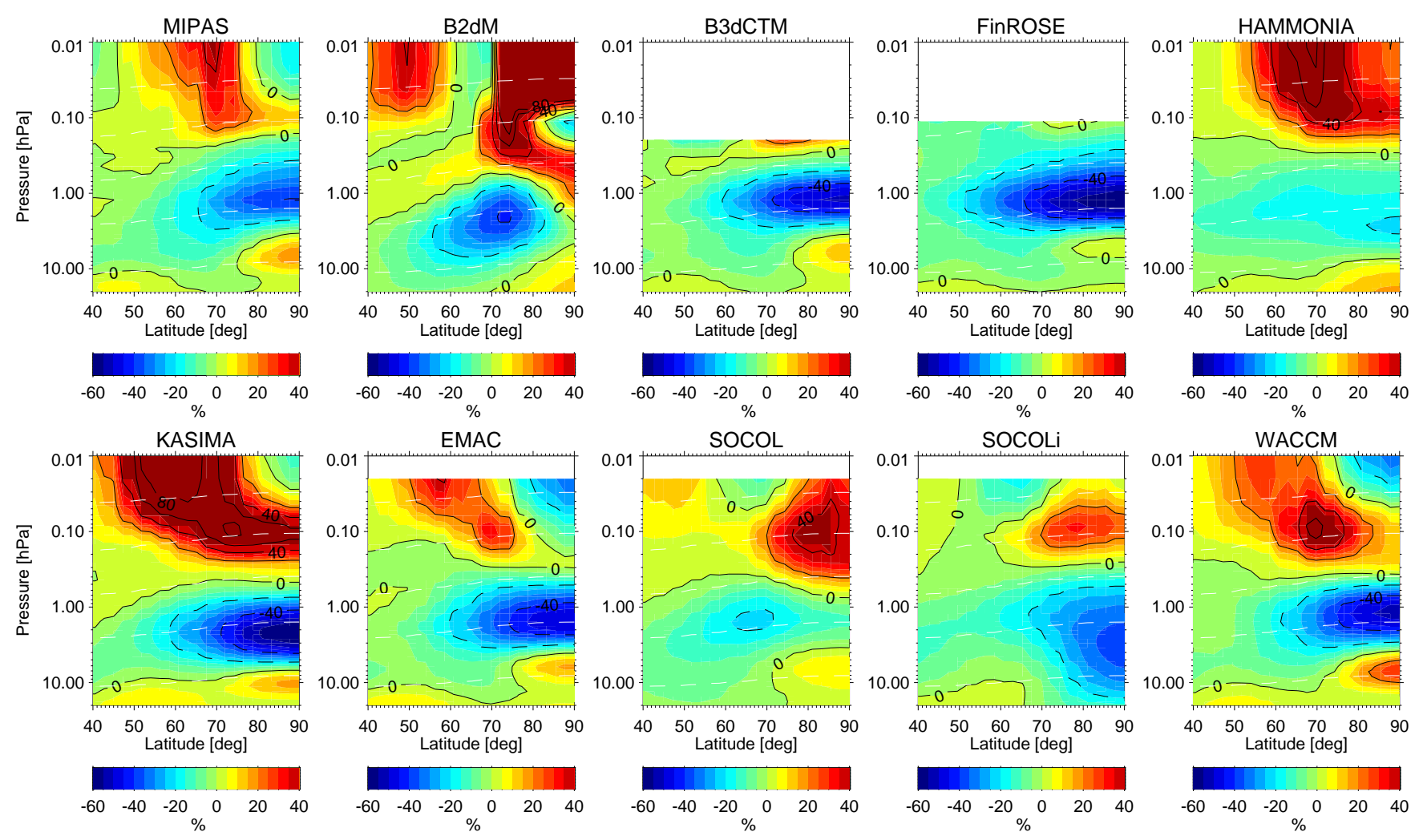

Fig. 30. Zonal mean relative $\mathrm{O}_{3}$ changes with respect to 26 October averaged over the period 16-26 November in MIPAS observations and model simulations. Solid contour lines reflect $20 \%$ steps.

an underestimation of the $\mathrm{OH} / \mathrm{HO}_{2}$ ratio in the upper polar stratosphere during the proton forcing. Alternatively, $\mathrm{H}_{2} \mathrm{O}_{2}$ formation by Reaction (R10) might be significantly overestimated in the models.

Meridional transport to illuminated latitudes, where $\mathrm{H}_{2} \mathrm{O}_{2}$ is photochemically destroyed, could also affect the magnitude of the SPE-related enhancements. $\mathrm{H}_{2} \mathrm{O}_{2}$ distributions simulated by $\mathrm{B} 2 \mathrm{dM}$, which has a very strong mixing barrier, might hence experience less photochemical losses than in other models. In fact, B2dM enhancements are more confined to the polar night region. Other models, however, show a similar meridional distribution as observed by MIPAS. It is thus unlikely, that differences in the efficiency of photochemical losses related to transport can explain the pronounced differences between observed and modeled $\mathrm{H}_{2} \mathrm{O}_{2}$ enhancements.

\subsection{Enhancements and repartitioning of chlorine species}

Enhancements of the chlorine species $\mathrm{ClO}, \mathrm{HOCl}$, and $\mathrm{ClONO}_{2}$ have been detected by MIPAS in the aftermath of the Halloween SPE in the NH polar stratosphere (von Clarmann et al., 2005; López-Puertas et al., 2005b). Short-term $\mathrm{ClO}$ and $\mathrm{HOCl}$ increases of the order of $0.2 \mathrm{ppbv}$ occurred immediately after the onset of the proton forcing on 29 Oc- tober. $\mathrm{ClONO}_{2}$ increases up to $0.4 \mathrm{ppbv}$ appeared approximately 2 days later, remaining in the stratosphere for several weeeks. SPE-related $\mathrm{HOCl}$ increases have also been observed by MLS on Aura during the January 2005 proton event (Damiani et al., 2008). These enhancements were accompanied by a $\mathrm{HCl}$ decrease of similar magnitude, thus clearly demonstrating SPE-induced chlorine activation. The conversion of $\mathrm{HCl}$ to active species occurred in presence of enhanced $\mathrm{OH}$ via the reaction

$\mathrm{HCl}+\mathrm{OH} \rightarrow \mathrm{Cl}+\mathrm{H}_{2} \mathrm{O}$.

$\mathrm{HCl}$ can also be incorporated into negative ions, from which chlorine is released mainly in the form of atomic chlorine or chlorine monoxide. There are also reverse reactions releasing $\mathrm{HCl}$, however, it has been shown in a recent publication (Winkler et al., 2009) that during large solar proton events, chlorine activation dominates, and negative ion reactions can act as a significant sink of $\mathrm{HCl}$, and a source of active chlorine. Atomic chlorine is rapidly converted to $\mathrm{ClO}$ by

$\mathrm{Cl}+\mathrm{O}_{3} \rightarrow \mathrm{ClO}+\mathrm{O}_{2}$.

In the polar night stratosphere, where SPE-generated $\mathrm{HO}_{\mathrm{x}}$ is dominated by $\mathrm{HO}_{2}, \mathrm{ClO}$ is further converted to $\mathrm{HOCl}$ :

$\mathrm{ClO}+\mathrm{HO}_{2} \rightarrow \mathrm{HOCl}+\mathrm{O}_{2}$. 

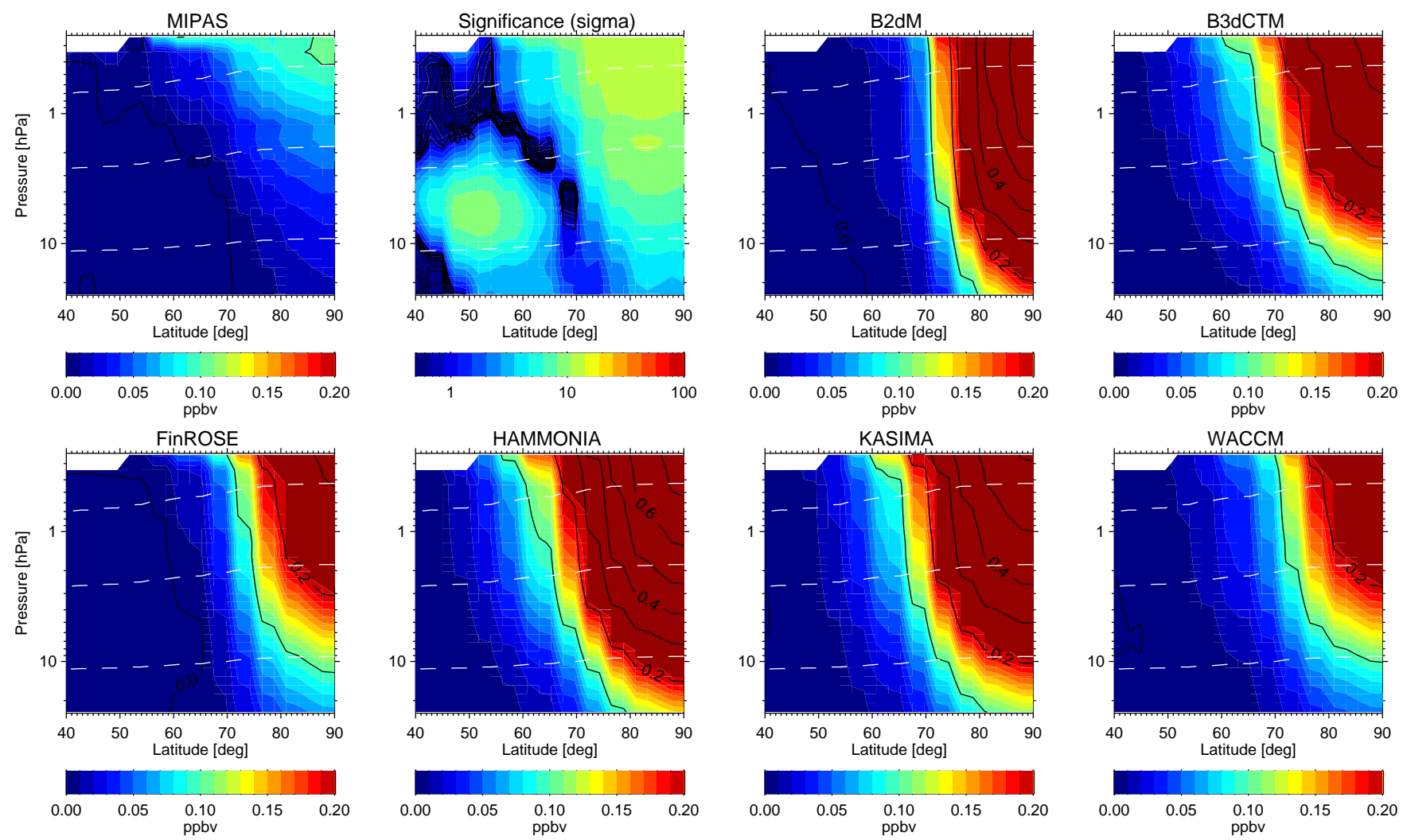

Fig. 31. Zonal mean $\mathrm{H}_{2} \mathrm{O}_{2}$ changes with respect to 26 October averaged over the period 28 October-4 November in MIPAS observations and model simulations. Solid contour lines reflect 0.1 ppbv steps. The significance of observed $\mathrm{H}_{2} \mathrm{O}_{2}$ changes (in units of $\sigma$ ) is shown in the upper second panel (from the left).

The chemical lifetime of nighttime $\mathrm{HOCl}$ is very long below the stratopause. Above and at sunlit conditions, $\mathrm{HOCl}$ is removed by the reaction

$\mathrm{HOCl}+\mathrm{OH} \rightarrow \mathrm{ClO}+\mathrm{H}_{2} \mathrm{O}$

and rapid photo-dissociation. Due to the high $\mathrm{HO}_{2} / \mathrm{OH}$ ratio in the nighttime stratosphere under SPE conditions, active chlorine is expected to be mainly in the form of $\mathrm{HOCl}$. Hence, ambient $\mathrm{ClO}$ should be reduced in contrast to the results obtained by von Clarmann et al. (2005) from MIPAS observations during the Halloween SPE. On the other hand, $\mathrm{OH}$ is the dominant $\mathrm{HO}_{\mathrm{x}}$ constituent during daytime and $\mathrm{HOCl}$ is quickly photolyzed even at high solar zenith angles. $\mathrm{ClO}$ enhancements might hence occur in the illuminated stratosphere, if SPE-related $\mathrm{HO}_{\mathrm{x}}$ increases were well above the background concentration. In fact, the $\mathrm{ClO}$ enhancements observed by MIPAS on 29-30 October 2003 (von Clarmann et al., 2005) took place outside the polar night region.

The mid-term evolution of polar ambient $\mathrm{ClO}$ during the period of the Halloween event is characterized by a continuous decrease related to seasonal variations (see Fig. 3) which makes the analysis of SPE-induced changes on a longer timescale difficult. Therefore, we restrict our anal- ysis to the period of the main proton event on 29-31 October. Figure 32 shows observed and modeled changes of the $\mathrm{ClO}$ zonal mean distribution, averaged over these days, with respect to 26-27 October. $\mathrm{ClO}$ increases of $\sim 0.1 \mathrm{ppbv}$ are found in the MIPAS observations at latitudes around $60^{\circ} \mathrm{N}$ in qualitative agreement with the previous analysis of von Clarmann et al. (2005). These enhancements are reproduced by none of the models. Evidently, simulated daytime $\mathrm{HO}_{\mathrm{x}}$ increases are too small compared to the ambient $\mathrm{HO}_{\mathrm{x}}$ abundances to alter noticeably the $\mathrm{ClO}$ availability. Although the observed enhancements are significant at the $2 \sigma$-level with respect to the average measurement precision (see Fig. 32, second panel), this important difference between the observations and the simulations should be carefully interpreted due to a possible systematic bias related to gain calibration errors in the measurements (see Sect. 2), particularly because the observed $\mathrm{ClO}$ change has been calculated from temporal averages belonging to different gain calibration periods. In the polar night region, both, observations and models show a $\mathrm{ClO}$ decrease. The observed $\mathrm{ClO}$ reduction of up to $0.2 \mathrm{ppbv}$ is considerably underestimated by the simulations, except for $\mathrm{CAO}$. The latter model overestimates the $\mathrm{ClO}$ reduction by approximately a factor of 10 . The unreasonably large $\mathrm{ClO}$ depletion in $\mathrm{CAO}$ is related to a high $\mathrm{ClO}$ availability before 

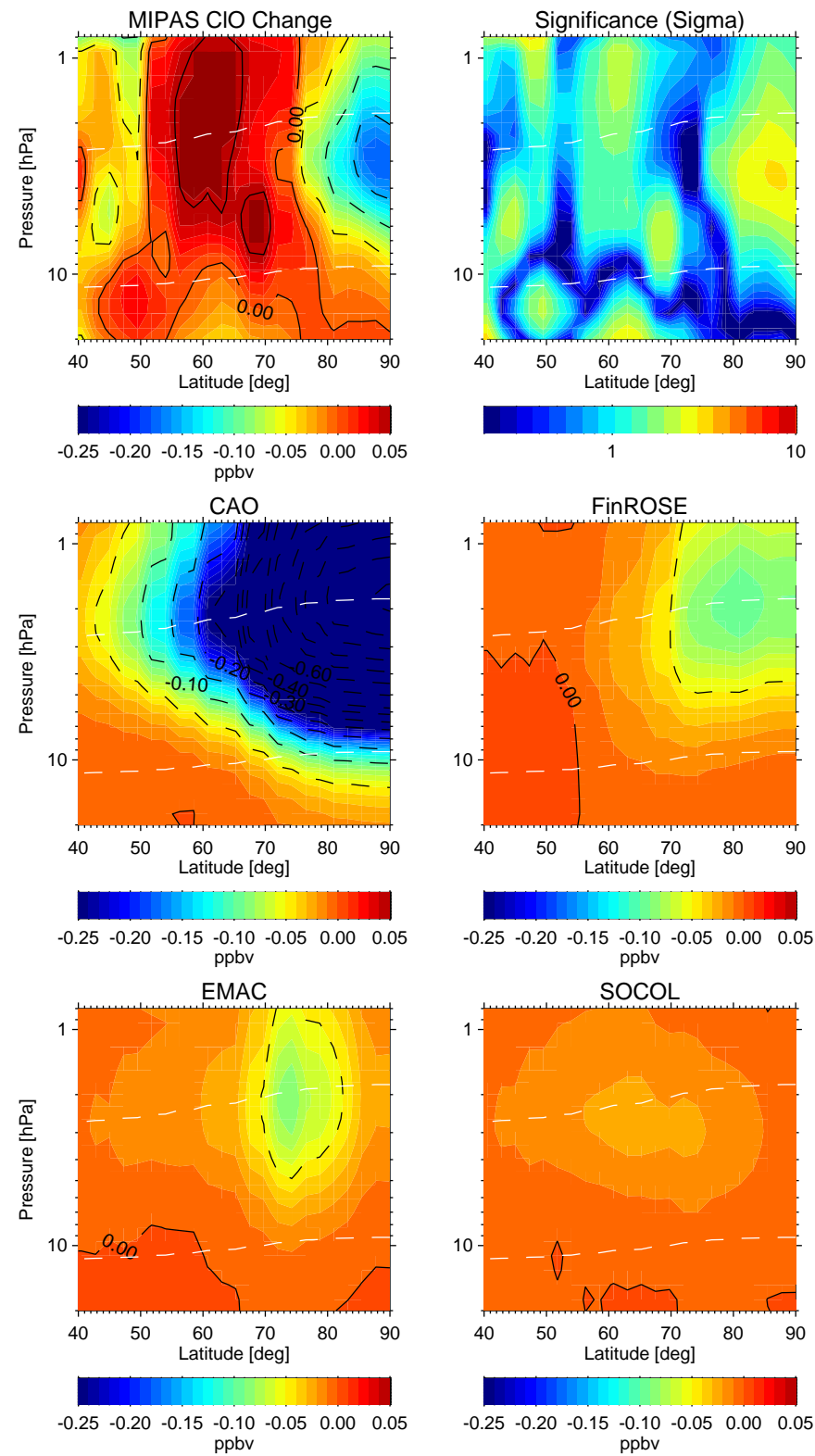

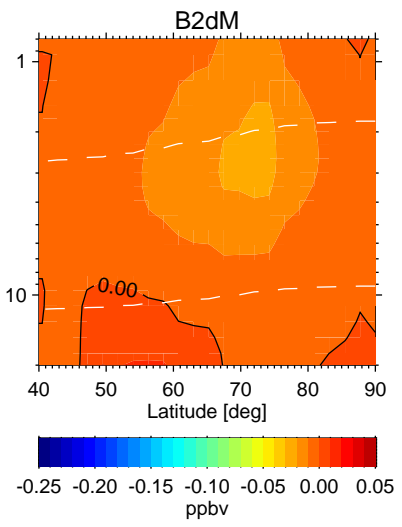

HAMMONIA

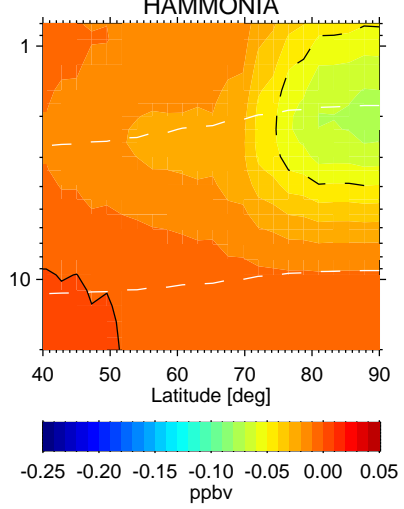

SOCOL

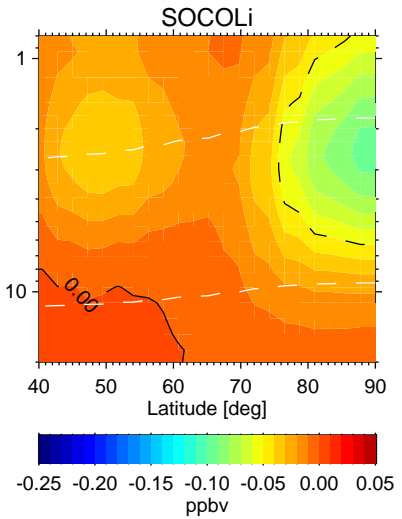

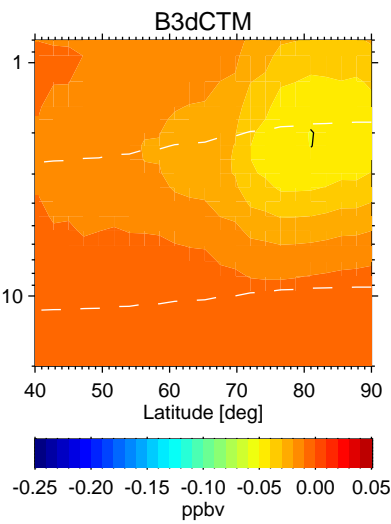
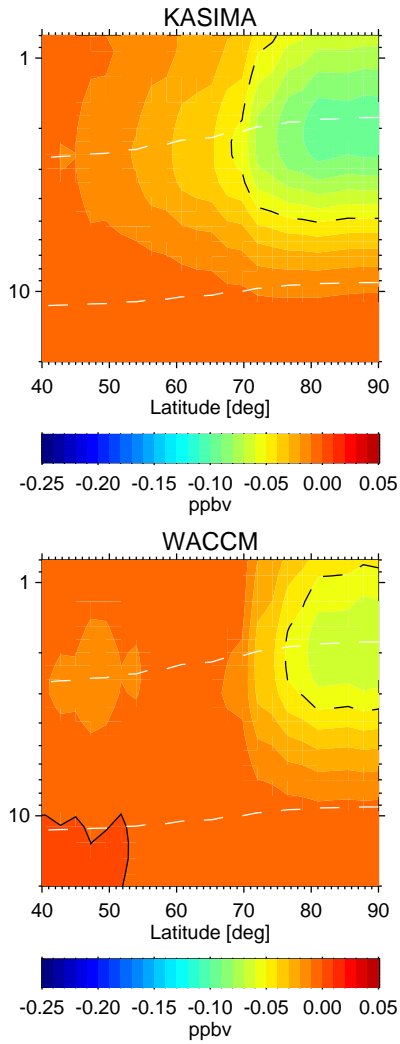

Fig. 32. Zonal mean $\mathrm{ClO}$ changes during the main proton forcing (29-31 October) with respect to 26-27 October in MIPAS observations and model simulations. Solid contour lines reflect 0.05 ppbv steps. The significance of observed $\mathrm{ClO}$ changes (in units of $\sigma$ ) is shown in the upper second panel (from the left).

the SPE and goes along with a $\mathrm{ClONO}_{2}$ buildup of a similar magnitude (see below). The reason for the higher background $\mathrm{ClO}$ concentrations in this particular model is most probably related to the use of a family approach for $\mathrm{ClO}_{\mathrm{y}}$. In contrast to the observations, the $\mathrm{ClO}$ decreases obtained by B2dM, EMAC, and SOCOL are not pole-centered but shifted slightly to lower latitudes. The remaining models (except $\mathrm{CAO}$ ) produce a very similar $\mathrm{ClO}$ signal.

The differences of observed and modeled $\mathrm{ClO}$ changes at latitudes poleward of $70^{\circ} \mathrm{N}$ are related to the background $\mathrm{ClO}$ abundances. Figure 33 shows the zonal mean distributions of $\mathrm{ClO}$ vmrs on 26-27 October prior to the onset of the proton forcing. $\mathrm{ClO}$ vmrs of more than $0.4 \mathrm{ppbv}$ have been observed around $2 \mathrm{hPa}$ in the entire $\mathrm{NH}$ with a slight decrease poleward of $70^{\circ} \mathrm{N}$. Maximum abundances were found at 60 $70^{\circ} \mathrm{N}$, exactly at the same latitudes where the $\mathrm{ClO}$ increases during the following days occurred. Although we cannot exclude that the observed $\mathrm{ClO}$ in this latitude range is affected by gain calibration errors, this coincidence is somehow remarkable. In principle, the enhanced $\mathrm{ClO}$ abundances around $60-70^{\circ} \mathrm{N}$ can be related to differences in the latitudinal distributions of daytime $\mathrm{OH}$ and $\mathrm{O}$, the first being responsible for $\mathrm{ClO}$ production and the latter for $\mathrm{ClO}$ removal. 

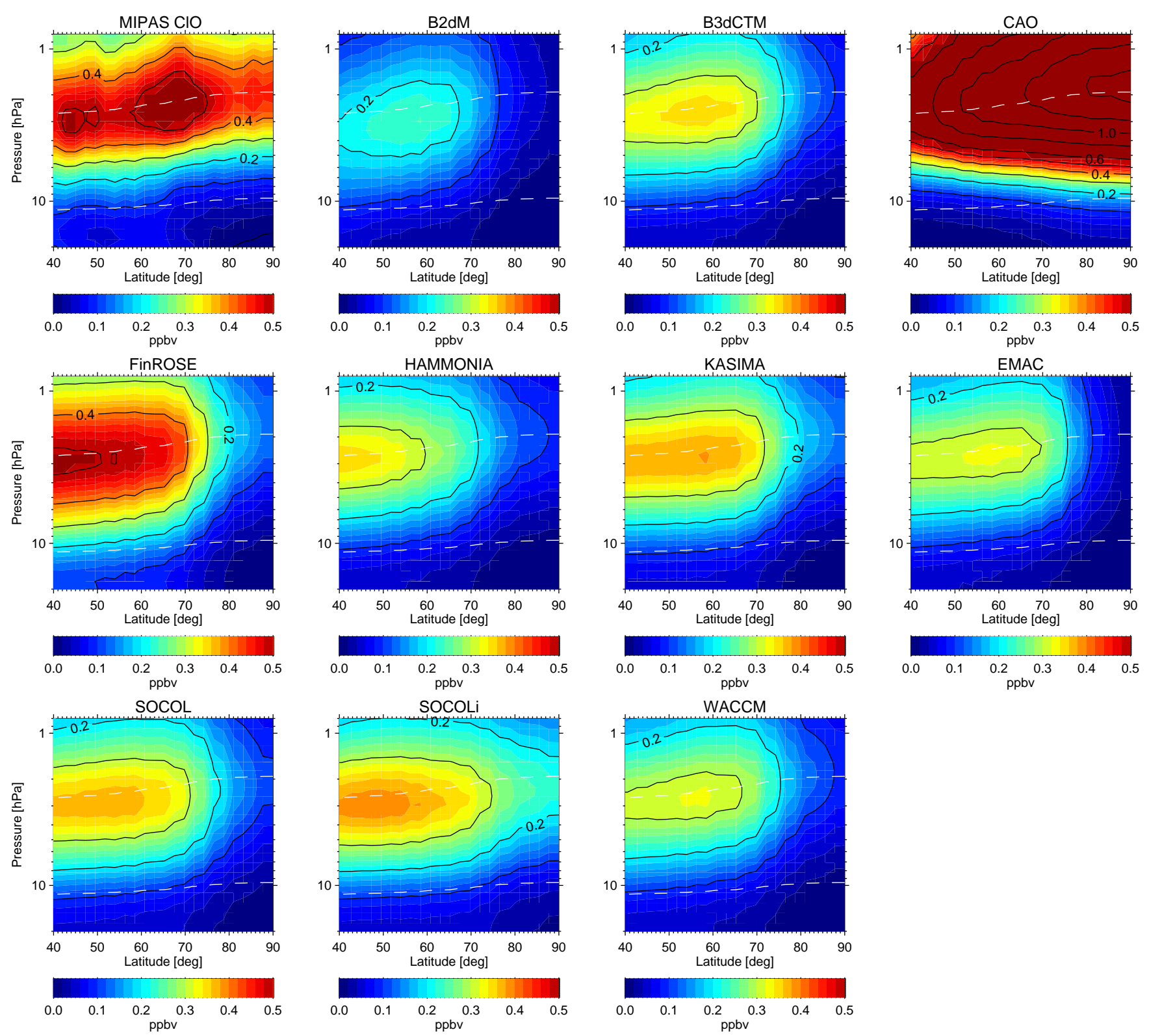

Fig. 33. Zonal mean $\mathrm{ClO}$ vmrs before the SPE 26-27 October in MIPAS observations and model simulations. Solid contour lines reflect 0.1 ppbv steps.

Modeled $\mathrm{ClO}$ abundances do not show this enhancement around $60-70^{\circ} \mathrm{N}$. Simulated $\mathrm{ClO}$ vmrs are also generally lower by $50 \%$ than those observed by MIPAS (except for FinROSE and CAO) and exhibit a pronounced decrease towards the polar night region. In some models (e.g. B2dM and EMAC) $\mathrm{ClO}$ has disappeared nearly completely at the pole. It is thus not surprising, that modeled $\mathrm{ClO}$ depletions at $70-90^{\circ} \mathrm{N}$ are less pronounced than in the observations in absolute terms. The much stronger modeled decrease of $\mathrm{ClO}$ towards the polar night region during pre-SPE conditions seems to be related to an overestimation of $\mathrm{ClO}$ losses. Since the sequestering into the $\mathrm{Cl}_{2} \mathrm{O}_{2}$ dimer is inefficient around $2 \mathrm{hPa}$ and simulated $\mathrm{HOCl}$ or $\mathrm{ClONO}_{2}$ distributions before the SPE do not indicate a conversion of $\mathrm{ClO}$ to these species, it is most likely that $\mathrm{ClO}$ is more efficiently converted to $\mathrm{HCl}$ than indicated by the observations. The faster conversion in the models might be related to the reaction path $\mathrm{ClO}+\mathrm{OH} \rightarrow \mathrm{HCl}+\mathrm{O}_{2}$ which has an uncertainty of its rate constant of several $100 \%$ (Sander et al., 2006). However, also dynamical reasons (i.e. differences in the magnitude of meridional mixing) cannot be excluded.

The temporal evolution of observed and modeled $\mathrm{HOCl}$ changes at $70-90^{\circ} \mathrm{N}$ until mid November is shown in Fig. 34. $\mathrm{HOCl}$ started to increase rapidly on 29 October, reaching 

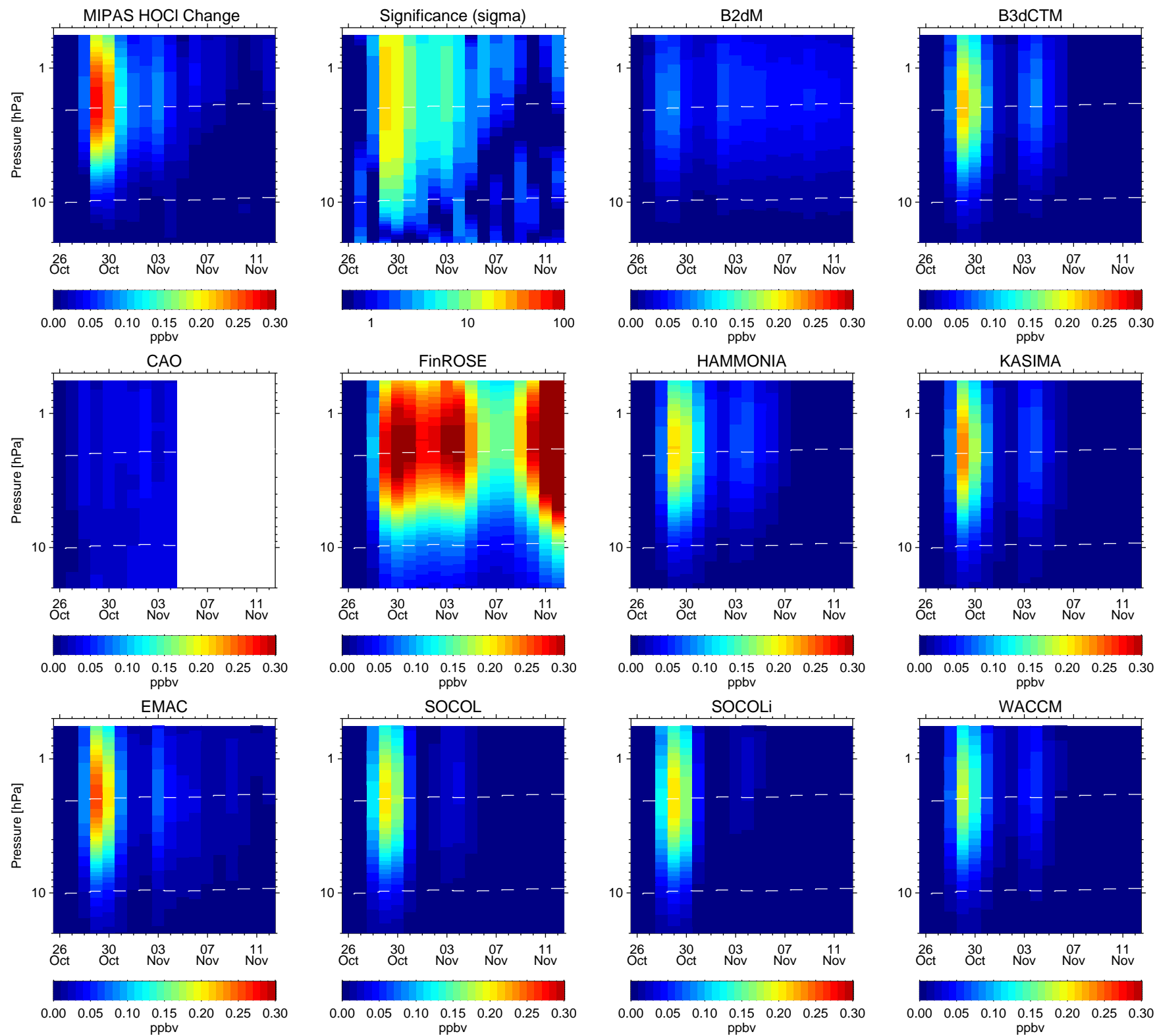

Fig. 34. Temporal evolution of area-weighterd averages of relative $\mathrm{HOCl}$ changes with respect to 26 October 2003 in MIPAS observations and model simulations at $70-90^{\circ} \mathrm{N}$, as well as differences between modeled and observed averages. The significance of observed $\mathrm{HOCl}$ changes (in units of $\sigma$ ) is shown in the upper second panel (from the left).

values around $0.25 \mathrm{ppbv}$, and diminished after 1 November within a few days. A smaller second increase occurred on 3 November related to the second, weaker SPE. The simulations show generally smaller enhancements (approximately $30 \%$ less on average), except FinROSE. This model overestimates significantly the observed enhancements by nearly a factor of 2. There, $\mathrm{HOCl}$ abundances remain enhanced after the SPE for nearly one week and show a second, even more pronounced enhancement around 11 November. A possible reason for the behavior of FinROSE could be the inclusion of the additional catalytic cycle

$$
\begin{aligned}
& \mathrm{Cl}+\mathrm{NO}_{2}+\mathrm{M} \rightarrow \mathrm{ClNO}_{2}+\mathrm{M} \\
& \mathrm{ClNO}_{2}+\mathrm{OH} \rightarrow \mathrm{HOCl}+\mathrm{NO}_{2},
\end{aligned}
$$

leading to additional $\mathrm{HOCl}$ production in the presence of $\mathrm{NO}_{2}$.

Smallest $\mathrm{HOCl}$ enhancements are obtained by B2dM and CAO. In the former model, the smaller response seems to be related to the small latitudinal extent of the $\mathrm{HOCl}$ enhancements (as comes clear from Fig. 35), resulting in relatively low averages for the $70-90^{\circ} \mathrm{N}$ region. The small latitudinal extend in B2dM is related to a very strong but small 

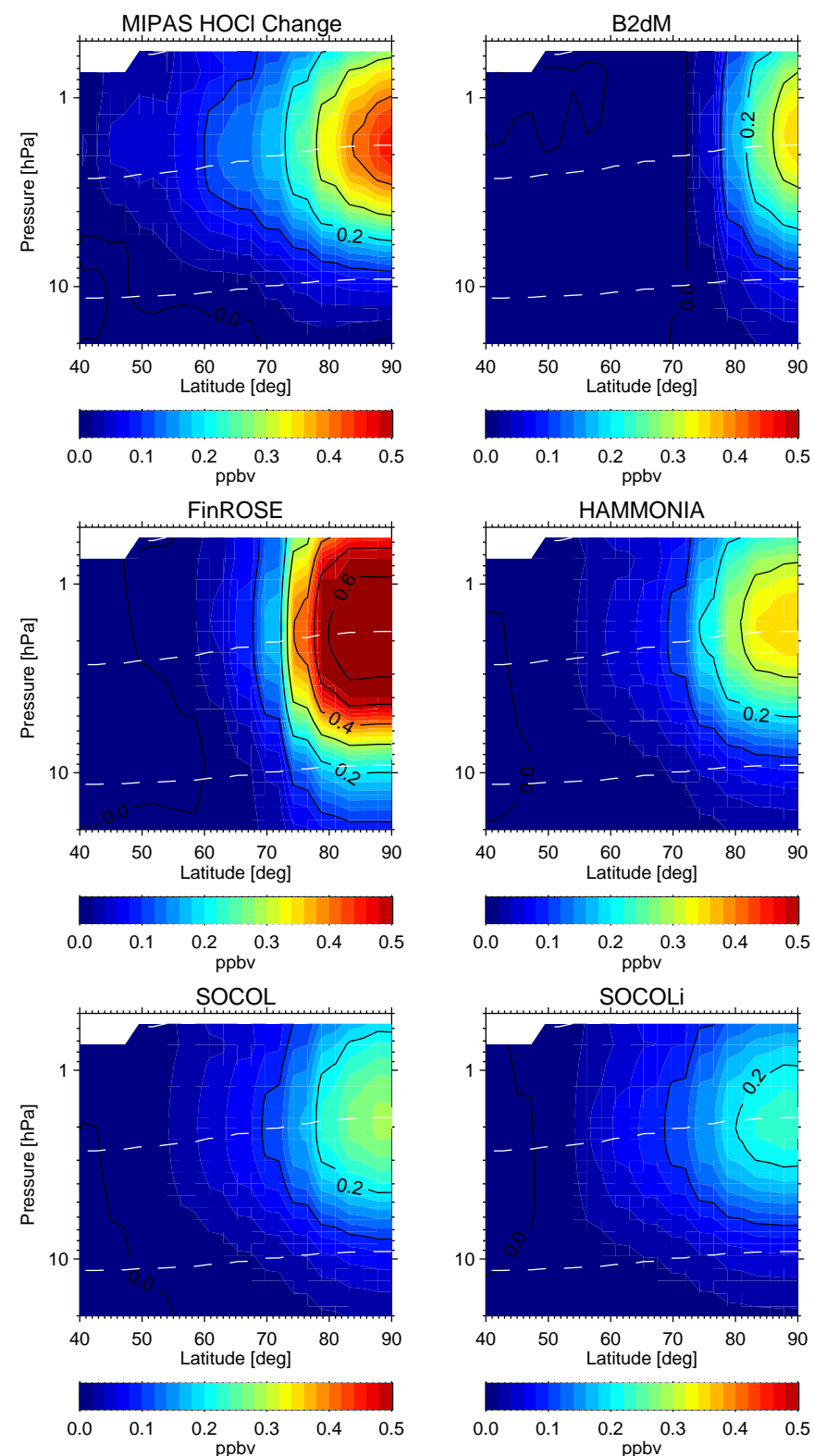
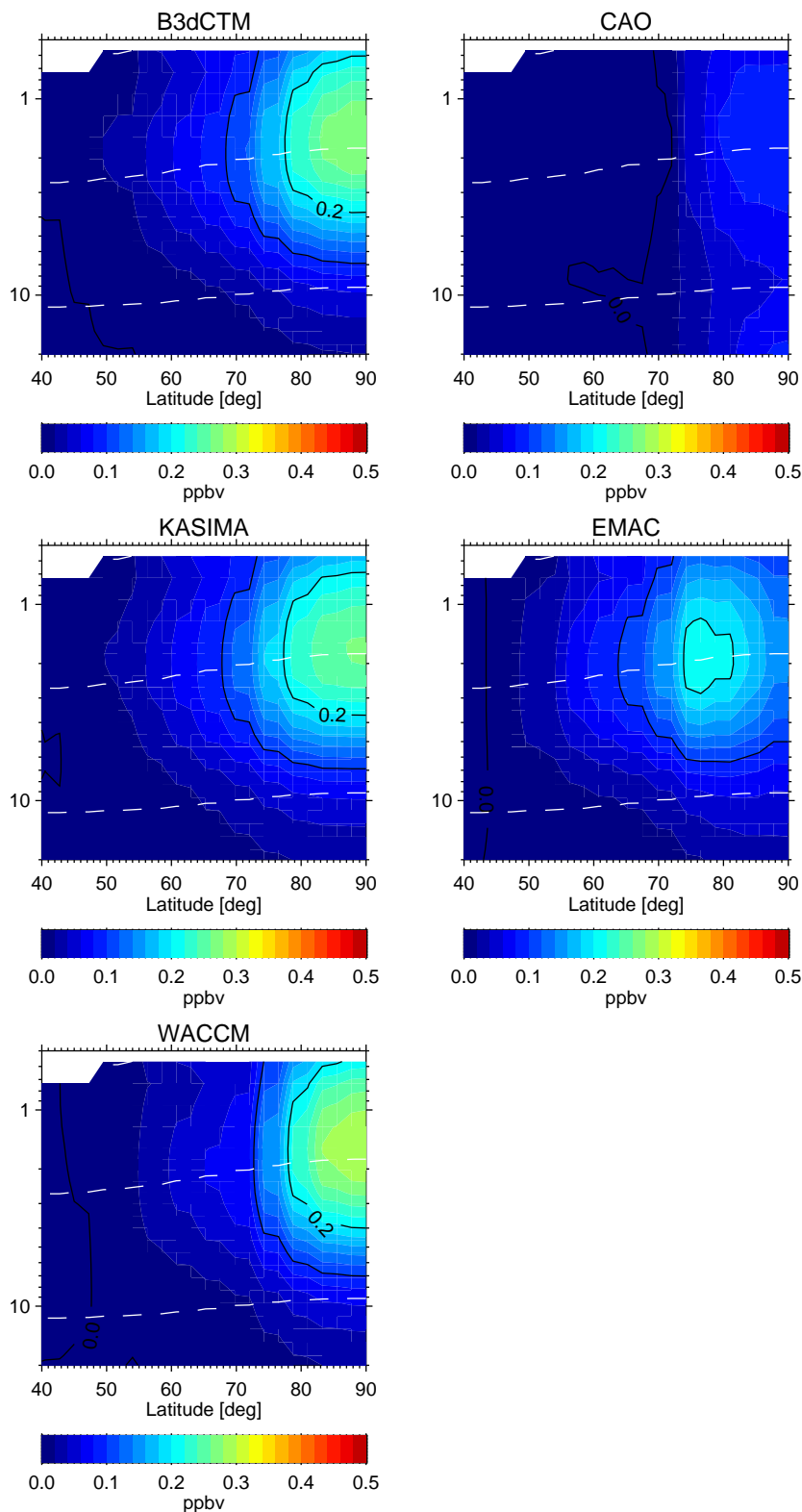

Fig. 35. Zonal mean $\mathrm{HOCl}$ changes during the main proton forcing (29-31 October) with respect to 26-27 October in MIPAS observations and model simulations. Solid contour lines reflect 0.1 ppbv steps.

vortex, probably as a result of the relatively poor horizontal resolution. Regarding the latter model, the small $\mathrm{HOCl}$ response is related to the unrealistic fast conversion of $\mathrm{ClO}$ to $\mathrm{ClONO}_{2}$, compensating the increased $\mathrm{HOCl}$ buildup via Reaction (R14) by reduced $\mathrm{ClO}$ abundances.

Figure 35 shows observed and modeled changes of the $\mathrm{HOCl}$ zonal mean distribution averaged 29-31 October with respect to 26-27 October. The pronounced anti-correlation of $\mathrm{HOCl}$ increases and $\mathrm{ClO}$ decreases (compare Figs. 35 and 32) indicates that ambient $\mathrm{ClO}$ is quickly converted to $\mathrm{HOCl}$ via Reaction (R14) during nighttime in the presence of proton forcing. However, $\mathrm{HOCl}$ increases are higher than the corresponding $\mathrm{ClO}$ losses, resulting in a net increase of active chlorine by approximately $0.2 \mathrm{ppbv}$ in the observations and most of the models. This can be explained by SPE-related chlorine activation via Reaction (R12). FinROSE, however, overestimates the chlorine activation by a factor of 3 .

The sharp decline of the $\mathrm{HOCl}$ enhancements after the proton forcing observed by MIPAS, and also reproduced by most models, must occur in the sunlit atmosphere close to the polar night terminator, since losses via Reaction (R15) are negligible in the polar night stratosphere after the SPE. This is also the reason for the relatively long lifetime of the $\mathrm{HOCl}$ enhancements in $\mathrm{B} 2 \mathrm{dM}$ where meridional redistribution is 

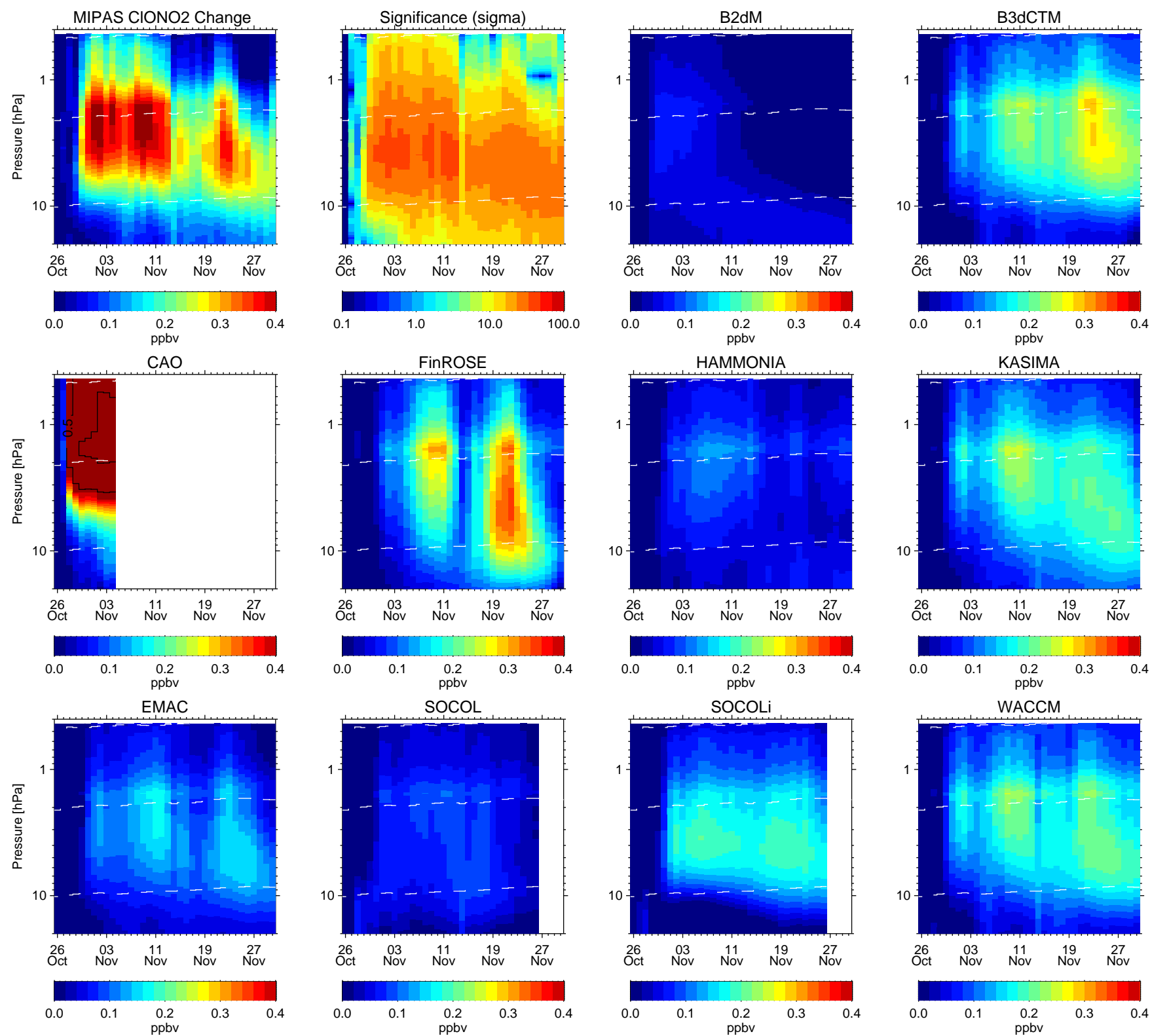

Fig. 36. Temporal evolution of area-weighted averages of relative $\mathrm{ClONO}_{2}$ changes with respect to 26 October 2003 in MIPAS observations and model simulations at $70-90^{\circ} \mathrm{N}$, as well as differences between modeled and observed averages. Contour lines reflect $0.5 \mathrm{ppbv}$ steps. The significance of observed $\mathrm{ClONO}_{2}$ changes (in units of $\sigma$ ) is shown in the upper second panel (from the left).

weak. This is not the case in the FinROSE model. There, the long lifetime of the $\mathrm{HOCl}$ enhancements related to the SPE, as well as the second buildup around 11 November, seem to be caused by an underestimation of chemical losses of $\mathrm{HOCl}$.

$\mathrm{ClONO}_{2}$ increases, occurring approximately two days after the SPE, are attributed to the termolecular reaction

$\mathrm{ClO}+\mathrm{NO}_{2}+\mathrm{M} \rightarrow \mathrm{ClONO}_{2}+\mathrm{M}$.

$\mathrm{ClONO}_{2}$ is removed mainly by photolysis in the sunlit atmosphere and, to a lesser extent, by reaction with atomic oxygen. Due to its pressure dependence, $\mathrm{ClONO}_{2}$ for- mation by Reaction (R18) is more effective at lower altitudes. Enhanced $\mathrm{NO}_{2}$ availability related to the SPE, however, is increasing with altitude, leading to a peak height of the observed $\mathrm{ClONO}_{2}$ enhancements around $3 \mathrm{hPa}$ $(\sim 36 \mathrm{~km})$. This is slightly higher than reported by LópezPuertas et al. (2005a) who based their analysis on an older MIPAS $\mathrm{ClONO}_{2}$ data version than used here.

The temporal evolution of observed and modeled $\mathrm{ClONO}_{2}$ changes at $70-90^{\circ} \mathrm{N}$ until the end of November is shown in Fig. 36. The observed enhancements of $0.4 \mathrm{ppbv}$ after the SPE remained in the stratosphere for about two weeks. 

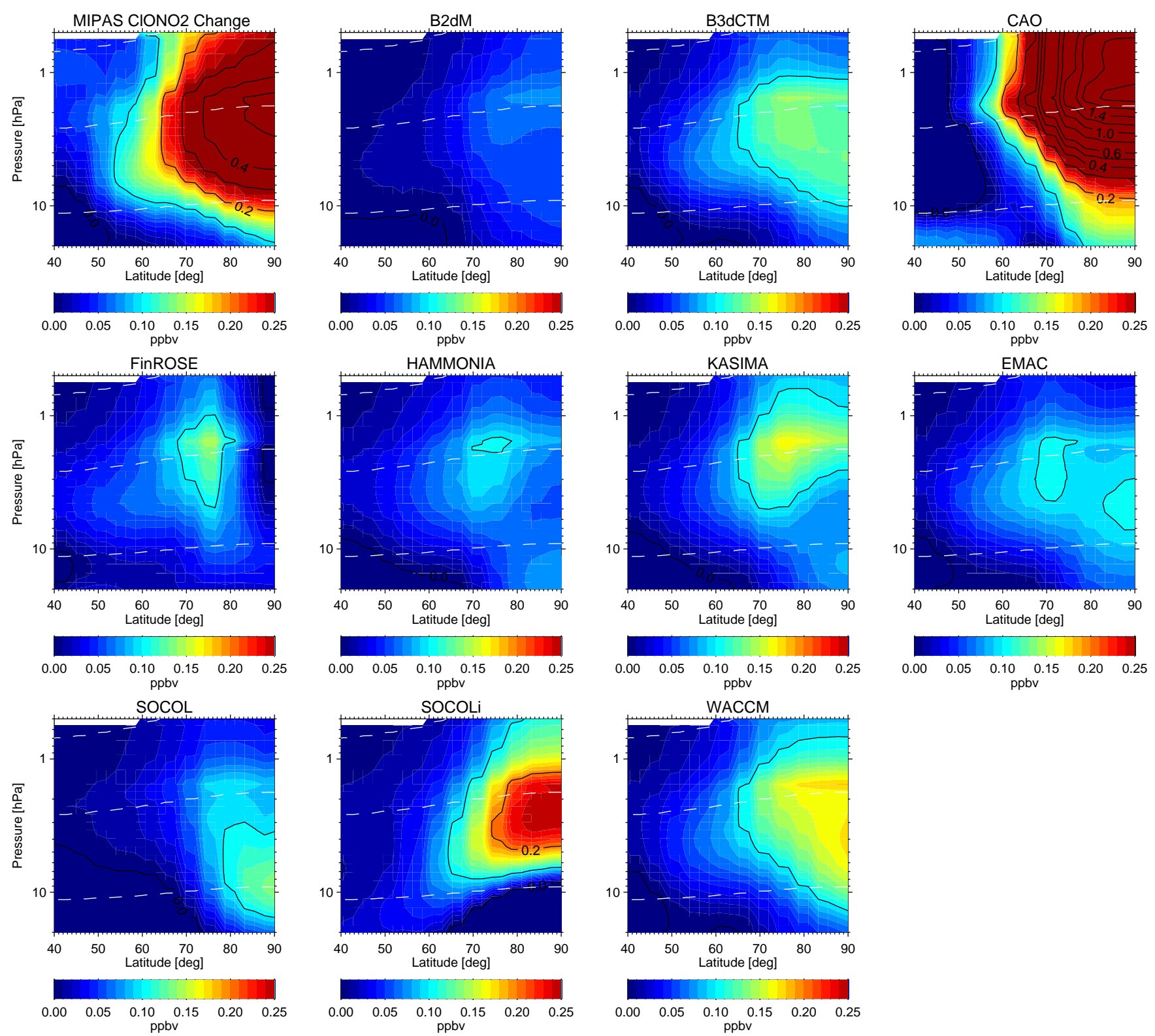

Fig. 37. Zonal mean $\mathrm{ClONO}_{2}$ changes after the main proton forcing (1-5 November) with respect to 26-27 October in MIPAS observations and model simulations. Solid contour lines reflect $0.1 \mathrm{ppbv}$ steps up to $0.6 \mathrm{ppbv}$ and $0.2 \mathrm{ppbv}$ steps above.

After a sudden decrease on 13 November, $\mathrm{ClONO}_{2}$ abundances increased again on 19 November, reaching a second, weaker maximum around 22 November. The modeled $\mathrm{ClONO}_{2}$ increases are generally smaller (except CAO, see discussion above) and show a different temporal evolution. The $\mathrm{ClONO}_{2}$ underestimation in the simulations, particularly during the first enhancement starting on 1 November, is related to the reduced $\mathrm{ClO}$ availability compared to the observations. As an exception, $\mathrm{CAO}$ yields a quasi-instantaneous $\mathrm{ClONO}_{2}$ increase with the onset of the proton forcing which can be explained by the use of a family approach for $\mathrm{NO}_{\mathrm{y}}$ and $\mathrm{ClO}_{\mathrm{y}}$ in this model.
Figure 37 shows the corresponding zonal mean distribution of the observed and modeled $\mathrm{ClONO}_{2}$ enhancements averaged over 1-5 November. From the observations, it is clear that $\mathrm{ClONO}_{2}$ is principally formed in the polar night region where high $\mathrm{NO}_{2}$ abundances are available and no photochemical losses occur. Most of the model simulations, except CAO, SOCOLi and WACCM, show negligible enhancements there. Instead, $\mathrm{ClONO}_{2}$ formation occurs around $70^{\circ} \mathrm{N}$, were daytime losses are still small but $\mathrm{ClO}$ is available, however, with a considerably smaller magnitude than observed. SOCOLi and WACCM simulations, which have a similar latitudinal distribution of $\mathrm{ClONO}_{2}$ changes as observed, exhibit 
higher $\mathrm{ClO}$ abundances in the polar night region than other models.

The observed temporal evolution of the $\mathrm{ClONO}_{2}$ changes in the second half of November is better captured by models based on ECMWF- and MERRA-driven meteorology up to the stratosphere (i.e. B3dCTM, FinROSE, KASIMA, and WACCM), which hints at a strong impact of vortex dynamics on the $\mathrm{ClONO}_{2}$ abundances. Wave-driven vortex excursions to illuminated latitudes, alternated by reformation of a polecentered vortex, are mainly responsible for the $\mathrm{ClONO}_{2}$ variability and particularly for the decrease around 13 November. The descending $\mathrm{NO}_{2}$ layer, formed during the SPE, acts as a reservoir for continuous $\mathrm{ClONO}_{2}$ formation in the following weeks after the SPE. Due to the reduced ClO availability in the polar stratosphere towards the end of November, additional $\mathrm{ClONO}_{2}$ buildup is observed only around $60-70^{\circ} \mathrm{N}$, in agreement with most of the model results (not shown). B2dM, SOCOL, and HAMMONIA, however, show very small $\mathrm{ClONO}_{2}$ increases in the second half of November. In the first model, this is related to the confinement of the $\mathrm{NO}_{2}$ layer to high latitudes, where no $\mathrm{ClO}$ is available. In the latter model, strong meridional mixing led to a dilution of the SPE-generated $\mathrm{NO}_{2}$ layer, such that insufficient $\mathrm{NO}_{2}$ was available for additional $\mathrm{ClONO}_{2}$ buildup.

\section{Conclusions}

We have compared stratospheric and mesospheric composition changes observed by MIPAS in the NH during and after the Halloween proton event with simulations performed with state-of-the-art GCMs and CTMs. The large number of models participating in the intercomparison exercise allowed for an evaluation of the overall ability of atmospheric models to reproduce observed atmospheric perturbations generated by SPEs, particularly with respect to $\mathrm{NO}_{\mathrm{y}}$ and ozone changes. This model validation represents a mandatory first step towards an accurate implementation of particle precipitation effects in long-term climate simulations. It has also allowed to test and identify deficiencies in the chemical schemes, particularly with respect to nitrogen and chlorine chemistry, being relevant for stratospheric ozone.

Observed SPE-related short-time increases of the minor species $\mathrm{HNO}_{4}$ and $\mathrm{H}_{2} \mathrm{O}_{2}$ have been identified for the first time and are qualitatively reproduced by the simulations. The observed enhancements of 0.2 and $0.1 \mathrm{ppbv}$, respectively, are overestimated by the models on average. Both observations and simulations give further evidence for an SPE-induced $\mathrm{CO}$ depletion. A clear isolation of these chemical losses from dynamical variability, however, is difficult.

In general, atmospheric models are able to reproduce most of the observed composition changes. In particular, simulated SPE-induced ozone losses agree within $5 \%$ with the observations on average. This excellent agreement is found on a short-term scale $\left(\mathrm{HO}_{\mathrm{x}}\right.$-driven $)$ in the mesosphere, as well as on a mid-term scale $\left(\mathrm{NO}_{\mathrm{x}}\right.$-driven $)$ in the stratosphere. Simulated $\mathrm{NO}_{\mathrm{y}}$ enhancements around $1 \mathrm{hPa}$ are on average $30 \%$ higher than indicated by the observations, while an underestimation of modeled $\mathrm{NO}_{\mathrm{y}}$ of the same order was found in the mesosphere. The systematic behavior in the stratosphere suggests that these differences are related to the simulated ionization rate profile shape, though other error sources related to the models' atmospheric background state and/or transport schemes cannot be excluded. WACCM simulations without inclusion of electron-induced ionization allowed for distinguishing the electron and proton-related contributions to the $\mathrm{NO}_{\mathrm{y}}$ enhancements. An upper stratospheric excess $\mathrm{NO}_{\mathrm{y}}$ production by electron-induced ionization of 5-10 ppbv ( $20 \%$ of the total SPE-induced production) could be identified from these simulations, particularly after the minor second event around 4-5 November. The excess ozone loss related to electron-induced ionization has been estimated to be around $5 \%$.

The impact of chemical NO losses due to reaction with atomic nitrogen (Reaction R2) on the SPE-induced $\mathrm{NO}_{\mathrm{y}}$ increases has been studied in detail. An important dependence of the net $\mathrm{NO}_{\mathrm{y}}$ generation on temperature and background $\mathrm{NO}_{\mathrm{x}}$ due to this mechanism has been identified. In the stratosphere, SPE-related $\mathrm{NO}_{\mathrm{y}}$ increases are reduced (enhanced) by approximately $10 \%$ if temperatures were $10 \mathrm{~K}$ lower/higher. This behavior might be of relevance for future implications of SPE effects for climate when considering a stratospheric cooling trend related to climate change. The reduced $\mathrm{NO}_{\mathrm{y}}$ production efficiency related to Reaction (R2) also implies limitations for models using family approaches in their chemical schemes, since this mechanism of $\mathrm{NO}_{\mathrm{y}}$ destruction is not taken implicitly into account in these models.

The analysis of the observed and modeled $\mathrm{NO}_{\mathrm{y}}$ partitioning in the aftermath of the Halloween SPE has clearly demonstrated the need to implement additional ion chemistry into the chemical schemes. Short-term $\mathrm{HNO}_{3}$ increases can only be reproduced by model calculations including ion-ion recombination between $\mathrm{NO}_{3}{ }^{-}$and $\mathrm{H}^{+}$cluster ions (Verronen et al., 2008). The partitioning of $\mathrm{HNO}_{3}$ and $\mathrm{N}_{2} \mathrm{O}_{5}$ in the following weeks after the SPE is significantly underestimated by the models that do not include $\mathrm{HNO}_{3}$ formation via water cluster ions (Böhringer et al., 1983). However, further work is required to tune the parameterizations of these mechanisms such that quantitative agreement with the observations can be achieved.

The overestimation of observed $\mathrm{H}_{2} \mathrm{O}_{2}$ and $\mathrm{HNO}_{4}$ enhancements by the models hints at an underestimation of the $\mathrm{OH} / \mathrm{HO}_{2}$ ratio in the upper polar stratosphere during the proton forcing. Further work is required to analyze in detail possible reasons for this behavior. The analysis of SPE-induced changes of the chlorine species $\mathrm{ClO}, \mathrm{HOCl}$ and $\mathrm{ClONO}_{2}$ has shown that the encountered differences between models and observations, particularly the underestimation of observed $\mathrm{ClONO}_{2}$ enhancements, are related to a smaller availability of $\mathrm{ClO}$ in the polar region already before the SPE. 
In general, the intercomparison has demonstrated that differences in the meteorology and/or initial state of the atmosphere in the simulations cause an important variability of the model results, even on a short timescale of only a few days. The model responses to the proton perturbation thus show a significant spread. On the other hand, this sensitivity of the simulated atmospheric responses to the background conditions, indicated by the spread in the model results, also implies that the real atmosphere's response to proton events depends strongly on the actual conditions.

Future HEPPA model-data intercomparison activities will focus on the assessment of indirect effects of energetic particle precipitation related to polar winter descent of upper atmospheric $\mathrm{NO}_{\mathrm{x}}$ generated by electron precipitation. This is motivated, on one hand, by the higher potential of indirect effects to influence middle atmospheric composition on longer time scales compared to direct effects (i.e. SPEs) and, on the other hand, by its large variability related to dynamical modulations, making its representation in current atmospheric models challenging.

Acknowledgements. The IAA team was supported by the Spanish project AYA200803498/ESP and by the project 200950I081 of CSIC. The IMK, AIMOS, University of Bremen, and HAMMONIA groups were supported by the Priority Program CAWSES of the German science foundation (DFG). The input of CAO was supported by Russian Science Foundation for Basic Research (grant No. 09-05-009949) and by contract No. 1-6-08 under Russian Sub-Program "Research and Investigation of Antarctica". The SOCOLi team received funding from the European Community's Seventh Framework Programme (FP7/2007-2013) under grant agreement No. 218816. The development and applications of CCM SOCOL supported by the Swiss National Science Foundation under grant CRSI122-130642(FUPSOL). The WACCM team was supported by the NASA Living With a Star Targeted Research and Technology Program. The National Center for Atmospheric Research is sponsored by the National Science Foundation. We acknowledge the support of the German Climate Computing Center (DKRZ) where the HAMMONIA computations were performed. The authors gratefully acknowledge ESA for providing MIPAS spectra. The authors would also like to thank C. Randall and three anonymous reviewers for helpful comments and suggestions.

Edited by: W. Ward

\section{References}

Agostinelli, S., Allison, J., Amako, K., Apostolakis, J., Araujo, H., Arce, P., Asai, M., Axen, D., Banerjee, S., Barrand, G., Behner, F., Bellagamba, L., Boudreau, J., Broglia, L., Brunengo, A., Burkhardt, H., Chauvie, S., Chuma, S., Chytracek, R., Cooperman, G., and Cosmo, G.: GEANT4-a simulation toolkit, Nucl. Instr. Meth., 506, 250-303, doi:10.1016/S0168-9002(03)013688, 2003.

Baumgaertner, A. J. G., Jöckel, P., Riede, H., Stiller, G., and Funke, B.: Energetic particle precipitation in ECHAM5/MESSy - Part
2: Solar proton events, Atmos. Chem. Phys., 10, 7285-7302, doi:10.5194/acp-10-7285-2010, 2010.

Böhringer, H., Fahey, D. W., Fehsenfeld, F. C., and Ferguson, E. E.: The role of ion-molecule reactions in the conversion of $\mathrm{N}_{2} \mathrm{O}_{5}$ to $\mathrm{HNO}_{3}$ in the stratosphere, Planet. Space. Sci., 31, 185-191, 1983.

Chipperfield, M. P. and Feng, W.: Comment on: Stratospheric Ozone Depletion at northern mid-latitudes in the 21 st century: The importance of future concentrations of greenhouse gases nitrous oxide and methane, Geophys. Res. Lett., 30, 1389, doi:10.1029/2002GL016353, 2003.

Chipperfield, M. P. and Jones, R. L.: Relative influences of atmospheric chemistry and transport on Arctic ozone trends, Nature, 400, 551-554, 1999.

Chou, M.-D. and Suarez, M. J.: An Efficient Thermal Infrared Radiation Parameterization for Use in General Circulation Models, Technical Report Series on Global Modeling and Data Assimilation NASA/TM-1994-104606, vol. 9, Goddard Space Flight Center, Greenbelt, Maryland 20771, 1994.

Chou, M.-D. and Suarez, M. J.: A Solar Radiation Parameterization for Atmospheric Studies, Technical Report Series on Global Modeling and Data Assimilation NASA/TM-1999-104606, Vol. 15, Goddard Space Flight Center, Greenbelt, Maryland 20771, 1999.

Damiani, A., Diego, P., Laurenza, M., Storini, M., and Rafanelli, C.: Ozone variability related to several SEP events occurring during solar cycle no. 23, Adv. Space Res., 43, 28-40, doi:10.1016/j.asr.2008.06.006, 2008.

Damski, J., Thölix, L., Backman, L., Kaurola, J., Taalas, P., Austin, J., Butchart, N., and Kulmala, M.: A chemistry-transport model simulation of middle atmospheric ozone from 1980 to 2019 using coupled chemistry GCM winds and temperatures, Atmos. Chem. Phys., 7, 2165-2181, doi:10.5194/acp-7-2165-2007, 2007a.

Damski, J., Thölix, L., Backman, L., Taalas., P., and Kulmala, M.: FinROSE - middle atmospheric chemistry transport model, Boreal Env. Res., 12, 535-550, 2007b.

de Zafra, R. L. and Smyshlyaev, S. P.: On the formation of $\mathrm{HNO}_{3}$ in the Antarctic mid to upper stratosphere in winter, J. Geophys. Res., 106, 23115-23125, doi:10.1029/2000JD000314, 2001.

Egorova, T., Rozanov, E., Zubov, V., Manzini, E., Schmutz, W., and Peter, T.: Chemistry-climate model SOCOL: a validation of the present-day climatology, Atmos. Chem. Phys., 5, 1557-1576, doi:10.5194/acp-5-1557-2005, 2005.

Egorova, T., Rozanov, E., Ozolin, Y., Shapiro, A., Calisto, M., Peter, T., and Schmutz, W.: The atmospheric effects of October 2003 solar proton event simulated with the chemistry-climate model SOCOL using complete and parameterized ion chemistry, J. Atmos. Solar-Terr. Phys., 73, 356-365, 2011.

Evans, D. and Greer, M.: Polar Orbiting Environmental Satellite Space Environment Monitor - 2: Instrument Descriptions and Archive Data Documentation, NOAA Technical Memorandum OAR SEC-93, Oceanic and Atmospheric Research Laboratories, Space Environment Center, Boulder, Colorado, 2000.

Fischer, H., Birk, M., Blom, C., Carli, B., Carlotti, M., von Clarmann, T., Delbouille, L., Dudhia, A., Ehhalt, D., Endemann, M., Flaud, J. M., Gessner, R., Kleinert, A., Koopman, R., Langen, J., López-Puertas, M., Mosner, P., Nett, H., Oelhaf, H., Perron, G., Remedios, J., Ridolfi, M., Stiller, G., and Zander, R.: MIPAS: an instrument for atmospheric and climate research, Atmos. Chem. 
Phys., 8, 2151-2188, doi:10.5194/acp-8-2151-2008, 2008.

Fomichev, V. L., Blanchet, J.-P., and Turner, D. S.: Matrix parameterization of the $15 \mu \mathrm{m} \mathrm{CO}_{2}$ band cooling in the middle and upper atmosphere for variable $\mathrm{CO}_{2}$ concentration, J. Geophys. Res., 103, 11505-11528, doi:10.1029/98JD00799, 1998.

Funke, B., López-Puertas, M., Stiller, G. P., von Clarmann, T., and Höpfner, M.: A new non-LTE Retrieval Method for Atmospheric Parameters From MIPAS-ENVISAT Emission Spectra, Adv. Space Res., 27, 1099-1104, 2001.

Funke, B., López-Puertas, M., von Clarmann, T., Stiller, G. P., Fischer, H., Glatthor, N., Grabowski, U., Höpfner, M., Kellmann, S., Kiefer, M., Linden, A., Mengistu Tsidu, G., Milz, M., Steck, T., and Wang, D. Y.: Retrieval of stratospheric $\mathrm{NO}_{x}$ from 5.3 and $6.2 \mu \mathrm{m}$ nonlocal thermodynamic equilibrium emissions measured by Michelson Interferometer for Passive Atmospheric Sounding (MIPAS) on Envisat, J. Geophys. Res., 110, D09302, doi:10.1029/2004JD005225, 2005.

Funke, B., López-Puertas, M., , Bermejo-Pantaleón, D., von Clarmann, T., Stiller, G. P., Höpfner, M., Grabowski, U., and Kaufmann, M.: Analysis of nonlocal thermodynamic equilibrium $\mathrm{CO} 4.7 \mu \mathrm{m}$ fundamental, isotopic and hot band emissions measured by the Michelson Interferometer for Passive Atmospheric Sounding on Envisat, J. Geophys. Res., 112, D11305, doi:10.1029/2006JD007933, 2007.

Funke, B., García-Comas, M., López-Puertas, M., Glatthor, N., Stiller, G. P., von Clarmann, T., Semeniuk, K., and McConnell, J. C.: Enhancement of $\mathrm{N}_{2} \mathrm{O}$ during the OctoberNovember 2003 solar proton events, Atmos. Chem. Phys., 8, 3805-3815, doi:10.5194/acp-8-3805-2008, 2008.

Funke, B., López-Puertas, M., García-Comas, M., Stiller, G. P., von Clarmann, T., Höpfner, M., Glatthor, N., Grabowski, U., Kellmann, S., and Linden, A.: Carbon monoxide distributions from the upper troposphere to the mesosphere inferred from $4.7 \mu \mathrm{m}$ non-local thermal equilibrium emissions measured by MIPAS on Envisat, Atmos. Chem. Phys., 9, 2387-2411, doi:10.5194/acp-92387-2009, 2009.

Garcia, R. R., Marsh, D. R., Kinnison, D. E., Boville, B. A., and Sassi, F.: Simulation of secular trends in the middle atmosphere, J. Geophys. Res., 112, D09301, doi:10.1029/2006JD007485, 2007.

Glatthor, N., von Clarmann, T., Fischer, H., Grabowski, U., Höpfner, M., Kellmann, S., Kiefer, M., Linden, A., Milz, M., Steck, T., Stiller, G. P., Mengistu Tsidu, G., Wang, D. Y., and Funke, B.: Spaceborne $\mathrm{ClO}$ observations by the Michelson Interferometer for Passive Atmospheric Sounding (MIPAS) before and during the Antarctic major warming in September/October 2002, J. Geophys. Res., 109, D11307, doi:10.1029/2003JD004440, 2004.

Glatthor, N., von Clarmann, T., Fischer, H., Funke, B., Grabowski, U., Höpfner, M., Kellmann, S., Kiefer, M., Linden, A., Milz, M., Steck, T., Stiller, G. P., Mengistu Tsidu, G., and Wang, D. Y.: Mixing processes during the Antarctic vortex split in September/October 2002 as inferred from source gas and ozone distributions from ENVISAT-MIPAS, J. Atmos. Sci., 62, 787-800, 2005.

Gopalswamy, N., Yashiro, S., Michalek, G., Vourlidas, A., Kaiser, M. L., and Howard, R. A.: Coronal mass ejections and other extreme characteristics of the 2003 OctoberNovember solar eruptions, J. Geophys. Res., 110, A09S15,
doi:10.1029/2004JA010958, 2005.

Heaps, M. G.: Parametrization of cosmic-ray ion-pair productionrate above $18 \mathrm{~km}$, Planet. Space Sci., 26, 513-517, 1978.

Höpfner, M., von Clarmann, T., Fischer, H., Funke, B., Glatthor, N., Grabowski, U., Kellmann, S., Kiefer, M., Linden, A., Milz, M., Steck, T., Stiller, G. P., Bernath, P., Blom, C. E., Blumenstock, Th., Boone, C., Chance, K., Coffey, M. T., Friedl-Vallon, F., Griffith, D., Hannigan, J. W., Hase, F., Jones, N., Jucks, K. W., Keim, C., Kleinert, A., Kouker, W., Liu, G. Y., Mahieu, E., Mellqvist, J., Mikuteit, S., Notholt, J., Oelhaf, H., Piesch, C., Reddmann, T., Ruhnke, R., Schneider, M., Strandberg, A., Toon, G., Walker, K. A., Warneke, T., Wetzel, G., Wood, S., and Zander, R.: Validation of MIPAS $\mathrm{ClONO}_{2}$ measurements, Atmos. Chem. Phys., 7, 257-281, doi:10.5194/acp-7-257-2007, 2007.

Jackman, C. H. and McPeters, R. D.: Solar Proton Events as Tests for the Fidelity of Middle Atmosphere Models, Physica Scripta., T18, 309-316, 1987.

Jackman, C. H., Fleming, E. L., and Vitt, F. M.: Influence of extremely large solar proton events in a changing stratosphere, J. Geophys. Res., 105, 11659-11670, 2000.

Jackman, C. H., DeLand, M. T., Labow, G. J., Fleming, E. L., Weisenstein, D. K., Ko, M. K. W., Sinnhuber, M., Anderson, J., and Russell, J. M.: The Influence of the Several Very Large Solar Proton Events in Years 2000-2003 on the Neutral Middle Atmosphere, Adv. Space Res., 35, 445-450, 2005 a.

Jackman, C. H., DeLand, M. T., Labow, G. J., Fleming, E. L., Weisenstein, D. K., Ko, M. K. W., Sinnhuber, M., and Russell, J. M.: Neutral atmospheric influences of the solar proton events in October-November 2003, J. Geophys. Res., 110, A09S27, doi:10.1029/2004JA010888, 2005b.

Jackman, C. H., Marsh, D. R., Vitt, F. M., Garcia, R. R., Fleming, E. L., Labow, G. J., Randall, C. E., López-Puertas, M., Funke, B., von Clarmann, T., and Stiller, G. P.: Short- and medium-term atmospheric constituent effects of very large solar proton events, Atmos. Chem. Phys., 8, 765-785, doi:10.5194/acp-8-765-2008, 2008.

Jackman, C. H., Marsh, D. R., Vitt, F. M., Garcia, R. R., Randall, C. E., Fleming, E. L., and Frith, S. M.: Long-term middle atmospheric influence of very large solar proton events, J. Geophys. Res., 114, D11304, doi:10.1029/2008JD011415, 2009.

Jöckel, P., Sander, R., Kerkweg, A., Tost, H., and Lelieveld, J.: Technical Note: The Modular Earth Submodel System (MESSy) - a new approach towards Earth System Modeling, Atmos. Chem. Phys., 5, 433-444, doi:10.5194/acp-5-433-2005, 2005.

Jöckel, P., Tost, H., Pozzer, A., Brühl, C., Buchholz, J., Ganzeveld, L., Hoor, P., Kerkweg, A., Lawrence, M. G., Sander, R., Steil, B., Stiller, G., Tanarhte, M., Taraborrelli, D., van Aardenne, J., and Lelieveld, J.: The atmospheric chemistry general circulation model ECHAM5/MESSy1: consistent simulation of ozone from the surface to the mesosphere, Atmos. Chem. Phys., 6, 50675104, doi:10.5194/acp-6-5067-2006, 2006.

Kinnersley, J. S.: Interannual variability of stratospheric zonal wind forced by the northern lower-stratospheric large-scale waves, J. Atmos. Sci., 55, 2270-2283, 1998.

Kinnison, D. E., Brasseur, G. P., Walters, S., Garcia, R. R., Marsh, D. R., Sassi, F., Harvey, V. L., Randall, C. E., Emmons, L., Lamarque, J. F., Hess, P., Orlando, J. J., Tie, X. X., Randel, W., Pan, L. L., Gettelman, A., Granier, C., Diehl, T., Niemeier, U., and Simmons, A. J.: Sensitivity of chemical tracers to meteoro- 
logical parameters in the MOZART-3 chemical transport model, J. Geophys. Res., 112, D20302, doi:10.1029/2006JD007879, 2007.

Klassen, A., Krucker, S., Kunow, H., Múller-Mellin, R., WimmerSchweingruber, R., Mann, G., and Posner, A.: Solar energetic electrons related to the 28 October 2003 flare, J. Geophys. Res., 110, A09S04, doi:10.1029/2004JA010910, 2005.

Kockarts, G.: Nitric oxide cooling in the terrestrial thermosphere, Geophys. Res. Lett., 7, 137-140, doi:10.1029/GL007i002p00137, 1980.

Kouker, W., Offermann, D., Küll, V., Reddmann, T., Ruhnke, R., and Franzen, A.: Streamers observed by the CRISTA experiment and simulated in the KASIMA model, J. Geophys. Res., 104, 16405-16418, 1999.

Krivolutsky, A. A. and Vyushkova, T. Y.: Three-dimensional photochemical transport model for the middle atmosphere (Basic variant), Scientific Report 1.3.2.15, Central Aerological Observatory, Russian Service for Hydrometeorology and Environmental Monitoring, 2002.

Krivolutsky, A. A., Kuminov, A. A., Repnev, A. I., Perejaslova, N. K., Nazarova, M. N., and Bazilevskay, G. A.: Model calculations of ozone response after solar proton event of November 1997, Geomagnetism and Aeronomy, 41, 243-252, 2001.

Krivolutsky, A. A., Klyuchnikova, A. V., Zakharov, G. R., Vyushkova, T. Y., and Kuminov, A. A.: Dynamical response of the middle atmosphere to solar proton event of July 2000: Threedimensional model simulations, Adv. Space Res., 37, 16021613, doi:10.1016/j.asr.2005.05.115, 2006.

Kutepov, A. and Fomichev, V.: Application of the second-order escape probability approximation to the solution of the NLTE vibration-rotational band radiative transfer problem, J. Atmos. Terr. Phys., 55, 1-6, doi:10.1016/0021-9169(93)90148-R, http:// www.sciencedirect.com/science/article/pii/002191699390148R, 1993.

Kylling, A., Albold, A., and Seckmeyer, G.: Transmittance of a cloud is wavelength - dependent in the UV-range: Physical interpretation, Geophys. Res. Lett., 24, 397-400, doi:10.1029/97GL00111, 1997.

López-Puertas, M., Funke, B., Gil-López, S., von Clarmann, T., Stiller, G. P., Höpfner, M., Kellmann, S., Fischer, H., and Jackman, C. H.: Observation of $\mathrm{NO}_{\mathrm{x}}$ Enhancement and Ozone Depletion in the Northern and Southern Hemispheres after the October-November 2003 Solar Proton Events, J. Geophys. Res., 110, A09S43, doi:10.1029/2005JA011050, 2005a.

López-Puertas, M., Funke, B., Gil-López, S., von Clarmann, T., Stiller, G. P., Höpfner, M., Kellmann, S., Mengistu Tsidu, G., Fischer, H., and Jackman, C. H.: $\mathrm{HNO}_{3}$, $\mathrm{N}_{2} \mathrm{O}_{5}$ and $\mathrm{ClONO}_{2}$ Enhancements after the October-November 2003 Solar Proton Events, J. Geophys. Res., 110, A09S44, doi:10.1029/2005JA011051, 2005b.

Marsh, D., Smith, A., G-Brasseur, Kaufmann, M., and Grossmann, K.: The existence of a tertiary ozone maximum in the high-latitude middle mesosphere, Geophys. Res. Lett., 28, 45314534, 2001.

Marsh, D. R., Garcia, R. R., Kinnison, D. E., Boville, B. A., Sassi, F., Solomon, S. C., and Matthes, K.: Modeling the whole atmosphere response to solar cycle changes in radiative and geomagnetic forcing, J. Geophys. Res., 112, D23306, doi:10.1029/2006JD008306, 2007.
Mengistu Tsidu, G., von Clarmann, T., Stiller, G. P., Höpfner, M., Fischer, H., Glatthor, N., Grabowski, U., Kellmann, S., Kiefer, M., Linden, A., Milz, M., Steck, T., Wang, D.-Y., and Funke, B.: Stratospheric $\mathrm{N}_{2} \mathrm{O}_{5}$ in the austral spring 2002 as retrieved from limb emission spectra recorded by the Michelson Interferometer for Passive Atmospheric Sounding (MIPAS), J. Geophys. Res., 109, D18301, doi:10.1029/2004JD004856, 2004.

Minschwaner, K. and Siskind, D. E.: A new calculation of nitric oxide photolysis in the stratosphere, mesosphere, and lower thermosphere, J. Geophys. Res., 98, 20401-20412, 1993.

Morgenstern, O., Giorgetta, M. A., Shibata, K., Eyring, V., Waugh, D. W., Shepherd, T. G., Akiyoshi, H., Austin, J., Baumgaertner, A. J. G., Bekki, S., Braesicke, P., Brühl, C., Chipperfield, M. P., Cugnet, D., Dameris, M., Dhomse, S., Frith, S. M., Garny, H., Gettelman, A., Hardiman, S. C., Hegglin, M. I., Jöckel, P., Kinnison, D. E., Lamarque, J.-F., Mancini, E., Manzini, E., Marchand, M., Michou, M., Nakamura, T., Nielsen, J. E., Olivié, D., Pitari, G., Plummer, D. A., Rozanov, E., Scinocca, J. F., Smale, D., Teyssèdre, H., Toohey, M., Tian, W., and Yamashita, Y.: Review of the formulation of present-generation stratospheric chemistryclimate models and associated external forcings, J. Geophys. Res., 115, D00M02, doi:10.1029/2009JD013728, 2010.

Orsolini, Y. J., Manney, G. L., Santee, M. L., and Randall, C. E.: An upper stratospheric layer of enhanced $\mathrm{HNO}_{3}$ following exceptional solar storms, Geophys. Res. Lett., 32, L12S01, doi:10.1029/2004GL021588, 2005.

Park, J. H., Ko, M. K. W., Jackman, C. H., Plumb, R. A., Kaye, J. A., and Sage, K. H. (Eds.): Models and Measurements Intercomparison II, NASA/TM-1999-209554, Langley Research Center, Hampton, Virginia, NASA-LARC, 1999.

Picone, J., Hedin, A., Drob, D., and Aikin, A.: NRLMSISE00 empirical model of the atmosphere: Statistical comparisons and scientific issues, J. Geophys. Res., 107, 1468, doi:10.1029/2002JA009430, 2002.

Porter, H. S., Jackman, C. H., and Green, A. E. S.: Efficiencies for production of atomic nitrogen and oxygen by relativistic proton impact in air, J. Chem. Phys., 65, 154-167, doi:10.1063/1.432812, 1976.

Prather, M. J.: Numerical advection by conservation of second order moments, J. Geophys. Res., 91, 6671-6681, 1986.

Randall, C. E., Harvey, V. L., Manney, G. L., Orsolini, Y. J., Codrescu, M., Sioris, C., Brohede, S., Haley, C. S., Gordley, L. L., Zawodny, J. M., and Russell III, J. M.: Stratospheric effects of energetic particle precipitation in 2003-2004, Geophys. Res. Lett., 32, L05802, doi:10.1029/2004GL022003, 2005.

Reddmann, T., Ruhnke, R., Versick, S., and Kouker, W.: Modeling disturbed stratospheric chemistry during solar-induced $\mathrm{NO}_{\mathrm{x}}$ enhancements observed with MIPAS/ENVISAT, J. Geophys. Res., 115, D00I11, doi:10.1029/2009JD012569, 2010.

Rienecker, M., Suarez, M., Todling, R., Bacmeister, J., Takacs, L., Liu, H.-C., Gu, W., Sienkiewicz, M., Koster, R., Gelaro, R., Stajner, I., and Nielsen, J.: The GEOS-5 Data Assimilation System Documentation of Versions 5.0.1, 5.1.0, and 5.2.0, Technical Report Series on Global Modeling and Data Assimilation, Volume 27 NASA/TM-2008-104606, vol. 27, Goddard Space Flight Center, Greenbelt, Maryland 20771, 2008.

Roble, R. G. and Ridley, E. C.: An auroral model for the NCAR thermospheric general circulation model (TGCM), Ann. Geophys., 5, 369-382, 1987. 
Rodgers, C. D.: Inverse Methods for Atmospheric Sounding: Theory and Practice, vol. 2 of Series on Atmospheric, Oceanic and Planetary Physics, F. W. Taylor, ed., World Scientific, 2000.

Roeckner, E., Brokopf, R., Esch, M., Giorgetta, M., Hagemann, S., Kornblueh, L., Manzini, E., Schlese, U., and Schulzweida, U.: Sensitivity of Simulated Climate to Horizontal and Vertical Resolution in the ECHAM5 Atmosphere Model, J. Climate, 19, 3771-3791, 2006.

Rohen, G. J., von Savigny, C., Sinnhuber, M., Llewellyn, E. J., Kaiser, J. W., Jackman, C. H., Kallenrode, M.-B., Schrőter, J., Eichmann, K.-U., Bovensmann, H., and Burrows, J. P.: Ozone depletion during the solar proton events of October/November 2003 as seen by SCIAMACHY, J. Geophys. Res., 110, A09S39, doi:10.1029/2004JA010984, 2005.

Rusch, D. W., Gérard, J.-C., Solomon, S., Crutzen, P. J., and Reid, G. C.: The effect of particle precipitation events on the neutral and ion chemistry of the middle atmosphere. I - Odd nitrogen, Planet. Space Sci., 29, 767-774, 1981.

Sander, S. P., Friedl, R. R., Golden, D. M., Kurylo, M. J., Huie, R. E., Orkin, V. L., Moortgat, G. K., Kolb, C. E., Molina, M. J., and Ravishankara, A. R.: Chemical kinetics and photochemical data for use in atmospheric studies : Evaluation number 13, JPL Publication 00-3, Jet Propulsion Laboratory, California Institute of Technology, Pasadena, CA, 2000.

Sander, S. P., Finlayson-Pitts, B. J., Friedl, R. R., Golden, D. M., Huie, R. E., Kolb, C. E., Kurylo, M. J., Molina, M. J., Moortgat, G. K., Orkin, V. L., and Ravishankara, A. R.: Chemical kinetics and Photochemical Data for the Use in Atmospheric Studies. Evaluation Number 14, JPL publication 02-25, Jet Propulsion Laboratory, California Institute of Technology, Pasadena, CA, 2003

Sander, S. P., Friedl, R. R., Ravishankara, A. R., Golden, D. M., Kolb, C. E., Kurylo, M. J., Molina, M. J., Moortgat, G. K., Keller-Rudek, H., Finlayson-Pitts, B. J., Wine, P., Huie, R. E., and Orkin, V. L.: Chemical kinetics and Photochemical Data for the Use in Atmospheric Studies. Evaluation Number 15, JPL publication 06-2, Jet Propulsion Laboratory, California Institute of Technology, Pasadena, CA, 2006.

Schmidt, H., Brasseur, G., Charron, M., Manzini, E., Giorgetta, M., Diehl, T., Formichev, V., Kinnison, D., Marsh, D., and Walters, S.: The HAMMONIA chemistry climate model: sensitivity of the mesopause region to the 11-year solar cycle and $\mathrm{CO}_{2}$ doubling, J. Climate, 19, 3903-3931, 2006.

Schraner, M., Rozanov, E., Schnadt Poberaj, C., Kenzelmann, P., Fischer, A. M., Zubov, V., Luo, B. P., Hoyle, C. R., Egorova, T., Fueglistaler, S., Brönnimann, S., Schmutz, W., and Peter, T.: Technical Note: Chemistry-climate model SOCOL: version 2.0 with improved transport and chemistry/microphysics schemes, Atmos. Chem. Phys., 8, 5957-5974, doi:10.5194/acp-8-59572008, 2008.

Seppälä, A., Verronen, P. T., Kyrölä, E., Hassinen, S., Backman, L., Hauchecorne, A., Bertaux, J. L., and Fussen, D.: Solar proton events of October-November 2003: Ozone depletion in the Northern Hemisphere winter as seen by GOMOS/Envisat, Geophys. Res. Lett., 31, L19107, doi:10.1029/2004GL021042, 2004.

Shine, K.: The middle atmosphere in the absence of dynamical heat fluxes, Q. J. Roy. Meteorol. Soc., 113, 603-633, 1987.

Simmons, A., Uppala, S., Dee, D., and Kobayashi, S.: ERAInterim: New ECMWF reanalysis products from 1989 on- wards, ECMWF Newsletter 110 - Winter 2006/07, Data Services ECMWF, Shinfield Park, Reading, UK, 2006.

Sinnhuber, M., Burrows, J. P., Chipperfield, M. P., Jackman, C. H., Kallenrode, M.-B., Künzi, K. F., and Quack, M.: A model study of the impact of magnetic field structure on atmospheric composition during solar proton events, Geophys. Res. Lett., 30, 1818, doi:10.1029/2003GL017265, 2003a.

Sinnhuber, B.-M., Weber, M., Amankwah, A., and Burrows, J. P.: Total Ozone during the unusual Antarctic winter of 2002, Geophys. Res. Lett., 30, 1580, doi:10.1029/2002GL016798, 2003b.

Sinnhuber, B.-M., Sheode, N., Sinnhuber, M., Chipperfield, M. P., and Feng, W.: The contribution of anthropogenic bromine emissions to past stratospheric ozone trends: a modelling study, Atmos. Chem. Phys., 9, 2863-2871, doi:10.5194/acp-9-2863-2009, 2009.

Solomon, S. and Crutzen, P. J.: Analysis of the August 1972 Solar Proton Event Including Chlorine Chemistry, J. Geophys. Res., 86, 1140-1146, 1981

Solomon, S. C. and Qian, L.: Solar extreme-ultraviolet irradiance for general circulation models, J. Geophys. Res., 110, A10306, doi:10.1029/2005JA011160, 2005.

Solomon, S., Rusch, D. W., Gérard, J.-C., Reid, G. C., and Crutzen, P. J.: The effect of particle precipitation events on the neutral and ion chemistry of the middle atmosphere. II - Odd hydrogen, Planet. Space Sci., 29, 885-892, 1981.

Steck, T., von Clarmann, T., Fischer, H., Funke, B., Glatthor, N., Grabowski, U., Hpfner, M., Kellmann, S., Kiefer, M., Linden, A., Milz, M., Stiller, G. P., Wang, D. Y., Allaart, M., Blumenstock, Th., von der Gathen, P., Hansen, G., Hase, F., Hochschild, G., Kopp, G., Kyrö, E., Oelhaf, H., Raffalski, U., Redondas Marrero, A., Remsberg, E., Russell III, J., Stebel, K., Steinbrecht, W., Wetzel, G., Yela, M., and Zhang, G.: Bias determination and precision validation of ozone profiles from MIPAS-Envisat retrieved with the IMK-IAA processor, Atmos. Chem. Phys., 7, 3639-3662, doi:10.5194/acp-7-3639-2007, 2007.

Stiller, G. P., von Clarmann, T., Brühl, C., Fischer, H., Funke, B., Glatthor, N., Grabowski, U., Höpfner, M., Jöckel, P., Kellmann, S., Kiefer, M., Linden, A., Lòpez-Puertas, M., Mengistu Tsidu, G., Milz, M., Steck, T., and Steil, B.: Global distributions of $\mathrm{HO}_{2} \mathrm{NO}_{2}$ as observed by the Michelson Interferometer for Passive Atmospheric Sounding (MIPAS), J. Geophys. Res., 112, D09314, doi:10.1029/2006JD007212, 2007.

Stiller, G. P., von Clarmann, T., Höpfner, M., Glatthor, N., Grabowski, U., Kellmann, S., Kleinert, A., Linden, A., Milz, M., Reddmann, T., Steck, T., Fischer, H., Funke, B., LópezPuertas, M., and Engel, A.: Global distribution of mean age of stratospheric air from MIPAS SF 6 measurements, Atmos. Chem. Phys., 8, 677-695, doi:10.5194/acp-8-677-2008, 2008.

Strobel, D. F.: Parametrization of the Atmospheric Heating Rate from 15 to $120 \mathrm{~km}$ due to $\mathrm{O}_{2}$ and $\mathrm{O}_{3}$ Absorption of Solar Radiation, J. Geophys. Res., 83, 6225-6230, 1978.

Swinder, W. and Gardner, M. E.: On the accuracy of certain approximations for the Chapman function, in: Environmental Research Papers No. 272, Air Force Cambridge Research, Bedford, MA, USA, 1967.

Tikhonov, A.: On the solution of incorrectly stated problems and method of regularization, Dokl. Akad. Nauk. SSSR, 151, 501504, 1963.

Turco, R. P. and Whitten, R. C.: A comparison of sev- 
eral computational techniques for solving some common aeronomic problem, J. Geophys. Res., 79, 3179-3185, doi:10.1029/JA079i022p03179, 1974.

Verronen, P. T., Seppälä, A., Kyrölä, E., Tamminen, J., Pickett, H. M., and Turunen, E.: Production of odd hydrogen in the mesosphere during the January 2005 solar proton event, Geophys. Res. Lett., 33, L24811, doi:10.1029/2006GL028115, 2006.

Verronen, P. T., Funke, B., López-Puertas, M., Stiller, G. P., von Clarmann, T., Enell, C.-F., Turunen, E., and Tamminen, J.: About the Increase of $\mathrm{HNO}_{3}$ in the Stratopause Region During the Halloween 2003 Solar Proton Event, Geophys. Res. Lett., 35, L20809, doi:10.1029/2008GL035312, 2008.

Versick, S.: Ableitung von $\mathrm{H}_{2} \mathrm{O}_{2}$ aus MIPAS/ENVISATBeobachtungen und Untersuchung der Wirkung von energetischen Teilchen auf den chemischen Zustand der mittleren Atmosphre, Ph.D. thesis, Karlsruhe, Karlsruher Institut für Technologie (KIT), urn:nbn:de:swb:90-197769, 2010.

von Clarmann, T., Glatthor, N., Grabowski, U., Höpfner, M., Kellmann, S., Kiefer, M., Linden, A., Mengistu Tsidu, G., Milz, M., Steck, T., Stiller, G. P., Wang, D. Y., Fischer, H., Funke, B., Gil-López, S., and López-Puertas, M.: Retrieval of temperature and tangent altitude pointing from limb emission spectra recorded from space by the Michelson Interferometer for Passive Atmospheric Sounding (MIPAS), J. Geophys. Res., 108, 4736, doi:10.1029/2003JD003602, 2003.

von Clarmann, T., Glatthor, N., Höpfner, M., Kellmann, S., Ruhnke, R., Stiller, G. P., Fischer, H., Funke, B., Gil-López, S., and López-Puertas, M.: Experimental Evidence of Perturbed Odd Hydrogen and Chlorine Chemistry After the October 2003 Solar Proton Events, J. Geophys. Res., 110, A09S45, doi:10.1029/2005JA011053, 2005.

von Clarmann, T., Glatthor, N., Grabowski, U., Höpfner, M., Kellmann, S., Linden, A., Mengistu Tsidu, G., Milz, M., Steck, T., Stiller, G. P., Fischer, H., and Funke, B.: Global stratospheric $\mathrm{HOCl}$ distributions retrieved from infrared limb emission spectra recorded by the Michelson Interferometer for Passive Atmospheric Sounding (MIPAS), J. Geophys. Res., 111, D05311, doi:10.1029/2005JD005939, 2006.
Wang, D. Y., Höpfner, M., Blom, C. E., Ward, W. E., Fischer, H., Blumenstock, T., Hase, F., Keim, C., Liu, G. Y., Mikuteit, S., Oelhaf, H., Wetzel, G., Cortesi, U., Mencaraglia, F., Bianchini, G., Redaelli, G., Pirre, M., Catoire, V., Huret, N., Vigouroux, C., De Mazière, M., Mahieu, E., Demoulin, P., Wood, S., Smale, D., Jones, N., Nakajima, H., Sugita, T., Urban, J., Murtagh, D., Boone, C. D., Bernath, P. F., Walker, K. A., Kuttippurath, J., Kleinböhl, A., Toon, G., and Piccolo, C.: Validation of MIPAS $\mathrm{HNO}_{3}$ operational data, Atmos. Chem. Phys., 7, 4905-4934, doi:10.5194/acp-7-4905-2007, 2007.

Winkler, H., Sinnhuber, M., Notholt, J., Kallenrode, M.-B., Steinhilber, F., Vogt, J., Zieger, B., Glassmeier, K.-H., and Stadelmann, A.: Modeling impacts of geomagnetic field variations on middle atmospheric ozone responses to solar proton events on long timescales, J. Geophys. Res., 113, D02302, doi:10.1029/2007JD008574, 2008.

Winkler, H., Kazeminejad, S., Sinnhuber, M., Kallenrode, M.B., and Notholt, J.: Conversion of mesospheric $\mathrm{HCl}$ into active chlorine during the solar proton event in July 2000 in the northern polar region, J. Geophys. Res., 114, D00I03, doi:10.1029/2008JD011587, 2009.

Wissing, J. M. and Kallenrode, M.-B.: Atmospheric Ionization Module OSnabrück (AIMOS) 1: A 3D model to determine atmospheric ionization by energetic charged particles from different populations, J. Geophys. Res., A06104, doi:10.1029/2008JA013884, 2009.

WMO: SPARC Report on the Evaluation of Chemistry-Climate Models, SPARC Report No. 5, WCRP-132, WMO/TD-No. 1526, 2010. 